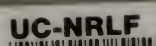

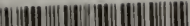

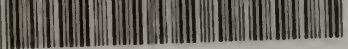

B 3313705 
L.C. 



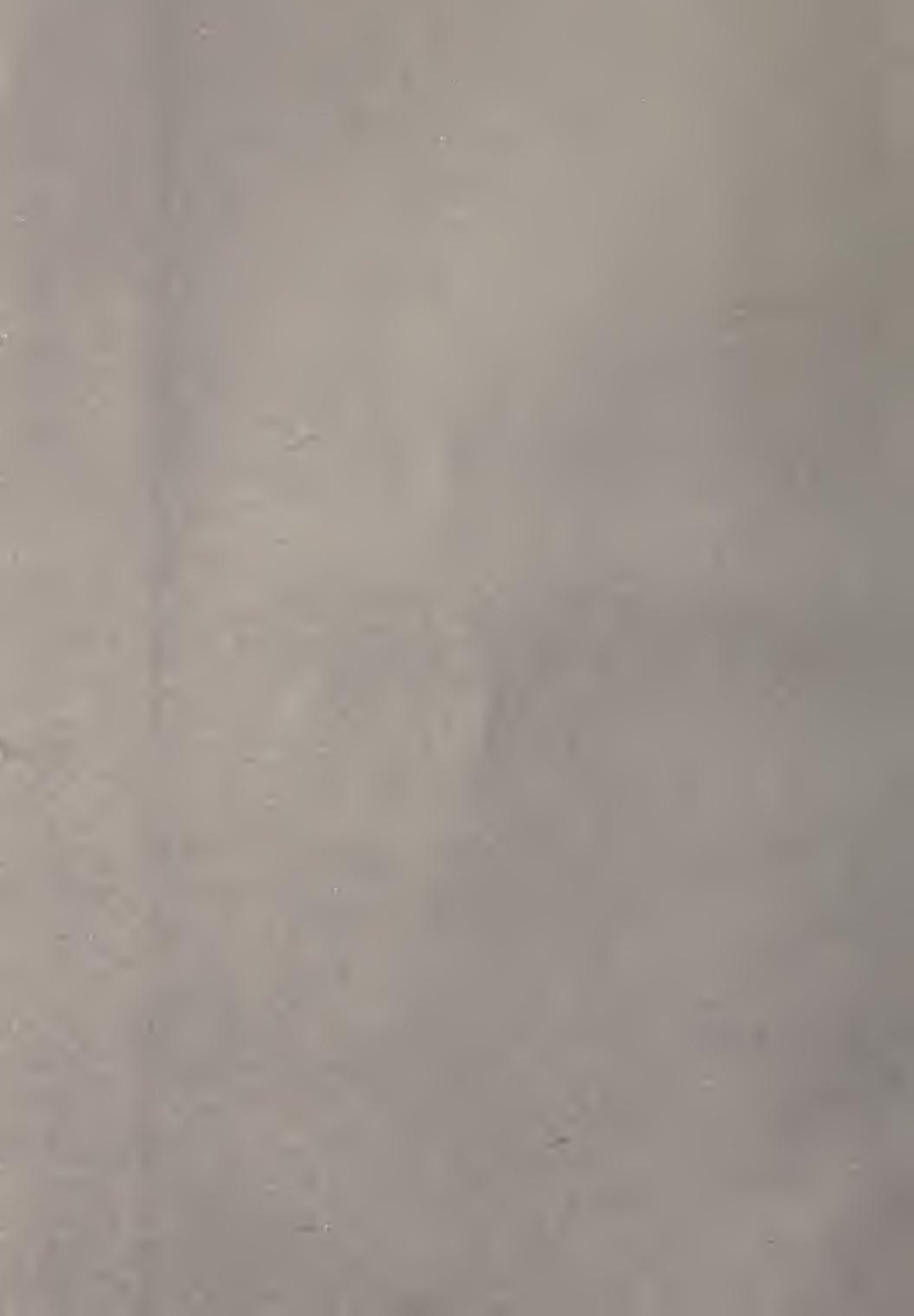


Digitized by the Internet Archive in 2007 with funding from Microsoft Corporation 

Just published, in 22 Vohumes, $18 \mathrm{mo}$.

SOLD TOGETHER OR SEPARATELY,

\section{AN}

\section{EASY COURSE}

\section{"x \\ DOMESTIC EDUCATION; \\ COMPRISING}

A Serieg of Elementar Treatiges

ON THE

VARIOUS BRANCHES OF JUVENILE INSTRUCTION;

TOGETHER WITH ADVICE TO PARENTS AND TUTORS FOR CONDUCT-

ING THE EDUCATION OF CHILDIEN:

Designed for the Use of Families and Schools.

By WILLIAM JILLARD HORT,

AUTHOR OF THE NEW PANTHEON, \&C.

LONDON:

PRINTED FOR

LONGMAN, HURST, REES, ORME, AND BROWN, PATERNOSTER-ROW.

Parents and others who have wished to conduct or superintend the education of children, have often been discouraged by their inability to plan a suitable course of studies for their young pupils, and by the difficulty of selecting, among the multitude of school-books, those which possess the greatest merit, or are best adapted to their respective objects. The design of this publication is to supply such persons with the best directions on these points, and to afford them the means, without any further assistance, of undertaking and carrying on the instruction of young persons with pleasure and success. It has been the anxious endeavour of the author, to comprise, within moderate limits, and in a uniform and connected course, all the essential elements of a respectable education. The series of treatises which he here submits to the public judgment, cannot fail, if carefully studied, to convey to the young student a large body of important information; and will, it is be: lieved, be found fully sufficient to qualify him to perform, with sattisfaction and credit, the various duties of any station in which he may be placet in life. In case, thowever, it should be desired to pursue the'education of some pupils furtheir than these volumes extend, some additional books have been pointed out with that view: a classed list has also been added of the most approved works on the several subjects of science and literature, forming; altogether, a valuable library, from which the teacher, or even the learner himself, may easily make his choice of those which are suited to his particular objects or pursuits. 
The Course of Domestic Education comprises the following Works, rehich are sold together or separately:-

1.

ADVICE to PARENTS and TUTORS, for conducting the EDUCATION of CHILDREN. Price 3s. half-bound.

2.

A FIRST SPELLING-BOOK; intended to lead the Pupil, by an easy and gradual Method, to a correct Pronunciation and Accentuation of the English Language. Price $1 s, 6 d$.

INTRODUCTORY ENGLISH READING-BOOK, intended to give easy Lessons in Reading; to convey useful Information; and to inculcate good Principles. $2 s .6 d$. 4.

The ENGLISH READING-BOOK, in Prose. Price $3 s .6 d$.

The ENGLISH READING-BOOK, in Verse. Price $3 s$.

An INTRODUCTION to ENGLISH GRAMMAR. Price 2s. $6 d$.

EXERCISES for the ILLUSTRATION and ENFORCEMENT of the RULES of the ENGLISH GRAMMAR. Price $2 s$.

The KEY to EXERCISES for Illustration and Enforcement of the Rules of the English Grammar. Price $2 s$.

An ENGLISH : SCHOOL DICTIONARY of SELECT WORDS, with their Meanings affixed, intended to be committed to Memory, as well as for Reference in Reading and Writing. Tó which is added, a List of the principal Heathen Deities of Greece, and of other Pagan Nations, and a Selection of Scripture Proper Names. 2s.6d.

An EPITOME of the HOLY BIBLE. Price $2 s .6 u$.

11.

INTROCUCTION to GEOGRAPHY, Modern and Antient, and to the Use of the Globes. Price $2 s, 6 d$.

An INTRODUCTION to ARITHMETIC. Price $2 s .6 d$.

An EPITOME of UNIVERSAL HISTORY. Price $4 s .6 d$.

An EPITOME of the HISTORY OF ENGLAND. Price $2 s .6 d$.

A GENERAL VIEW of the SCIENCES and ARTS. In 2 Vols. Price $8 s$.

An INTRODUCTION to NATURAL HISTORY, with numerous Wood Cuts. Gs.

An EASY GRAMMAR of the FRENCH LANGUAGE. Price $4 s$.

EXERCISES adapted to the Grammar of the French Language. Price $3 s .6 d$.

KEY to the FRENCH EXERCISES. Price $2 s, 6 d$.

21.

ELEMENTS of FRENCH CONVERSATION, including familiar Phrases and easy Dialogues, each Subject being preceded by a Vocabulary. Price $2 s .6 c l$. 22.

Le NOUVEAU LECTEUR FRANCAIS, à I'Usage des Mères de Famille qui veulent instruire leurs Enfaus, et de tous ceux qui sont engagés dans les écoles. Price $4 s .6 d$.

Complete in 22 Volumes, in a Case, $3 l .13 s .6 d$.

$$
\text { Also, by Mr. Hort, }
$$

The NEW PANTHEON; or, an Introduction to the Mythology of the Ancients, in Question and Answer. To which are added, an Accentuated Index, Questions for Exercise, and Poetical Illustrations of Grecian Mythology, from Honier and Virgil. In 18mo. The Fifth Edition; considerably enlarged, by the Addition of the Oriental and the Northern Mythology. With 17 Engravings. Price $5 s .6 d$. Bound.

An INTRODUCTION to the STUDY of CHRONOLOGY and ANCIENT HISTORY, in Question and Answer. In 18mo. Price 4s. Bound and lettered. The Second Edition.

An INTRODUCTION to MODERN HISTORY, from the Birth of Christ to the present Time, in Continuation of an Introduction to Claronology and Ancient History. In 2 Vols. $18 \mathrm{mo}$. Price $10 \mathrm{~s} .6 \mathrm{~d}$. Bound and lettered.

-6 From these jittle volumes the juvenile reader may obtain a clear and useful Comperdium owylodern and Universal History; they are creditable to Mr. Hort's industry and judgment, and deserve attention from persons concerned in educa-

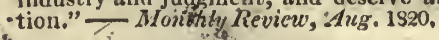

$$
\text { 4. }
$$

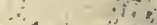

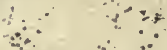


Complete, in One large Volume 8vo. of 1500 pages, closely printed, Price 2l. 10s. boards,

\section{AN \\ ENCYCLOPADIA}

\section{or \\ GA R D E N I N G: \\ GOMPRISING THE}

THEORY AND PRACTICE

or

HORTICULTURE, FLORICULTÚRE,

\section{ARBORICULTURE,}

\section{AND \\ LANDSCAPE-GARDENING;}

INCLUDING

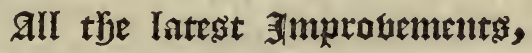

A GENERAL HISTORY OF GARDENING IN ALL COUNTRIES

AND A STATISTICAL VIEW OF ITS PRESENT STATE,

WITH SUGGESTIONS FOR ITS FUTURE PROGRESS, IN THE BRITISH ISLES.

By J. C. LOUDON, F.L.S. H.S. \&c. AUTHOR OF

" A TREATISE ON FORMING AND IMPROVING COUNTRY RESIDENCES."

ILLUSTRATED WITH

SIX HUNDRED ENGRAVINGS ON WOOD

BY BRANSTON.

PRINTED FOR LONGMAN, HURST; REES, ORME, AND BROWN, PATERNOSTER-ROW, LONDON.

T His Work is by far the most complete body of Gardening ever

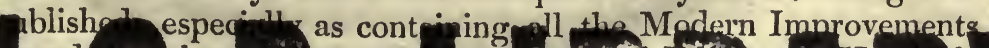

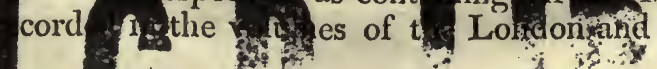


tural Societies, and all other Improvements both foreign and domestic up to the present time; and, considering the great number of Engravings and the immense quantity of matter it contains, it is, perhaps, the cheapest book ever published. It is calculated by its Indexes to serve both as a Gardener's Kalendar and Gardener's Dictionary; it contains a copious Introduction to Botany; engraved plans and elevations of all manner of hot-houses, ornamental buildings, kitchen gardens, flower gardens, shrubberies, pleasure grounds, and parks ; of many curious fruits and flowers; of all the garden implements, utensils, and machines. Besides the culinary, fruit, and flower gardening, and the laying out of grounds, it treats of trees, planting, forest management, nurseries, market gardens, and botanic gardens; of gardeners' societies, and lodges; of the duties of head gardeners in every situation and servitude, from that of the tradesman's town garden, of a few poles in extent, to the first rate gardens of the nobility, including public and royal gardens; it treats of the improvement of the taste of the patrons and employers of gardeners; of the education of young gardeners, and the general conduct of a gardener's life : in short it is of itself a gardener's library, and contains more matter than the four folio volumes of Miller's Dictionary.

No work is so well fitted for being presented by a gentleman to his head gardener, or by a head gardener to his deserving apprentice.

Preparing for Publication,

AN

ENCYCLOP ADDIA OF AGRICULTURE,

In One large Volume, 8 vo.

ILLUSTRATED WITH

NUMEROUS WUOD ENGRAVINGS

BY BRANSTON.

*** This Work is on the Plan of the Encyclopædia of

Gardening. 


\title{
EDINBURGH REVIEW
}

OF

\section{BOWDLER'S FAMILY SHAKSPEARE.}

\author{
No. 71.-October, 1821.
}

Art. III. The Family Shakspeare. In Ten Volumes $12 m o$. In which nothing is added to the Text; but those Words and Expressions are omitted which cannot with Propriety be read aloud in a Family. By Thomas Bowdler, Esq., F.R.S. \& S. A. Price 3l. 3s. London. Longman and Co., 1818.

$W_{\mathrm{E}}$ have long intended to notice this very meritorious publication; and are of opinion, that it requires nothing more than a notice to bring it into general circulation. We are not ourselves, we confess, particularly squeamish about incorrect expressions and allusions; and in the learned languages especially, which seldom come into the hands of the more delicate sex, and can rarely be perused by any one for the gratification of a depraved taste, we have not been very anxious about the dissemination of castrated editions; but in an author of such unbounded and deserved popularity as our great Dramatist, whose volumes are constantly in the hands of almost all who can read of both sexes, it is undoubtedly of great consequence to take care that youth runs no risk of corruption in the pursuit of innocent amusement or valuable instruction; or rather, that no offence is offered to delicacy in the midst of the purest gratification of taste.

Now it is quite undeniable, that there are many passages in Shakspeare, which a father could not read aloud to his children - a brother to his sister - or a gentleman to a lady: - and every one almost must have felt or witnessed the extreme awkwardness, and even distress, that arises from suddenly stumbling upon such expressions, when it is almost too late to avoid them, and when the readiest wit cannot suggest any paraphrase, which shall not betray, by its harshness, the embarrassment from which it has arisen. Those who recollect such scenes, must all rejoice, we should think, that Mr. Bowdler has provided a security against their recurrence ; and, as what cannot be pronounced in decent company cannot well afford much pleasure in the closet, we think it is better every way, that what cannot be spoken, and ought not to have been 'written, should now cease to be printed. 
We have only farther to observe, that Mr. Bowdler has not executed his task in any thing of a precise or prudish spirit; that he has left many things in the text which, to a delicate taste, must still appear coarse and reprehensible: and only effaced those gross indecencies which every one must have felt as blemishes, and by the removal of which no imaginable excellence can be affected. It is comfortable to be able to add, that this purification has been accomplished with surprisingly little loss either of weight or value; and that the base alloy in the pure metal of Shakspeare has been found to amount to an inconceivably small proportion. It is infinitely to his credit that, with the most luxuriant fancy which ever fell to the lot of a mortal, and with no great restraints from the training or habits of his early life, he is by far the purest of the dramatists of his own or the succeeding age, - and has resisted, in a great degree, the corrupting example of his contemporaries. In them, as well as in him, it is indeed remarkable, that the obscenities which occur, are rather offensive than corrupting - and seem suggested rather by the misdirected wantonness of too lively a fancy, than by a vicious taste, or partiality to profligate indulgence; - while in Dryden and Congreve, the indecency belongs not to the jest, but to the character and action; and immodest speech is the cold and impudent exponent of licentious principles. In the one, it is the fantastic colouring of a coarse and grotesque buffoonery - in the other, the shameless speech of rakes, who make a boast of their profligacy. It is owing to this circumstance, perhaps, that it has in general been found easy to extirpate the offensive expressions of our great poet, without any injury to the context, or any visible scar or blank in the composition. They turn out not to be so much cankers in the flowers, as weeds that have sprung up by their side - not flaws in the metal, but impurities that have gathered on its surface - and that, so far from being missed on their removal, the work generally appears more natural and harmonious without them. We do not pretend to have gone over the whole work with attention - or even to have actually collated any considerable part of it: but we have examined three plays of rather a ticklish description - Othello, Troilus and Cressida, and Measure for Measure - and feel quite assured, from these specimens, that the work has been executed in the spirit, and with the success which we have represented.

Mr. B. has in general followed the very best text - and the work is very neatly printed. We hope, however, that the publishers will soon be encouraged to give us another edition, on a larger letter. * For we rather suspect, from some casual experiments of our own, that few papas will be able to read this, in a winter-evening to their children, without the undramatic aid of spectacles.

* The Publishers beg to say the hiñt is taken, and that they are printing a handsome octavo edition, for the accommodation of papas, while the simaller edition may continue to please their younger friends. 


\section{WORKS RECENTLY PUBLISHED,}

BY

LONGMAN, HURST, REES, ORME, AND BROWN,

LONDON.

1.

TRAVELS IN THE INTERIOR OF SOUTHERN AFRICA.

By WILLIAM J. BURCHELL, Esq.

With an entirely new large Map, numerous coloured Engravings, and Fifty Vignettes, from the Author's original Drawings.

In 4to. Vol. I. Price 4l. 14s. 6d.

Mr. Burchell's Researches in the Interior of Africa, during five years, over $\mathbf{4 5 0 0}$ miles of ground, besides numberless lateral excursions, in regions never before trodden by European foot, have produced a multitude of discoveries and observations which have never until now been laid before the public.

2.

THE PRIVATE AND CONFIDENTIAL CORRESPONDENCE or.

CHARLES TALBOT, DUKE OF SHREWSBURY,

Principal Minister of King William for a considerable Period of his Reign.

By the Rev. ARCHDEACON COXE.

In 1 Vol. 4to. Price 3l. 3s. Bds.

Also, by the same Author,

MEMOIRS of the DUKE of MARLBOROUGH. 6 Vols. 8vo., and 4to. Atlas. Price $5 l$. 5s. Boards.

HISTORY of the HOUSE of AUSTRIA, from 1218 to 1792. 5 Vols. 8 vo. Price $3 l .13 s .6 d$. Boards.

HISTORY of the BOURBON KINGS of SPAIN, 1700-1788. 5 Vols. 8vo. Price $8 l$. Boards.

MEMOIRS of SIR ROBERT WALPOLE. 4 Vols. 8vo. Price 21. 8s. Boards.

MEMOIRS of HORATIO, LORD WALPOLE. 2 Vols. 8vo. Price 1l. 6s. Boards.

\section{3.}

TRAVELS IN GEORGIA, PERSIA, ARMENIA, ANCIENT BABYLONIA, \&c. \&c. DURING THE YEARS $1817,1818,1819,1820$.

By SIR ROBERT KER PORTER, \&c. \&c.

Vol. II. which completes the Work. In 4to. With numerous Engravings of Portraits, Costumes, Antiquities, \&c. \&c. Price 4l. 14s.6d. Boards.

Vol, I. Price 4l. 14s. 6d, Boards. 
4 Works printed for Longman, Hurst, Rees, Orme, and Brown.

19.

\section{BODY AND SOUL,}

Consisting of A SERIES OF LIVELy AND PATHeTiC STORIES.

Calculated to excite the attention and interest of the Religious World.

Contents : - The Town Rector. - Philosophical Painter. - Merchant's Family. - Sick Penitent. - Unitarian. - Clerical Conference. - Lunatic Asylum. - Liturgy. - Assizes. - Athanasian Creed. - Sea Captain. - Domiciliary Visits.

In Post 8vo. Price $12 \mathrm{~s}$.

20.

THE HISTORY

THE DESTRUCTION OF JERUSALEM,

AS CONNECTED WITH THE SCRIPTURE PROPHECIES.

By the Rev. GEORGE WILKINS, A.M.

Domestic Chaplain to the Earl of Kinnoull, Vicar of St. Mary's in the Town, and of Lowdham in the County, of Nottingham.

In 8ro. Price 10s. $6 d$. Boards. The Third Edition.

$-21$.

TRAVELS IN THE INTERIOR OF BRAZIL;

WITH A TARTICULAR ACCOUNT OF THE GOLD AND DIAMOND DISTRICTS.

INCLUDING A VOYAGE TO THE RIO DE LA PLATE.

By JOHN MAWE, Mineralogist.

Second Edition. Illustrated with coloured Plates and a Map.

8vo. Price 18s. Boards.

\section{2.}

\section{THE REMAINS OF HENRY KIRKE WHITE,}

SELECTED, WITH PREFATORY REMARKS,

i By.ROBERT SOUTHEY, Esq.

Volume the Third. In 8vo. Price 9s. Boards.

Also may be had,

The first Two Volumes. Price 1l. 1s.

\section{3.}

\section{SONGS OF ZION,}

BEING IMITATIONS OF PSALMS.

- By. J. MONTGOMERY.

In Foolscap 8vo. Price 5s.

By the same Author,

GREENLAND, and other Poems. 'Second Edition. Price 8s. Boards. The WORLD before the FLOOD. Fifth Edition. Price 9s.

The WEST INDIES, and other Poems. Fifth Edition. Price 6s.

The W.ANDERER of SWITZERLAND. Eighth Edition. 'Price 6s.

VERSES to the MEMORY of R. REYNOLDS. Price $2 s$.

POLYHYMNIA; or Select Airs of celebrated Foreign. Composers, adapted to English Words, written expressly for this Work, Price 6s. 


\section{4. \\ LECTURES \\ ON \\ THE ELEMENTS OF BOTANY.}

Containing the Descriptive Anatomy of those Organs, on which the Growth and Preservation of the Vegetable depend.

By ANTHONY TODD THOMSON, F.L.S.

Member of the Royal College of Surgeons, \&c. \&c.

In 8 vo. Price $1 l$. $8 s$. Boards. Illustrated with Plates and numerous Wood-Cuts. Volume I.

25.

THE DIFFERENT MODES OF CULTIVATING THE PINE-APPLE,

From its first Introduction into Europe, to the late Improvements of T. A. Knight, Esq.

By a MEMBER of the HORTICULTURAL SOCIETY.

In 8 vo. Price 9s. Boards. With 74 Wood Engravings, exhibiting the best Plans of Pine--Stoves and Pits.

26.

SKETCHES OF THE CHARACTER, MANNERS, AND PRESENT STATE OF

THE HIGHLANDERS OF SCOTLAND.

With Details of the Military Service of the Highland Regiments. By COLONEL DAVID STEWART.

In 2 Vols. 8vo. The Second Edition. Price 1l. 8s. Boards. Illustrated by a Map of the Highlands.

27.

\section{ORIENTAL LITERATURE.}

APPLIED TO THE ILLUSTRATION OF THE SACRED SCRIPTURES;

Especially with Reference to Antiquities, Traditions, and Manners; collected from the most celebrated Writers and Travellers, Ancient and Modern.

Designed as a Sequel to Oriental Customs.

By the Rev. SAMUEL BURDER, A.M.

In 2 large Vols, 8vo, Closely printed. Price $1 l$. 10s. Boards.

This Work, besides a great body of interesting matter selected from the most important modern Publications, contains much valuable Criticism from a Work of Dr. Rosenmüller, of Leipsig, lately published in German, and now first translated into English.

Just published, by the same Author.

ORIENTAL CUSTOMS; or, an Illustration of the Sacred Scriptures, by an Explanatory Application of the Customs and Manners of the Eastern Nations. In 2 Vols. 8vo. The Sixth Edition, considerably enlarged. Price $1 l$. 5 s. Boards.

28.

SELECT WORKS OF THE BRITISH POETS,

WITH BIOGRAPHICAL AND CRITICAI, PREFACES,

By Dr. AIKIN.

In 10 Vols. Royal 18mo. Price $3 l_{0}-10$ Vols, Post $18 \mathrm{mo}$. Price $2 l_{\text {. }}$ Also in 1 large Vol. 8 vo. of 812 Pages, Price 18s. Boards. 
8 Works printed for Longman, Hurst, Rees, Orme, and Brown

\author{
42. \\ AN ACCOUNT OF CEYLON, \\ WITH TRAVELS IN THE INTERIOR OF THE ISLAND. \\ By JOHN DAVY, M.D. F.R.S. .
}

In 4to. With a new Map and other Engravings. Price 9l. 13s. 6d. Boards.

43.

ANNALS OF THE

REIGN OF KING GEORGE THE THIRD; BROUGHT DOWN TO HIS DEATH.

By JOHN AIKIN, M.D.

The Second Edition. In 2 Vols. 8vo. Price 1l. 5s. Boards.

41.

PRINCIPLES OF EDUCATION,

INTELLECTUAL, MORAL, AND PHYSICAL.

By the Reverend LANT CARPENTER, LL.D.

In 8vo. Price 12s. Boards.

$$
45 .
$$

SYSTEMATIC EDUCATION;

OR, ELEMENTARY INSTRUCTION IN THE VARIOUS DEPARTMENTS

OF LITERATURE AND SCIENCE,

With Practical Rules for studying each Branch of Useful Knowledge.

By the Rev. W. SHEPHERD, the Rev. IAANT CARPENTER, LL.D. and the Rev. J. JOYCE.

Third Edition. In 2 Vols. 8vo. Illustrated with Plates by Lowry, \&c. Price 1l. 11s. 6d. Boards.

46.

THE PRINCIPLES AND DOCTRINES OF

ASSURANCES, ANNUITIES ON LIVES,

AND CONTINGENT REVERSIONS,

STATED AND EXPLAINED.

By WILLIAM MORGAN, Esq. F.R.S.

Actuary of the Equitable Life Insurance Office.

1 Vol. 8vo. Price $12 s$.

47.

Memoirs of the Protector OLIVER CROMWELL,

AND HIS SONS, RICHARD AND HENRY.

By OLIVER CROMWELL, Esq.

A Descendant of the Family.

With Portraits, from original Pictures.

Second Edition. 2 Vols. 8yo. Price $1 l .8 s$. Boards.

48.

A SYSTEM OF UNIVERSAL GEOGRAPHY.

By M. MALTE BRUN,

Editor of the "Annales des Voyages," \&c.

Parts I. to V. Price 7s. 6d, each.

The Work is to be completed in Seven Octavo Volumes, Five of which have been already published in the Original, containing 665 pages of letter-press each, nearly double the quantity of an ordinary volume.

The Translation is printed on fine demy paper, and will be published Quarterly, in Parts, or Half-Volumos, Price $7 s, 6 d$. each. 


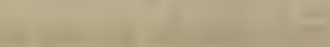

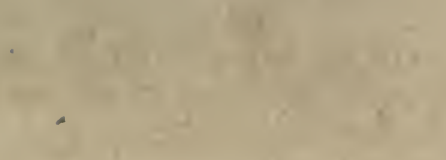

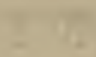

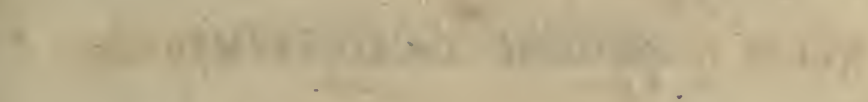

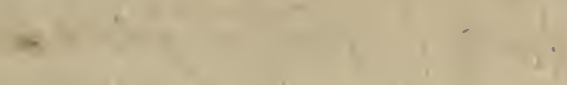

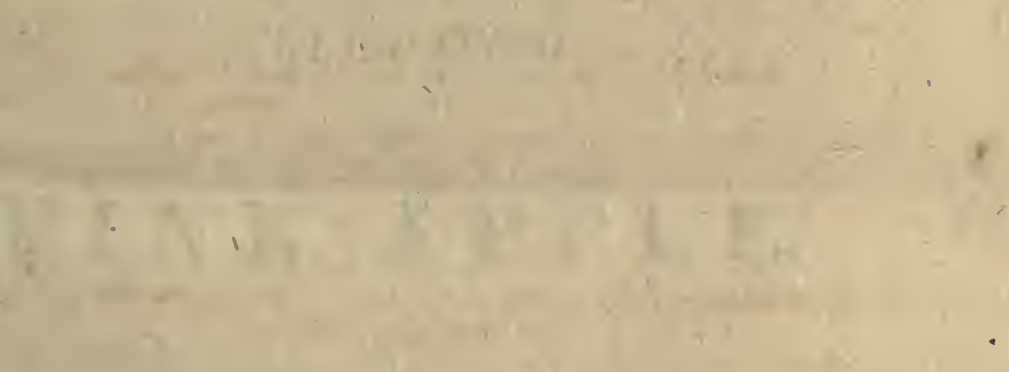

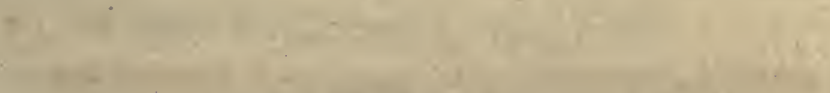

, 1.

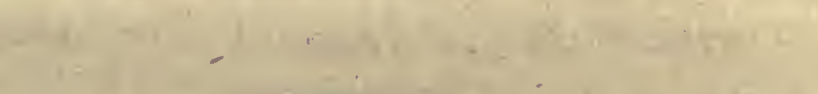

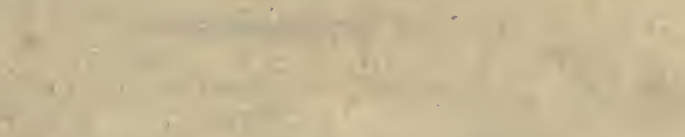

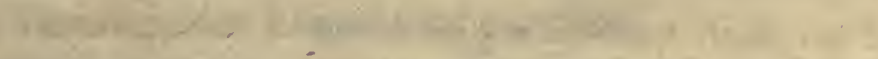

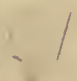

$$
\begin{aligned}
& \therefore \text { (1) }
\end{aligned}
$$

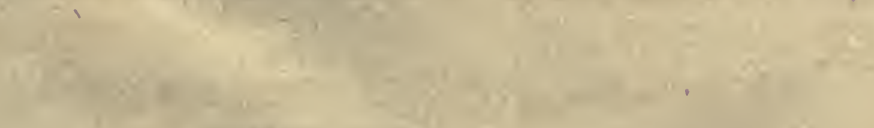

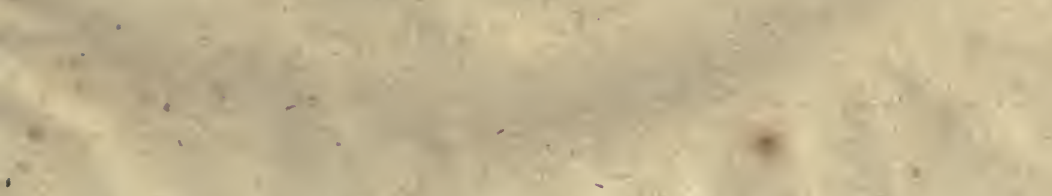




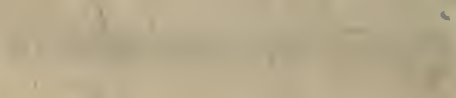

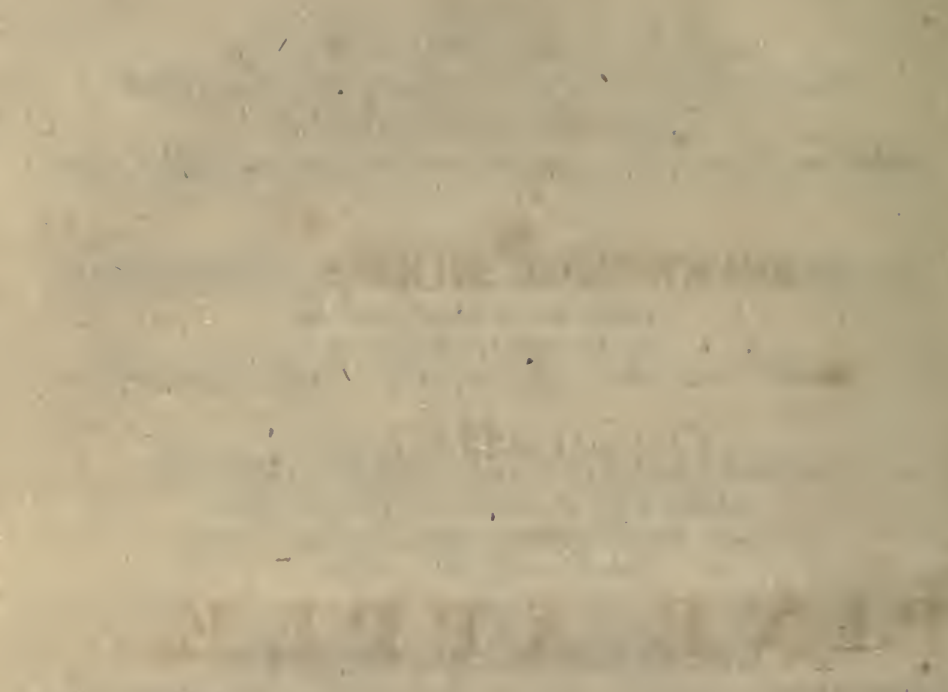

4.

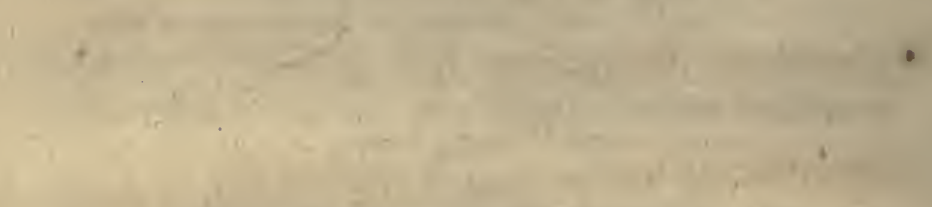

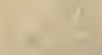

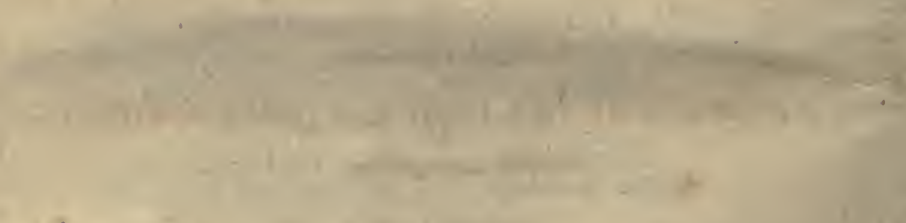

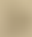

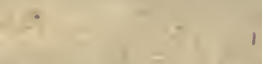

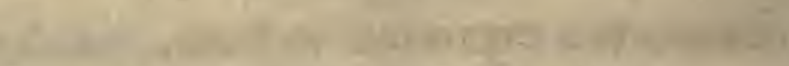

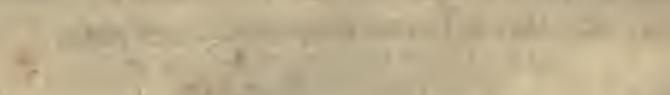

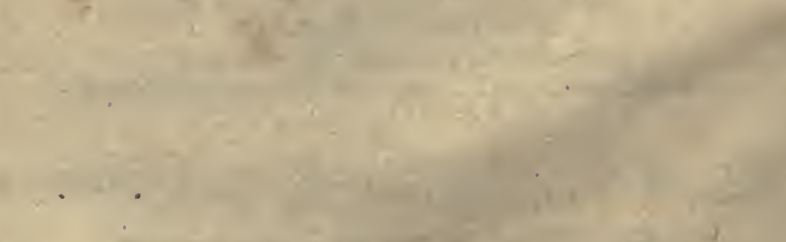

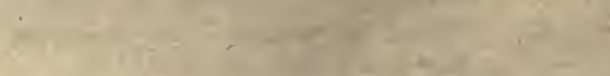

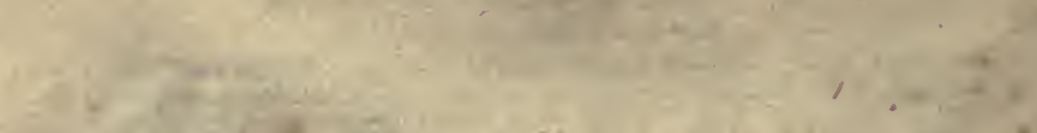

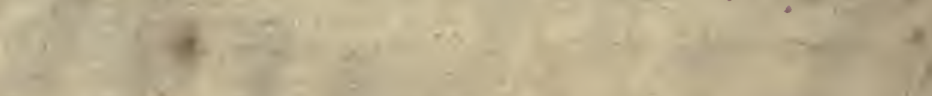


THE

\section{DIFFERENT MODES}

OT

\section{CULTIVATING}

THE

\section{P I N E - A P P L E,}

FROM

ITS FIRST INTRODUCTION INTO EUROPE

TO THE

LATE IMPROVEMENTS OF T. A. KNIGHT, ESQ.

BY A MEMBER OF THE HORTICULTURAL SOCIETY.

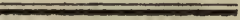

WITH

Twentu=four Ëngraninga on talood, EXHIBITING THE BEST PLANS OF PINE-STOVES AND PITS.

\section{LONDON:}

PRINTED FOR

LONGMAN, HURST, REES, ORME, AND BROWN, PATERNOSTER-ROW. 
New-Street-Square. 


\section{INTRODUCTION.}

A considerable interest has been excited in the Horticultural world by the experiments of T. A. Knight, Esq. on the culture of the Pine Apple. Our object is to add our efforts to those of that eminent Horticulturist, in promoting the culture of that king of fruits.

The "means which we consider as most likely to attain our object, is the bringing together accounts of all the different modes of treating that Plant, which have hitherto been adopted in Europe; and the sources from which we have drawn the means, are the different publications which have appeared on the Pine Apple, and our own observations on its management, by those Gardeners who are its most successful cultivators. 
The British publications which treat exclusively, or principally, of the Pine Apple, are :

1767. John Giles, of Lewisham. A Method of raising Pines and Melons, 8vo.

1769. Adam Taylor, Gardener at Devizes, in Wiltshire. A Treatise on the Ananas and on Melons, 8vo.

1779. William Speechly, Gardener to the Duke of Portland, at Welbeck, in Nottinghamshire. A Treatise on the culture of the Pine Apple, and the managemant of the Hothouse, \&c. 8 vo.

1808. William Griffin, Gardener to J. C. Girardot, Esq. at Kelham, near Nottingham. A Treatise on the culture of the Pine Apple, 8 vo.

1818. Thomas Baldwin, Gardener to the Marquis of Hertford, at Ragley, in Warwick- 
shire. A Treatise on the culture of the Ananas, \&c. $12 \mathrm{mo}$.

The Authors who have treated on the Pine Apple, as a part of their general subject, include nearly all those who have written on Horticulture since the commencement of the 18th century; the principal are, Bradley, Miller, Justice, Abercrombie, M·Phail, and Nicol, in their respective works; and T. A. Knight, Esq., and Peter Mársland, Esq., in the Transactions of the London and Caledonian Horticultural Societies.

The Foreign publications on the Pine Apple are few, and of little value; because the Continental Gardeners have never been very successful in its culture. Professor Thouin and M. Bosc, are the principal French Authors who have noticed the subject, and this only in general works, such as Rosier's Dictionary, \&c. Kirchner is almost the only German writer who has written on this fruit, in his Practische Anleitung für 
Gartenkunst, published in 1796, and devoted more particularly to the culture of the Pine and the Grape. Some other foreign tracts on the subject in the Banksian Library are merely translations from La Cours chapter on the subject, and from English authors.

The most eminent. cultivators of the Pine Apple in England, at the present time, are, Mr. Thomas Baldwin, Gardener to the Marquis of Hertford, at Ragley, in Warwickshire; Mr. William Griffin, Gardener to Samuel Smith, Esq., at Woodhall Park, Hertfordshire; William Townsend Aiton, Esq. Gardener to the King, at Kensington; Mr. James Andrews, Commercial Gardener, Lambeth ; and. Mr. Isaac Oldacre, Gardener to Lady Banks, at Springrove, Middlesex.

A number of other gardeners might be mentioned, as excelling in the culture of this fruit ; but the above have been first-rate cultivators for several years. 
On the Continent the Pine Apple is cultivated most extensively in Russia; it occurs but seldom in France or Germany ; and only in a few gardens in Italy. It has happened to us to have visited the principal Continental Gardens, as well as the English ones alluded to above, and various others; and we mention this to justify the extension of our remarks, not only to domestic, but foreign practices; and to account for our not confining ourselves merely to what is contained in books, but discussing also the modes of culture actually practised in different gardens. We shall first notice the introduction of - the Pine Apple into Europe, and next the different varieties in cultivation; we shall then glance at the Continental practices, and finally detail those of our own country. 


\section{This Day is published,}

By Longman, Hurst, Rees, Orme, \& Brown, London,

\section{An ENCYCLOPÆDIA of GARDENING;}

Comprising the Theory and Practice of Horticulture, Floriculture, Arboriculture, and Landscape Gardening; including all the latest Improvements, a general History of Gardening in all Countries; and a Statistical View of its present State, with Suggestions for its future Progress, in the British Isles.

\section{By J.C. LOUDON, F.L.S. H.S. \&c.,}

Author of "A Treatise on forming and improving Country Residences."

Complete, in One large Volume, 8vo. of 1500 Pages, closely printed, with Six Hundred Engravings' on Wood, Price £2. 10s.

This Work claims the Attention of the Public :

1. By the comprehensiveness of its plan, by which, for the first time, every part of the subject of Gardening is brought together ${ }_{2}$ and presented in one systematic whole.

2. By its being the only work which contains all the modern improvements in Gardening, foreign as well as domestic.

3. By the addition of a Kalendarial Index, by which the practical part of the work may be consulted monthly, as the operations are to be performed; and a copious General Index, by which the whole may be consulted alphabetically. Thus the work will serve as a Gardener's Kalendar, and Gardener's Dictionary : both, it is confidently hoped, far more complete than any hitherto presented to the public.

By means of a copious page, by condensed descriptive tables of fruits, culinary vegetables, and flowers, and by the local introduction of such illustrative engravings as greatly shorten the necessity of verbal description, this immense body of matter has been comprised in one thick volume. 


\section{CONTENTS.}

CHAP. I.

Of the Pine Apple; its Culture in the West Indies. Introduction to Holland. - And to England ...... 1

\section{CHAP. II.}

Of the varieties of the Pine Apple .....................

\section{CHAP. III.}

Foreign modes of cultivating the Pine Apple ......... 11

SEcr. I. Culture of the Pine Apple in Holland ..... 12

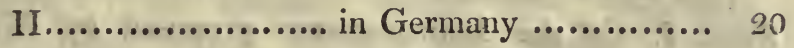

III................... in Russia ............... 22

IV..................... in France................ 24

V...................... in Italy .................. 26

VI. .................. in other parts of Europe 29

\section{CHAP. IV.}

Of the different modes of cultivating the Pine Apple, which have been, or are practised in Britain by practical Gardeners 
Sect. I. Mode of cultivating the Pine Apple, by Telende, in $1719 \ldots \ldots \ldots \ldots \ldots \ldots . . . .31$ II..........by Miller .............................. 34

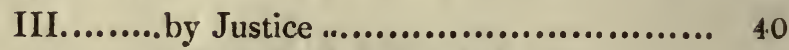

IV......... by Giles ........................... 43

V......... by Taylor ............................ 45

VI........ by Speechly.......................... 49

VII....... by M'Phail .......................... 67

VIII..... by Nicol ............................. 88

IX........ by Griffin ............................ 104

X......... by Baldwin ......................... 110

XI........ by Abercrombie....................... 120

XII....... by Andrews ......................... 125

XIII....... by Gunter ............................ 129

XIV....... by Oldacre ........................... 133

XV. ..... by Aiton ........................... 138

\section{CHAP. V.}

Improvements recently attempted in the culture of the Pine Apple .............................................. 146 SECT. I. Of the Improvements proposed by $\mathrm{Mr}$. Knight ................................... 148 II. Of other Improvements proposed ......... 170 


\section{ON THE \\ CULTIVATION \\ OF THE}

\section{PINE APPLE.}

\section{CHAP. I.}

OF THE PINE APPLE.

Its Culture in the West and East Indies. - Introduction to Holland. - To England.

The Pine Apple is the Bromelia Ananas of Linneus; of the artificial class and order Hexandria Monogynia; and of the natural order of Jussieu, Bromeleæ. The generic name was originally Ananas, from Nana, its common name in the Brazils; and the Queen Pine is named the Ananas Ovata, in the earlier editions of Miller's Dictionary; but Linneus changed it to Bromelia, in memory of Olaus Bromel, a Swedish naturalist, and included under it the Karatas, or Wild Pine, till then considered, a distinct genus. The English name of Pine Apple appears to have 
taken its rise from the resemblance of the fruit to the cone of some species of the Pine tree.

There are twelve species of Bromelia, described by Persoon; the fruit of all which may be considered edible, and is occasionally made use of by the natives. Six of these species are naturalized in the West Indies; and the rest are found wild in Chili, Peru, and other parts of South America.

The Bromelia Ananas is the only species in general cultivation; it is cultivated abundantly in both the Indies, and in China. It is said to grow wild. in Africa; but Linneus ascribes it to New Spain and Surinam; and Acosta. (Histoire Naturelle des Indes, ) says, it was first sent from the province of Santa Croce, in Brazil, into the West, and afterwards into the East Indies and China. Persoon considers it as a native of South America; and Baron Humboldt and the Prince Maximilian found it in the Caraccas, in the Brazils.

Whichever way it was introduced from South America to the West Indies, its culture in these islands, and particularly in Jamaica, has been carried on for an unknown length of time. It is vulgarly supposed in this country, that it grows wild there; but, from the best information which we have been able to collect, the true Ananas is only cultivated in gardens, or grounds under spade culture; and there much in the same way as cabbages are in this country, and produces its fruit in 
from fifteen to eighteen months after planting the crown. The common weight of the fruit is from half a pound to three pounds; and it abounds chiefly in the dry season. In the rainy season, which includes nearly half the year, ripe Pine Apples are more scarce in the gardens of Jamaica than in the hot-houses of England.

In the neighbourhood of Calcutta it is cultivated in the same manner as in Jamaica, and, when liberally supplied with water, by a system of surface-irrigation, the first is said to attain a large size, and to be in season most months of the year.

The first attempts to cultivate the Pine Apple in Europe seem to have been made about the end of the seventeenth century, by M. Le Cour (or La Court, as written by Collinson), a wealthy Flemish merchant, who had a fine garden at Drieoeck, near Leyden. Of this garden he published an account in 1732, and died in 1737.

It was visited by Miller and Justice, who speak of its proprietor as one of the greatest encouragers of gardening in his time; of having curious walls and hot-houses; and as being the first person who succeeded in cultivating the Pine Apple. It was from him, Miller observes, (Dictionary, Art. Bromelia, ) that our gardens were first supplied, through Sir Matthew Decker, of Richmond, in the year 1719; though, as a botanic plant, it had been introduced so far back as 1690 , by Mr. Bentick, afterwards Earl of Portsmouth. 
"When I say," observes Mr. Cowel of Hoxtor, in his Curious and Profitable Gardener, Lon. 1730, p. 2\%. " that the first Pine Apples that were cultivated in England, were in Sir Matthew Decker's gardens at Richmond, I mean the first that were cultivated with success, were in those gardens; for long before we had plants of them brought to us, but had not before that time conveniences for bringing them to fruit, or even of keeping the plants alive."

"The Pine Apple," he adds, in the same page, " is now (1730) found in almost every curious garden."

The fruit of the Ananas was sent to Europe, and especially to Holland, as a preserve, for many years before the Ananas plant was introduced.

That it found its way even to England in this state, so early as the sixteenth century, is evident from what Lord Bacon says of it in his Essay on Colonies; and also from a picture in the possession of the Earl of Waldegrave, representing Charles II. in a garden, and Rose, the royal gardener, presenting his Majesty with a Pine Apple. This picture, Lord Walpole informs us, was bequeathed by Mr. London, who was Rose's apprentice, to the Rev. Mr. Pennicott, of Thames Ditton, by whom it was presented to himself. It does not appear, however, that the Pine was cultivated either by Rose or London, otherwise it would certainly have been noticed in the publications, which, if not written by, at least passed under the 
name, and received the sanction of London and Wise; and also of Evelyn, Ray, Rea, and other gardening writers of these times. In short, it is evident from Ray's letters, that the idea of heating green-houses by fire was quite new in 1684, and first adopted by Mr. Watts, gardener, to the apothecaries at Chelsea in that year; and Miller states, (Dict. Art. Tan,) that there were very few tan-beds used in England before the year-1719. The Pine Apple, therefore, could not be cultivated in the seventeenth century in England.

Of late years the Pine Apple has been sent to England in abundance, attached to the entire plant, and a cargo has arrived from Providence Island, in the Bermudas, in six weeks. This facility of cultivation, and their more general culture, has greatly lessened their price, and rendered them common. They are sold in fruit-stands in the London streets, in one or two places, during the summer months.; and moderate-sized fruit may be had from half-acrown to a crown each; or at two shillings a pound. 


\section{CHAP. II.}

OF THE VARIETIES OF THE PINE APPLE.

OF the Pine Apple, as of most other fruits that have been long in cultivation, there are many varieties. The principal part of those cultivated in this country have been obtained from the West India islands; but some also have been raised in this country from seed.

Speechly states, that, in the year 1768 , he raised seventy plants from seeds that were sent to the Duke of Portland from the West Indies, most of which varied distinctly either in the leaves or fruit, but the quality of the latter was very inferior.

The most esteemed varieties in present cultivation are:

1. The Old Queen. Fruit oval-shaped, and of a gold colour. Esteemed the hardiest kind, and fruited in fifteen or eighteen months. The fruit grows to a large size, often weighing from three to four pounds. It is much more certain of shewing fruit at a proper age and season than most of the other sorts, and has a just preference in most hothouses. 
2. Ripley's New Queen. A sub-variety of the Old Queen, with a large elegant fruit; fruited also in an equally short period.

3. Welbeck Seedling; fruit small, generally broader at the head than at the base; of a pale yellow, or sulphur colour, with very flat pips; flesh white and tender, rich in flavour, with less acidity than is found in most other pines. Hort. Trans. iv. 213.

4. Pyramidal, or Brown Sugar-loaf. Coneshaped, and dark coloured till it ripens; the leaves brownish, the flesh yellow.

5. Prickly Striped Sugar-loaf. Cone-shaped, the fruit of a golden colour, the leaves striped with black or purple lines.

6. Smooth Striped Sugar-loaf; similar to the above, but the leaves not prickly.

7. Havannah. Tankard-shaped; dark coloured till it ripens.

8. Montserrat. The leaves of a dark brown, inclining to purple in the inside; fruit middle-sized and tun-shaped, and the pips or protuberances of the fruit larger and. flatter than in the other kinds.

9. King Pine, or Shining Green. The leaves of a grass-green, with few prickles, the pulp hard and rather stringy, but of good flavor when ripe.

10. Green, or St. Vincent's Pine. A rare variety; when ripe the fruit is of an olive hue, middlesized, and pyramidical. 
11. Black Antigua. The fruit is shaped like the frustrum of a pyramid : leaves of a brownish tinge, and drooping at the extremities, with strong prickles, thinly scattered. The pips of the fruit are large, often an inch over; and it attains a large size, weighing from three to four pounds. It is of a dark colour till it ripens; very juicy, and high flavoured.

12. Black Jamaica. The fruit is large, and the plant similar in character and habits to the above.

13. Providence Pine. There are two varieties, the white and green; the fruit is larger than that of any of the kinds cultivated in this country; the form inclining to pyramidical; the colour, at first, brownish grey, but, when mature, of a pale yellow. The flesh yellow and melting, abounding with quick lively juice. Speechly produced in the gardens at Welbeck, in 1794, a fruit that weighed five pounds and a quarter, or eighty-four ounces, and from a plant that was not a large one. Griffin had, in 1803, two plants placed under his care, which fruited in.July 1804; the fruit of one plant weighing seven pounds two ounces, and the other nine pounds three ounces, avoirdupois. This sort, and the two preceding, require generally three years, and sometimes four or five, to produce their fruit.

14. Blood-red; fruit equal in bulk at both ends. Pips of moderate size; colour brick-red; flesh 
white and opaque; leaves of a changeable hue; the flavor of the fruit being inferior to that of most others; this is to be considered merely as a curious variety. Hort. Trans. iv. 214.

15. Silver-striped Queen. Leaves beautifully striped with white, yellow, and red; but the plant, though elegant, is a reluctant fruiter.

16. Variegated-leaved Pines. Besides the Striped-leaved Queen, there are several sorts with beautifully varied leaves and fruits ; but in general they are tardy in fruiting, and more to be con. sidered as ornamental than as useful varieties.

To these may be added, as sorts not generally known, or of inferior value:

The Smooth Pine. Miller.

The Smooth Long Narrow-leaved Pine. Ibid.

The Grunda Pine.' Ibid.

The Bogwarp Pine. Ibid.

The Surinam Pine. Ibid.

The Antigua Queen. Speechly.

The Green Providence, or Old Providence, from one of the Bermuda islands of that name.

New Sorts. Pine plants are frequently imported from the West India islands, and in this case generally bear their names. In general, however, these plants are far inferior, both as to kinds and condition, to those grown, and to be procured from nurserymen in this country. They are ge- 
nerally infested with the bug, and very uncertain in their time of fruiting, as well as to its flavor. If these were to be enumerated, the list of pines known in this country would amount to upwards of forty sorts. Specimens of above thirty sorts are grown in the gardens of Mr. Gunter, at Earl'scourt.

The Pine Apple, as every gardener knows, is propagated in the same manner by all those who grow it; that is, by that singular production in which the fruit terminates, called a crown, and by suckers; these are planted in small pots, or in beds of rotten tan, earth, or dung, at first, and shifted in regular gradation into pots of different sizes, at the discretion of the cultivator. 


\section{CHAP. III.}

FOREIGN MODES OF CULTIVATING THE PINE APPLE.

Culture of the Pine Apple in Holland, - France, - Germany, Italy, \&;. .

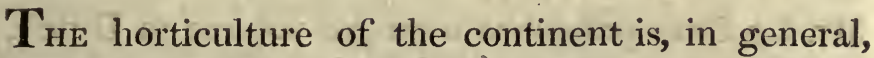
copied from that of Holland, as was our culture, and that of every other country two centuries ago. Excepting in Holland, therefore, the English gardener will find very little to learn in other countries; but it is worth while to know how little is to be known in one quarter, that we may be the more assiduous in our attention to such quarters as are likely to furnish us with information.

For this purpose, we shall take a short view of the culture of the Pine Apple in the principal parts of the Continent.

Whether Le Cour was the first who imported Pine plants from the West Indies, is less certain than that he was the first to attempt their culture with success. Professor Bradley, in his General Treatise of Husbandry and Gardening for July 1724, p.206. gives a description of the Pine Apple, and the introduction of it into Holland by Mr. Le Cour. He says, that there were in the Amsterdam gardens 
about two hundred plants, chiefly from Surinam and Curaçao, but some from the Dutch factories in the East Indies, which were in good health; but the art of bringing them to fruit was not known till Mr. Le Cour took them in hand. Miller says, that after a great many trials, with little or no success, Mr. Le Cour did at length hit upon a proper degree of heat and management, so as to produce fruit equally good (though not so large), as that which is produced in the West Indies. About the year 1737, the year before his death, Mr. Le Cour published a quarto volume in Dutch, containing the result of his observations on gardens, trees, and flowers ; with explanatory descriptions of his stoves.

From this work, and from the statements of Professor Bradley, (Treatise on Husbandry and Gardening, for June 1724, p. 161.) we learn that Le Cour's mode of treating the Pine plant was very similar to that adopted at Sir Matthew Decker's garden at Richmond, to be afterwards described; but we shall give this gentleman's practice, as related by himself.

\section{Sect. I.}

Culture of the Pine Apple by Mr. Le Cour in the beginning of the 18th century, at Drïeock, near Leyden.

I Distinguish, he says, three different species of Pine Apple ; the first and best has green leaves, gar- 
nished with fine prickles, fruit of which I have had seven inches high, and thirteen inches in circumference ; this sort, if it is kept cool before it shows fruit, and then advances slowly by somewhat more heat, grows larger and more pointed than that which has been kept warmer and in a growing state during winter. The leaves of the second sort are larger and broader, of a darker green mixed with red; it does not produce fruit of so large a size, but its knobs are broader and larger, yet flater; the unripe fruit being of a reddish brown, and when ripe of a deep yellow, with brownish yellow spots on the knobs; this sort has not so pleasant a taste as the first, which, when unripe, is of a darker green, and when ripe, with lighter yellow knobs, on which account I cultivate chiefly the following sort.

This is called the Smooth Ananas, on account of its being without prickles, but the ends of the leaves grow longer, narrower, and more upright : the fruit is smaller. The Ananas cannot bear the cold of our winter, and must have in summer a more permanent warmth and less change in the winter than we commonly have in our climate; and must therefore not only be put during the winter into stoves, but even during the summer under glass frames, and the pots placed in a hot-bed of tan. However, it is with these plants, as it is with all others from a warmer climate; when they by degrees have been accustomed to our colder climate, they become more hardy, and can bear more 
cold and change of weather, and therefore produce better fruit than those which are sent to us from abroad and have been reared in a warmer country more congenial to their nature. It is therefore necessary that we should try to get plants that have already been accustomed to our country, by propagation from suckers for a number of years, for in that case they may be reared with very little trouble.

The most convenient time to take away the suckers is from the middle of June to the end of the month. Both suckers and crowns must be put in sandy earth in little pots, as in this manner they strike their roots best; but when the plants have grown larger, they must be transplanted in the following year in richer and less sandy earth, and in larger pots, care being taken that the earth is not loosened from the roots in shifting them. The most convenient time for transplanting them is in March, when the plants must be taken from the hot-house and put in a bed of earth under a frame. Care must be taken in shifting them into other pots, to make the earth adhere well to the roots, and to water them well afterwards, and not to use too large pots, as they take up more room, are not so easily handled, and are less proper for growing large fruit than those of a moderate size; the most convenient pots for transplanting are ten inches in diameter within the rim, seven inches at bottom, and ten and a half inches deep. 
The plants, when growing, commonly require a great deal of water, and more when they set their fruit. They should then be watered frequently all over their leaves. Afterwards they must be treated with more caution, and be less watered; for too much water would be injurious about the time of the ripening of the fruit, which would get watery, and of a transparent greenish yellow, and be of infe. rior taste and smell. Too little water dries them up, and makes the marrow perish in the leaves, the first signs of which are, when you hold the green leaves towards the light, you will perceive them speckled with yellowish spots. To produce proper fruit, the plant of a sucker or crown must have grown well and bulky, at least for three years ; the first sign of setting fruit is, that its leaves spread a little, and the plant opens a little in the heart where the fruit soon shews itself like the head of a large nail. As the fruit and stalk grow higher, the fruit grows rounder, with pointed little leaves like thistles, on some reddish, and on others whitish spreading leaves. After the fruit has grown about a montli; and is of the size of a walnut, there appears out of each knob a three-leaved pointed little flower, which, in the Common Ananas, is of a pale blue colour; on the Red Ananas, deep blue; and on the third sort; the Smooth Ananas, almost violet. This flower does not fall off with the increase of the fruit, but shrivels up, and leaves some visible remains behind when, the fruit has attained its full maturity. 
The time, from the beginning of the fruit to its perfect maturity; cannot be limited to a certain number of days and weeks, since it depends very much on the weather of two summers following. During the spring, when the plants are in the hothouse, a very natural growth may be obtained by heating the stove, and by the sun shining at right angles on the glass, which growth may be continued during the summer. In autumn this cannot be the case, because the sun has less power, and the rains common to that season diminish it still more; therefore, from December at latest, more and more artificial heat must be given to the plants, until they begin in the middle of February, or at farthest in the beginning of March, to show their fruit, which then, with good summer weather and proper treatment, will attain to maturity in the beginning of July, and thus are five months ripening; the fruit, which shows itself in the beginning of March, wants at least a fortnight more to ripen; that which appears in the middle of March wants a month more, and consequently is six months coming to maturity; that which shows itself in April wants still more, and seldom becomes so ripe as to obtain its proper taste and smell. The agreeable smell which the ripe Ananas emits on lifting up the sashes, is the surest proof of maturity: it is then of a deep yellow, and the knobs have brownish yellow spots.

The time for removing the plants from the bark bed into the flued pit, and hence again into the bark bed, cannot be fixed, as this depends on the 
weather, and on the length of summer or winter. In some years I have been obliged to put them in a hot-house in September, and keep them there until April; but in common years they are moved into the hot-house on the 10th or 12th of October, and from thence again into the hot-bed of $\tan$ in the middle of March. The flues must be dried by heating them before the plants are brought into the hot-house, not only to remove the damp which, on the first heating, is powerful and injurious, but also to discover whether there are any openings by which the smoke may escape into the hot-house, for they must be carefully stopped up. This pit or wintering house may be of any convenient length or breadth; supposing two joined together, then the fire flues (fig. 1. a. a.) may be formed at the extreme ends; the smoke may first enter and fill a vault of the whole width and length of the pit (b.); it may afterwards enter a flue (c. c.) and pass round the pit, and then out by a chimney in the back wall.

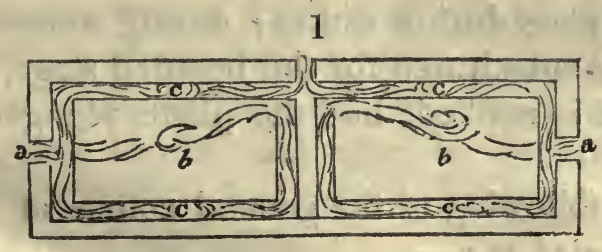

The sashes of the pits at Drieoeck are six feet wide, and three and a-half feet broad, and each has a cover of boards which are raised up and let down by means of cords and pullies, the better to retain 
the heat in the winter months (fig. 2.) Their slope forms an angle, with the horizon of about twenty degrees.

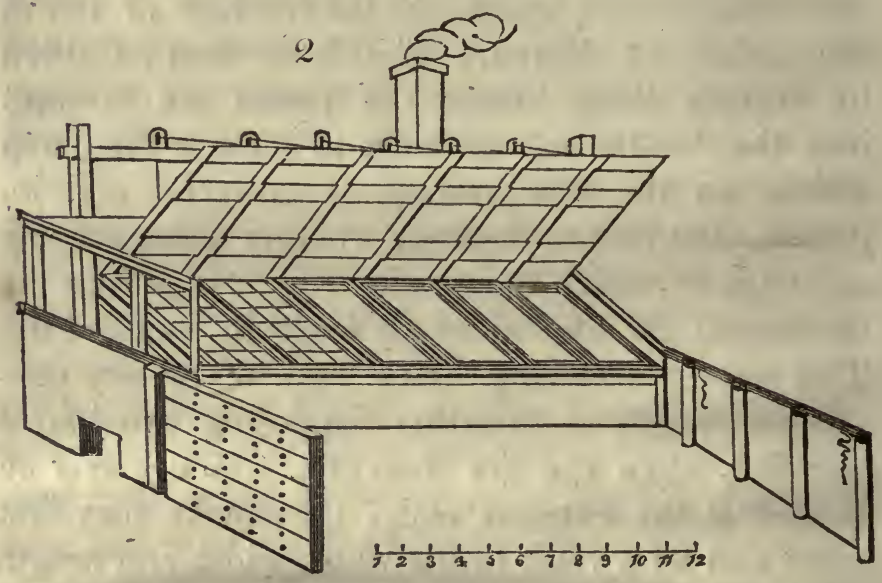

In these pits a boarded stage is formed, on which the plants are set, so as to be almost touching the glass during winter; during summer a bed of tan is substituted for the boarded stage, and no fire-heat is applied, but the plants plunged in the $\tan$.

The following is the general course of temperature aimed at :-

Temperature during the first fourteen days in October, when the plants are removed from the hot-beds of bark to the stages in the flued pits, $87^{\circ}$ Fah. 
Temperature from this time till the 20th of the January following, from $55^{\circ}$ to $64^{\circ}$.

Temperature from January to March not under $55^{\circ}$. Lowest degree admissible during winter $42^{\circ}$. Highest summer heat $105^{\circ}$.

Temperature of the bark hot-beds, in which the plants are placed to fruit when air is given, $103^{\circ}$.

Ordinary summer heat for the fruiting plants $96^{\circ}$.

In Holland and Flanders, at the present day, the Pine Apple is never grown in any other manner than in pits and hot-beds. The crowns and suckers are struck and forwarded, from three to six, or nine months, in hot-beds, and afterwards removed to pits. These pits differ from ours in being rather steeper in the roof, and generally the fruiting pits have a passage at the back, with a flue against the back wall; and an entrance door to the passage at one end. In some the passage and flue are in fiont, and in others a passage and flue are conducted round the house, leaving the pit in the middle; but this is rather an uncommon form, and chiefly to be met with in pits or stoves for ornamental plants. The fuel in general use is peat, and the glass is well covered with boards and matting or canvas or thatch every night after sun-set, excepting in the warmest part of the season.

The soil used by the Dutch is good garden earth, mixed with a third part of well-rotten hot-bed dung, or cow dung, and a sufficient quantity of sand to render it fiee and pervious to moisture. 
The gardeners there are by no means so particular in the article of soil, as many are in this country; their object seems to be to make it rich and free; without being very anxious as to employing virgin soil only, or any particular kind of dung. They generally, however, keep the mixture some time in heaps, and turn it over once or twice before using it. At the same time we have seen them shifting Pines, and using a black rich earth newly dug out of an adjoining plat of turnips; only mixing it with a little rotten dung and white sand.

They shift their plants in spring, and refresh the surfaces of the pots in autumn, and they seem on the whole to fruit them in larger pots than we do; but they leave off shifting them nine or ten months before the fruit is expected to appear, wishing to have the pots filled with roots at this crisis. They seldom fruit a crown plant under two years, and more generally three, from the time it is taken from the fruit; large suckers they fruit earlier, according to their size when taken off the mother plant; some which come out from near the bottom of the stem they earth up, and do not take off at all. These come early into fruit, but it is not large.

\section{SECT. II.}

Culture of the Pine Apple in Germany.

The Germans took their horticulture from the Dutch, as they did their landscape gardening from 
the French. They seem to have tried the culture of the Pine Apple almost immediately after its introduction to Holland; for, according to Beckmann, it was ripened by Dr. Kaltschmidt at Breslaw in 1702, who sent some fruit to the Imperial Court; but he states also that its culture was first attempted by Baron Munchausen, a great encourager of gardening, and a botanist who had a fine demesne and garden at Schwobber, near Hamelin, in Westphalia. From the account of these gardens in the Neuremberg Hesperides, they appear to have been grown both in pits, and on stages in larger houses.

The king of Prussia grew the Pine Apple extensively at Potsdam; he followed the Dutch manner in every thing, and had a gardener from that country who attended exclusively to the forcing department at Sans Souci. The quantity of glass there was greater than any where else in Germany: the whole was kept in high order and good culture for many years ; but after the king's death, in 1786, it soon fell into neglect; the glass of most of the peach-houses and vineries was removed or destroyed; the Pine plants were neglected and diminished in numbers, from time to time. In 1813 the royal gardens at Sans Souci contained only about two dozen of Pine plants, which were kept in a lofty opaque roofed conservatory, and these, as may be easily imagined, were by no means in a thriving condition.

Before the French Revolution, the Pine Apple was cultivated at most of the court gardens in Ger. c 3 
many; but in the year 1814 , there were very few in the empire.

\section{SECT. III.}

\section{Culture of the Pine Apple in Russia.}

The Pine Apple is extensively cultivated in the imperial gardens in the neighbourhood of Petersburg and Moscow, and also in those of a few of the greatest nobility and mercantile men adjoining those cities. Nothing can be more wonderful than to contemplate the resources by which this plant, requiring not less than from 50 to 70 degrees of heat at all times of the year, is preserved in existence through a winter of seven months, during the whole of which the ground is covered with snow, and Fahrenheit's thermometer, often for weeks together, at $20^{\circ}$ below Zero.

The head gardeners of the emperor, and the great nobles of Russia, are, for the greater part, Britons; and the sort of houses they erect, and the mode of culture they follow, is as nearly as circumstances will admit, those of Speechly or Nicol.

The culture of the grape is, to a certain extent, combined with that of the Pine Apple; the former is trained on the rafters, and the latter grown in a pit, surrounded by flues and a path. In addition to the flues, many of the fruiting-houses have stoves built in them, on the German con- 
struction, which are used in the most severe weather. Sometimes there is a double roof of glass; but more generally the roof, ends, and fronts, are covered with boards; which not only prevents the weight of sudden falls of snow from breaking the glass, but by admitting of a coating of snow over them, prevents, in a considerable degree, the internal heat from escaping. This covering, or a covering of matts or canvass, as practised near Moscow, and from which the snow is raked off as fast as it falls, is sometimes kept on night and day for three months together. The plants being all the while in a dormant state, it is remarkable how little they suffer.

The best ranges of hot-houses in the neighbourhood of Petersburg, have been imported there from Leith, or London. At Moscow, where the same facility of importation is not afforded, they are constructed on the spot, in a very rude manner; in the best of them, the interstices between the sashes and rafters are so large, that they have to be stuffed with moss. Still it is astonishing how well the Pine Apple is preserved in them through a long 'winter, and what excellent peaches and grapes they produce during summer. The cause seems to be owing to the great care and skill of the gardeners, in keeping the plants in a dormant state, when there is but little light; and in applying powerfully all the agents of growth and culture, during the short, but warm Russian summer.

There are some German gardeners in Russia, C 4 
who cultivate the Pine Apple in pits as in Holland; and crowns and suckers are forwarded in this way by them, and also by the British gardeners settled in that country.

\section{SECT. IV.}

Culture of the Pine Apple in France.

The culture of the Pine Apple does not appear to have been commenced in France till after the middle of the eighteenth century, and then only in the royal gardens at Versailles, in those of the Duke of Orleans at Mousseaux, and one or two others. It has never been cultivated by above a dozen persons in that country; nor is it grown by so great a number-at the present time. The best are in the garden of M. Boursault, within the boundary of Paris ; and the next those of the king at Trianon and Versailles, and of the banker Lafitte, at his country-seat, a few leagues from the capital.

M. Boursault grows them in low houses, which may be termed pits, being without glass in the front or ends; the plants are plunged in tan, and kept as near the glass as possible; and the soil used is good garden earth, or free soil (terrefranche), with about half its bulk of poudrette, or desiccated nightsoil. M. Boursault tried them formerly in the poudrette alone, but found they did not succeed so well as when a smaller quantity 
was used. He produces fruit from half a pound to two pounds in weight, and it is said of a good flavour.

Rosier states, that M. Mallet, a curious horticulturist, grew ananas in a peculiarly constructed frame of his own invention (fig. 3.); but we could see none of these frames in use in any way, and were

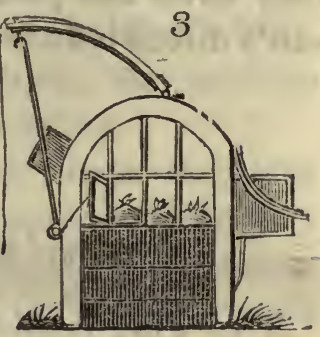
informed by different persons, that they were too expensive in their first cost to succeed.

The Pine plants in the royal gardens, did not appear to us so well cultivated as those of $M$. Boursault; they were very much drawn, and seemed too sparingly watered. All the Pine plants which we have seen in France, and also in Italy, had this yellow sickly appearance; and the fruit produced was universally of small size; one of three pips is thought worth presenting to table. It is certainly a very singular fact, and not hitherto explained, that the Pine plant in a climate where it gets more light than in Germany, Britain, or Russia, should yet be less green than in those countries. Had the reverse been the case, the circumstance would not have been surprising; but that more grêênth should be produced in the northern hemisphere, and under the torrid zone, than under what might be considered as a happy medium between two extremes, is astonishing, and leads to a suspicion of deficiency of management. 
The cause seems referable to deficiency of water, and too great heat during night; for during day they have the precaution to shade them from the sun's direct influence.

\section{SECT. V.}

Culture of the Pine Apple in Italy.

The- Pine Apple was grown in Italy before the revolution, by the Pope, at Naples, and by the king of Sardinia, at Turin. The late king of Sardinia sent his gardener to England, to study the culture of this fruit; and he returned and published in $177 \%$, a pamphlet on the subject. He recommends it to be grown in pits, much the same as those of the Dutch, but without flues, which is still the general practice in Italy. After the possession of Piedmont by the French, the royal palaces and gardens were neglected, and in 1819, when we saw them, they were not restored.

At the royal gardens, and those of Prince Leopold, at Portici, near Naples, a few Pines are grown in pits, by two German gardeners, that of Prince Leopold, an intelligent man and a good botanist; but the plants, notwithstanding the fine climate, are etiolated, slender, and pale, with very small fruit. The pits were entirely sunk in the ground, narrow, and without flues, and they were shaded in the day-time with a net. It appeared to us, that they were much too tenderly treated; if 
uncovered in the night-time, or planted in the open garden, and left exposed all the summer, and covered with double glass frames during winter, without any fire heat ; but, if occasion required, surrounded by linings of dung, we have no doubt they would succeed much better.

At Caserta, a royal palace about eighteen miles from Naples, the Pine Apple is grown in a style much superior. The gardens and grounds there, were laid out by M. Græffer, a German gardener, who was formerly a partner in the firm of Gordon, Thomson, \& Co. London nurserymen. The hot-houses are built exactly in the English style; the Pines raised and forwarded in pits, and fruited in broad low houses, with vines trained under the rafters, in Speechly's manner. M. Græffer died in 1816, and his son has still the care of the royal gardens, and in 1819 had the Pines, in what would be considered in this country, middling good order. They were certainly of a much less vivid green than those of England or Holland, and the fruit was smaller ; M. Græffer, jun. never having been out of Italy, was not aware of the difference; but on enquiring into his mode of treatment, we were led to suspect a deficiency of water and of moisture, by watering the flues and paths of the house, and too great a heat kept up during the night. The air of Italy is, at most periods of the year, much drier than that of the north of Europe; that of France and Germany is also drier than the air of Holland, Britain, and Russia; and perhaps this 
difference in atmospheric moisture, and the overheating at night, may, in some measure, account for the difference in the colour of the foliage of the Pine and other plants kept under glass in France and Italy.

There are some Pines grown at Rome, Florence, and Genoa; but they are not much better than those of Portici. The greatest number, and the finest plants and fruit which we saw in Italy, was in the Vice-regal gardens at Monza, near Milan, under the management of a most intelligent Italian gardener, a pupil of Professor Thouin of Paris, Signior Luigi Vilaresi. The treatment is in all respects that of the Dutch; the plants are forwarded in frames, and sometimes in the open air for a month or two during summer; they are fruited in large pits, with a walk behind, and when more plants come into fruit than are wanted, they are retarded, or preserved, by being placed in a division of the pit without bark, and where they receive abundance of air in the day-time, but no water. The plants here were large and long-leaved, but still not so green and stocky as those of England, and the fruit did not appear to be above one and a half, or two pounds in weight. On enquiry, we found no air was ever left to the pits in the night-time. 


\section{Sect. VI.}

Culture of the Pine Apple in other parts of Europe.

The Pine Apple has been fruited at Stockholm, and in one or two places besides in Sweden; and also in the Court gardens at Copenhagen, and by De Conninck, and some of the rich merchants of Denmark; but we could hear of none being grown in either of these countries, when we visited them in 1813 and 1814.

It is said to be cultivated in Spain, near the sea coast; and also at Lisbon. We know it was grown by the late M. De Vismes, near the latter city; and we believe it is now grown by some English merchants at Seville; but this is all we know. It does not appear to be grown in European Turkey. 


\section{CHAP. IV.}

OF THE DIFFERENT MODES OF CULTIVATING THE PINE APPLE WHICH HAVE BEEN, AND ARE PRACTISED IN BRITAIN BY PRACTICAL GARDENERS.

THE Pine Apple plant, as already observed, seems to have been first introduced by Mr. Bentick, afterwards re-introduced from Holland in 1719, and then first cultivated for its fruit in Sir Matthew-Decker's garden at Richmond. Here, according to Professor Bradley, the gardener, "Mr. Henry Telende, imitated so successfully M. Le Cour's newly discovered method of cultivating this delicious fruit, that he is likely to ripen forty of them in the present (1724) autumn." (Husb. and Gard. for June 1724, p. 161.) He elsewhere tells us that " the late instance of bringing the Ananas or Pine Apple to perfection in England, by the ingenuity of Mr. Telende at Sir Matthew Decker's, has so far gained upon the curious, that already many of our nobility have undertaken the same improvement; and 'tis not to be doubted but a year or two more will make this undertaking much more general." He mentions " their being brought to extraordinary perfection at the garden of the right honourable Spencer Compton, Speaker of the House of Commons, at Chiswick; and at that curious gentleman's, Mr. John Warner, Rother- 
hithe." He informs us that an excellent stove on a new plan, with a bark pit, was built by William Parker, Esq. near Croydon, in Surry, to make " experiments in ripening fiuits that has not been tried;" and that Mr. Fairchild, in 1722, built one at Hoxton for Pine Apples and other tender plants, in which the fire flues were raised above the surface of the floor, by which means all danger firom damps was avoided. Mr. Cowel, as before observed, (p. 4.) states that in 1730 Pine Apple stoves were to be found in almost every curious garden. Mr. Telende's mode of cultivating the Pine Apple is detailed by Professor Bradley in 1724, and the most generally approved mode of culture from that time to the middle of the eighteenth century may be considered as given by Miller in his Dictionary: The improvements which have since been made by practical gardeners, may be ranged under the heads of Justice, Speechly, Abercrombie, M·Phail, Nicol, Griffin, Baldwin, Andrews, Oldacre, Gunter, Grange, and Aiton. To each of these names we shall devote a section; and under each, consider in succession, the form of house, soil, general treatment, insects, and fruit produced.

\section{Sect. I.}

Mode of cultivating the Pine Apple practised by Mr. Henry Telende, in the Garden of Sir M. Decker, at Richmond, 1719, to 1730 , or later.

Form of House. For the education and ripening of this fruit, Mr. Telende employed a frame made of 
deal, closely jointed : the length eleven feet, divided equally into four lights ; the width seven feet and a half; three feet high at the back, and about ten inches in front. The pit was somewhat more than five feet deep in the ground; the sides were lined with brick, and the bottom covered with pebbles.

The stove or fruiting-house used was that with iron plates over the flues; which, for greater warmth, was covered thick with thatch, and the glasses were well guarded with shutters; and that the fire might be constant, he burnt only such turf as is commonly used in Holland, agreeable to M. Le Cour's method.

General Management. About the middle of February, he "puts in as much hot dung or horselitter as will raise the bed about a foot high, and then lays on the tanner's bark as equally as possible, till the case of brick-work is filled, beating down the tan gently with a prong, or pressing it down easily with a board. A bed of this kind will take up three hundred bushels of tan, and if it be well made, will heat in about fifteen days, provided the frame and glasses are set over it. When the bed breathes a right heat, which we are to judge of by a thermometer, the plants are brought from the stove to it, either to have their pots quite plunged into the bark; or, if upon opening the holes for them, the bark be found too hot, then to be set in only half way, laying a few pebbles under the bottom of each pot, that the water may pass freely through them. Care must be taken not to remove the pots in frost 
or snow ; and to examine the bed from time to time, whether the bark grows mouldy, musty, or dry, which it will often do in the summer: in such case, it must be watered to recoverits heat. A bed thus prepared and managed will maintain a constant degree of heat, sufficient to give these plants the utmost vigour they require, from the end of February to the end of October; and then the plants must be again removed into the stove or conservatory. In excessive heats the glasses are tilted up at the back of the frame; and when the evenings are cool, the bed must be carefully covered with substantial mattresses of straw. A bed of this kind sinks about a foot, which is convenient; for otherwise the plants would be too tall for the frame, before the time of housing them.

" The thermometer used by Mr. Telende had a tube twenty-four inches long, and one-eighth of an inch in diameter. When the spirit rose only to fifteen inches, he accounted the air cold for his plants; at sixteen and a half temperate; at eighteen warm, which was his standard for Pine Apple heat; at twenty inches, hot air; and at twenty-one inches, sultry."

Insects. Nothing is said on this subject.

Fruit produced. Mr. Cowel says (Curious and Profitable Gardener, p. 27.) that all gentlemen who had eaten Pines abroad allowed those raised by Mr. Telende to be as good and as large as they found in the West Indies. Bradley says, forty Pines were likely to ripen in the autumn of 1724 . 


\section{Sect. II.}

Of the Culture of the Pine, as given by Phillip Miller in his Gardener's Dictionary.

Form of House. It was formerly the practice, Miller observes, to build dry stoves, in which the plants were kept in winter, placed on scaffolds, after the manner in which orange-trees are placed in a green-house; and in summer, in hot-beds of tanners' bark, under frames. But it is now the practice, he adds, to erect low stoves, called the succession-house, with pits therein for the hot-bed. It is also necessary to have a bark-pit under a deep frame, for bringing forward the suckers and crowns to supply the succession-house.

Mr. Miller's fruiting-house has upright glasses in front, high enough to admit a person to walk upright on the walk in front of the house. Over the upright glasses there must be a range of sloping glasses, "which must run to join the roof, which should come so far from the back wall as to cover the flues and the walk behind the tan-pit; for if the sloping glasses are of length sufficient to reach nearly over the bed, the plants will require no more light: therefore these glasses should not be longer than is absolutely necessary, that they may be the more manageable."

The difference between this stove and that of Speechly is, that in the latter the sloping sashes reach to the back wall, by which means, instead of 
a useless opaque roof over the path, an excellent place is formed for training a vine; and this being at all times the hottest part of the house, such vines as are there trained will produce very early and high-flavoured fiuit.

The succession-house of Miller has no upright glass, and only a walk at the back of the house : the bark-pit may be partly sunk in the ground, if the situation be dry; or if wet, kept above it. The flue makes three returns against the back wall, beginning from the level of the walk. Many persons, he says, have made tan-beds, with two flues running through the back wall, and covered with glasses, like common hot-beds ; but, besides the inconvenience of taking off the glasses when the plants want water, the damps rise in winter when the glasses are closely shut, and there is danger of the tan taking fire.

The improvement on this plan consists in detaching the flue from the back wall, and separating it from the tan by a vacuity of two or three inches; or, what is still better, placing the flue in front similarly detached, and surrounded by air on all sides.

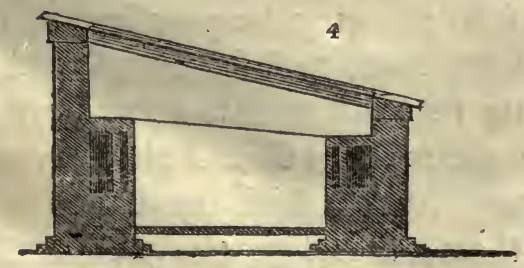

$\mathrm{D} \stackrel{\oplus}{\sim}$ 
Soil. "As to the earth in which Pines should be planted, if you havea rich good kitchen-garden mould, not too heavy, so as to detain the moisture too long, nor over light and sandy, it will be very proper for them without any mixture : but where this is wanting, you should procure some fresh earth from a good pasture, which should be mixed with about a third part of rotten neats' dung, or the dung of an old melon or cucumber bed, which is well consumed. These should be mixed six or eight months at least before they are used, but if it be a year, it will be the better; and should be often turned, that their parts may be the better united, as also the clods well broken. This earth should not be screened very fine, but only cleared of the great stones. You should always avoid mixing any sand with the earth, unless it be extremely stiff, and then it will be necessary to have it mixed at least six months or a year before it is used : and it must be frequently turned, that the sand may be incorporated in the earth, so as to divide its parts ; but you should not put more than a sixth part of sand, for too much is very injurious to these plants.

General Management. "There are some persons who frequently shift these plants from pot to pot; but this is by no means to be practised by those who propose to have large well-flavoured fruit: for unless the pots be filled with the roots by the time the plants begin to show their fruit, they commonly produce small fruit, which have generally large - crowns on them; therefore the plants will not re- 
quire to be potted oftener than twice in a season. The first time should be about the end of April, when the suckers and crowns of the former year's fruit (which remained all the winter in those pots in which they were first planted) should be shifted into larger pots. The second time for shifting them is in the beginning of August, when you should shift those plants which are of a proper size for fruiting the following spring. At each of these times of shifting the plants, the bark-bed should be stirred up, and some new bark added, to raise the bed up to the height it was at first made ; and when the pots are plunged again into the bark-bed, the plants should be watered gently all over their leaves, to wash off the filth, and to settle the earth to the roots of the plants. If the bark-bed be well stirred, and a quantity of good fresh bark added to the bed, at this latter shifting, it will be of great service to the plants; and they may remain in the same tan until the beginning of November, or sometimes later, according to the mildness of the season.

"Iil the summer season, when the weather is warm, the plants must be frequently watered; but you should not give them large quantities at a time: you must also be very carefiul that the moisture is not detained in the pots by the holes being stopped, for that will soon destroy the plants. In very warm weather they should be watered twice or three times a.week; but in a cool season, once a week will be often enough; and during the summer season, you 
should once a week water them gently all over their leaves, which will wash the filth from off them, and thereby greatly promote the growth of the plants. During the winter season, these plants will not require to be watered oftener than once a week, according as you find the earth in the pots to dry: nor should you give them too much at each time; for it is much better to give them a little water often than to over-water them, especially at this season."

Insects. After describing the white scale or mealy pine-bug (cocus hesperidum, L.) he says, " wherever these insects appear on the plants, the safest method will be to take the plants out of the pots, and clear the earth from the roots ; then prepare a large tub, which should be filled with water, in which there has been a strong infusion of tobaccostalks; into this tub you should put the plants, placing some sticks across the tub, to keep the plants immersed in water. In this water they should remain twenty-four hours; then take them out, and with a sponge wash off all the insects from the leaves and roots, which may be easily effected when the insects are killed by the infusion; then cut off all the small fibres of the roots, and dip the plants into a tub of fair water, washing them therein. Then you should pot them in fresh earth, and having stirred up the bark-bed, and added some new $\tan$ to give a fresh heat to the bed, the pots should be plunged again, observing to water them all over the leaves (as was before directed), and this should 
be repeated once a week during the summer season; for I observe these insects always multiply much faster where the plants are kept dry, than in such places where the plants are sometimes sprinkled over with water, and kept in a growing state. And the same is also observed in America; for it is in long droughts that the insects make such destruction in the sugar-canes. And in those islands, where they have had several very dry seasons, they have increased to such a degree as to destroy the greatest part of the canes in the islands, rendering them not only unfit for sugar, but poison the juice of the plant, so as to disqualify it for making rum; whereby many planters have been ruined.

"As these insects are frequently brought over from America on the ananas plants, those persons who procure their plants from thence should look carefully over them when they receive them, to see they have none of these insects on them; for if they have, they will soon be propagated over all the plants in the stove where these are placed: therefore, whenever they are observed, the plants should be soaked (as was before directed) before they are planted into pots.."

Fruit produced. Miller finds suckers and crowns, if equal in size and strength, fruit equally soon; and has seen as good fruit produced from plants received from the West Indies, as from any he has seen, and some three times larger than any he saw in M. Le Cour's garden. 


\section{SECT. III.}

Culture of the Pine Apple, by James Justice, Esq. F.R.S. at Crichton, near Edinburgh, in 1732, and for some years afterwards.

THrs gentleman was one of the greatest amateurs of gardening of his time, and a most successful cultivator of every thing he attempted. He had a fine garden at Crichton, near Edinburgh, and corresponded with various foreign horticulturists of Holland and Italy, as well as with Miller, Bradley, and other eminent English gardeners of his time.

Form of House. Justice, writing in 1754, says, "There have of late years been erected in England and Scotland, many sorts of stoves for the culture of the Pine Apple; but I am sure, after many experiments, that the plan here annexed is the best.

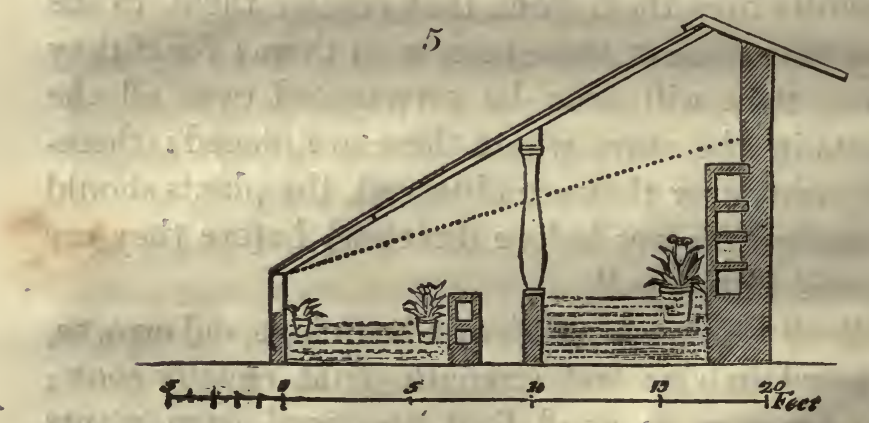

In this stove, (fig. 5.) with one fire, I can do the business of two stoves, which must have two fires, and cultivate the old as well as the young plants." The front and ends of this house are of glass, as well as the roof; the flue enters from behind at one end, 
passes along the middle of the house, returns on itself, and then makes four returns in the back wall. The path-way enters from behind, at the end opposite to that at which the flue enters; proceeds to the middle of the house, along the middle, till it meets the flue at the opposite; and then it turns round till it meets the flue against the back wall, close by the furnace. By this arrangement of the walk, no interruption is given to the flue; which is of great consequence, where it has so many returns to perform. A furnace invented by Mr. James Scot, of Turnham Green, a commercial Pine-grower of those days, is recommended. It is cast in one piece, and requires a wrought-iron door and a cast-iron plate to build over the chamber. Justice agrees with Miller in recommending the furnace to be built within the house, (but supplied from without) in order that no heat may be lost.

The plan given requires no succession-house; but he describes a frame used by many persons for growing young Pines, "made in the same manner as common hot-bed frames, but higher and broader; that is, three feet higher at the back, sloping to one and a half in front, and six feet wide." These cover a tan-pit causewayed at bottom, and surrounded by a stone wall. It is very proper, he says, to have these frames at work as well as the stoves. He also mentions flued pits, such as are described by Miller (Sect. 2.) Both stoves and pits he covers with boards, tarpauling, or mats, at night; and the fuel he uses is coal or peat, avoiding wood as of too rapid consumption. 
Soil. 'Two-thirds of good loamy kitchen-garden mould, one-third of old rotten cows' dung, or hotbed dung, and to every eight barrowfuls of this a barrowful of sea-sand. He adds, "If your ground is naturally sandy, after having mixed it with the dung above mentioned, add thereto a third of good fat marl; which succeeded so well with me, that in this compost I had much larger fruit than in any other compound which I used to give them, which induced me to put, at all times, a good deal of marl in the compost I used for these plants." This mixture should lie for six months in those parts of the garden which are airy and least exposed to the sun; after the first three months, turn it over every fortnight. Scots Gardeners' Directory, $2 \mathrm{~d}$ edit. p. 124.

General management. The same as is given by Miller. He tried some plants turned out of the pots with their balls, and planted in the bark for the last nine months before the fruit ripened, and found the fruit larger and earlier, but not better flavoured than that of the plants in pots. In shifting, he never cuts off any of the leaves ; "for it is certain," he adds, " that the leaves of all plants and trees bear the same office to them, as the pulmonary vessels do to human bodies." He waters over the leaves when the plants have shewn fruit; because the fruit stalks, occupying what in young plants was a hollow tube, no injury can happen. P.129.

Insects. At the first appearance of the bug, he picks off the scale with a pin; and if that does not 
clean the leaves, he washes with a sponge; and, in extreme cases, uses Miller's mode.

Fruit produced. The object of all his directions is, " to have fruit large, good, and early, in a right season; viz. from the middle of June to the middle of September, but no later; for the rays of the sun, at that time, have not strength enough to give them that poignancy of smell and taste that they ought to have." P. 134. " Cut fruit when their smell is strongest and most poignant; if too ripe, they soon turn insipidly sweet, and have no more taste than an orange. Cut them about ten o'clock in the forenoon, with about four inches of stalk to them. When the fruit is to be sent to a distance, cut a day or more before they are ripe, with a larger portion of stalk to them, and wrap them very close in paper, to preserve them from the air ; otherwise their flavour will escape." P. 132.

\section{SECT. IV.}

Culture of the Pine Apple, by John Giles, at Lewisham, in Kent, 1767.

THIs author, who was gardener to Lady Boyd, and afterwards foreman in the Lewisham nursery, says, he writes after many years' practice and observation; and that his treatise will be found " of more real advantage to a young unexperienced gardener, than his giving a premium of five or ten guineas to a mercenary old one (who perhaps might have had some practice, with a trifling de- 
gree of success, ) to learn - what? why, to spoil his plants, with the loss of both money and reputation."

"Notwithstanding the directions of Miller, Hill, (probably alluding to a letter on the Pine Apple in "Gardener's New Calendar," written by Sir John Hill, under his assumed name of Barnes,) Meader, \&c. who have endeavoured to explore the method how the Pine Apple is to be grown; yet, upon trial, the success has always fallen much short of their expectation. For these reasons, Mr. Giles "presents the public with explicit directions for managing and bringing to perfection the Pine Apple; in which all the obstacles and difficulties which gardeners have met with in raising that fruit are remedied, and the true method pointed out in a clear and satisfactory manner." Preface, p. vii.

Form of House. The plants are brought forward in pits, and afterwards fruited in a stove forty feet long and twelve feet wide, with a pit six feet wide, surrounded by a path, and a flue which makes three returns in a flue close under the back wall. The front of the pit is about three, and the back about five feet from the glass. It will fruit, he says, a hundred plants annually, they being brought forward in the low pits or frames, and removed to the fruiting-house in September or October.

The obvious objection to the plan of his house is the having no flue in front.

Soil. A rich hazely loam from a well-pastured common. This soil alone, he says, not only answers well for Pines, but for most vegetables. 
General Management. He recommends keeping a moist atmosphere in the house, and giving abumdance of air when the plants are in fruit. His other directions relate to mere routine practices, and offer nothing else worth quoting.

Insects. A moist atmosphere, he says, will keep down these. "It is only poor plants," he says, "which are not in a good state of health, that are infested with insects. They are encouraged by the warmth and dryness of the air of the stove, and the bad state of the plants ; but where cleanliness and moisture are attended to, there will never be any worth notice." P. 36.

Fruit produced. He fruits the Queen Pine in two years, at the usual season; but does not state to what size the fruit attains.

\section{Sect. V.}

Culture of the Pine Apple, by Adam Taylor, Gardener at Devizes, in Wiltshire, 1769.

This author, who was gardener to J. Sutton, Esq. at New Park, professes " to lay down a mode by which the Pine Apple may be produced in higher perfection, with more ease and less expense than has been hitherto known in this climate." He offers his treatise with confidence, as not being founded on hypothesis, but on some years' experience; and it may be depended on, as " it admits of the attestation of many persons whose taste and judgment are unquestionable." 
" The present way," he says, " of raising Pine Apples, is made so chargeable by the erection of hot-houses, and the consumption of fuel, that many, even of tolerable fortunes, have been deterred by the consideration of it, from raising this desirable fruit. It is farther attended with trouble, and much uncertainty; and the fruit itself rarely answers the expense either in size, number, or quality. But by the practice now recommended, these several inconveniences are sufficiently obviated. There are very few, even of commercial gardeners, who are not able to accumulate the necessary quantity of horse-dung, which is the principal article for this valuable end. And by such application of it, they shall not fail to find their hopes abundantly answered, and their labour well repaid." P. 3.

Form of House. He both rears and fruits them in a pit. This he forms either of boards, or of brick-work three feet deep, and of any convenient length and width; and on the walls or boards, which inclose the tan, he places a frame two and a half feet deep in front, and four feet high behind. The ends and front are of glass, and the latter is formed into small sashes, which slide in a groove. The back is formed of inch boards, and against these he places a powerful lining of dung.

The pit he fills with tan, or dung, as may be most convenient; dung, he says, does as well as tan, and only requires a little more trouble, which is amply repaid to the gardener by the value of the 
dung to the garden, when no longer in active fermentation.

An anonymous annotator (to the copy of Taylor's book, in the library of the Horticultural Society) says, "I find by experience, that the dung of four horses is sufficient to work two frames twenty-six feet each in length, and six in breadth; one for the fruiting-house, the other for succession plants; and that it may be reasonably expected to cut forty fruit yearly after the first year, and the dung as valuable for the field or garden, as if this use had not been made of it." P. 3.

Soil. "Take one load of mould from under the turf of a good pasture, and, if it be very light, add. to it the fourth part of a load of good mellow loam: but if it be of itself of a loamy nature, mix into it two or three bushels of sea-sand. Then take the fourth part of a load of dung from a cow-yard, if it can be thence procured; but if not, take the same quantity of good rotten dung from your old cucumber or melon beds. Mix these well together, and turn the whole three or four times, that it may thoroughly imbibe the air. All the large clods should be well broken, but not sifted or screened, as is the practice with many; so shall you have a compost, which is excellently adapted to the growth and nourishment of the plants.". P. 15.

General Management. He takes great care to keep his' plants in a dormant state during winter;' but about the end of March and April, he applies - 
linings, and brings them into a growing state, shifting all those not intended for fruiting that season. He covers the frames at night throughout the year with straw, and a sail-cloth over, excepting in the warmest part of summer; at that season, during fine showers, he removes the sashes entirely, and lets the plants receive a gentle watering. $\mathrm{He}$ frequently waters over the leaves in the afternoons with a pot having a fine rose, and shuts up early; which he finds produces a moist heat, rapid growth, and keeps down insects. In winter he uses a tin pipe, to keep the water from touching the leaves of the plants; and as he has a very low temperature at that season, he gives them very little.

Insects. These he is not much troubled with; but he says, "Such plants as are attacked by them, should be immediately taken out of the frame, and plunged into a moderate hot-bed made of dung; this hot-bed should be covered with one or two cucumber-frames, adapted to the height of the plants. Let these frames be covered with lights; so as to confine the steam of the dung. As soon as the plants receive the heat of this bed, water them all over the tops of the leaves with cold water. This will effectually destroy the insects ; after which the plants are to be restored to the covered frame again. A trial or two of this will convince any person of the infallible efficacy of it." P. 38.

It thus appears that he destroys them by the operation of the ammoniacal gas, much in the same manner as does Mr. Baldwin. 
Fruit produced. He says nothing of the weight of the fruit, but he calculates on fruiting the plants in two years, and ripening the fruit only in summer and autumn, or between July and October inclusive; and he prefers the Queen Pine to all others.

\section{Sect. VI.}

Culture of the Pine Apple by William Speechly, gardener to his Grace the Duke of Portland, at Welbeck, in Nottinghamshire, 1779.

THE culture of the Pine, Mr. Speechly observes, has already been treated of by many persons, who have varied much in the methods they have recommended. Far from meaning to depreciate their labours, he adds, "my advice and pretensions rest solely upon the success which I have met with in my experiments." He went to serve the Duke of Portland in $176 \%$, and published his book after eleven years' experience. He continued at Welbeck till about the year 1800 .

Form of House. The great object of $\mathrm{Mr}$. Speechly seems to have been to combine the culture of the Pine and Vine; and for this purpose he adopted one form both for his succession and fruiting-house; training Vines up the rafters, and on the upper part of the back wall. 


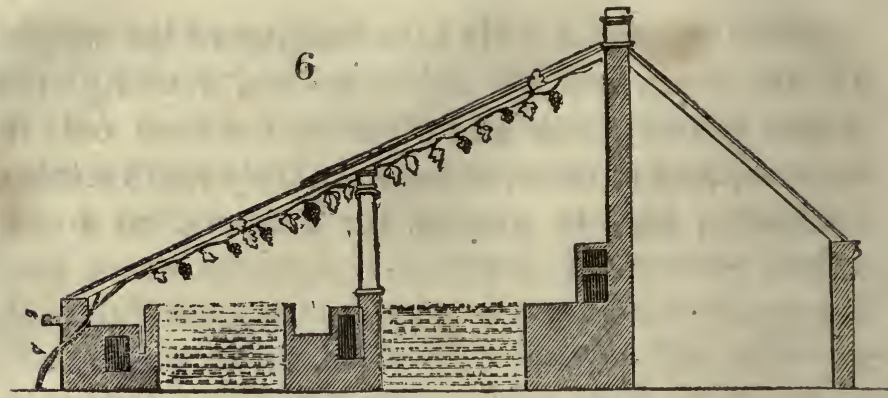

In many places small stoves of a particular construction (in the which the Pines stand very near the glass) are erected solely for the purpose of Fruiting-houses. These, from their being always kept up to a high degree of heat, are by gardeners usually termed Roasters. '(fig. \%.) When there is such conveniency, it is customary, when any Pine-plants show fruit in the large stoves, to remove such plants (especially the most promising) directly into the fruiting-house; where, from the high degree of heat kept, they generally swell their fruit astonishingly.

It is observable that Pines always succeed best in stoves that have been newly erected; on which account, some of the more curious in the cultivation of this fruit have judged it expedient to pull down and rebuild their Pine-stoves every ten or twelve years. Although I cannot subscribe to such expensive mode of procedure, I shall here beg to state the many advantages that accrue from keeping Pine-stoves in good and proper repair.

First, by keeping the flues clean from soot, and 
air-proof, they will heat the house better, and much less fuel will serve.

Secondly, by a due attention to keeping the inside of the roof, \&c. duly painted, and by constantly white-washing the walls and flues in every part of the house, the plants will be greatly benefited, both from having a better reflection and from cleanliness.

A further advantage in stoves newly built may also here be remarked. Where tan only is used, the beds are always filled at the first with new tan entire; but afterwards, constantly with new and old tan intermixt.

Lastly, it is probable that stoves, newly erected, derive their greatest benefit from the good condition of the glass-work; for, however well it may be kept in repair afterwards, it is certain that there never is so much light in an old stove as was at the first. Dirt will find its way into the cavities between the squares, \&c. which, obstructing the sun's rays, darkens and gives a gloominess to the stove.

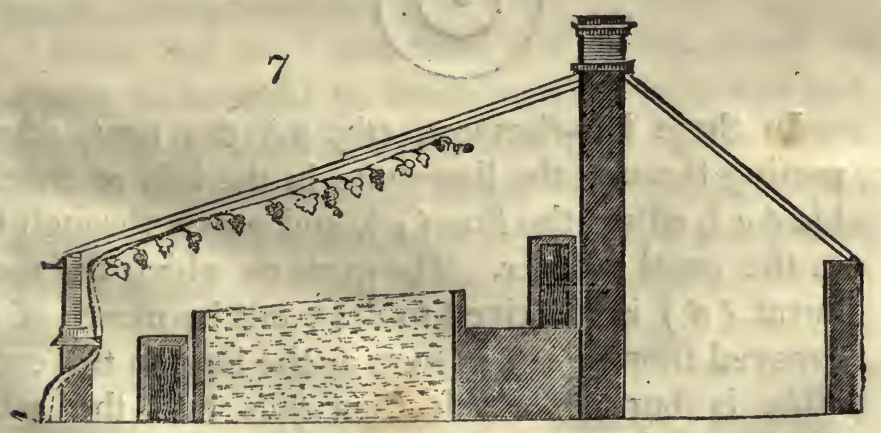

I 2 
He describes a Pine-stove to be heated by steari, in which the vapour is admitted to a brick vault, over which is tlre bed of tan or earth ; this is surrounded by a path and smoke-flues, exactly as in the common form of hot-house.

He also gives a plan of a furnace for burning lime as.well as heating hot-houses, as erected at Billing, in Northamptonshire, and at Lady E. Ponsonby's, at Bishop's Court, in Ireland; and, subsequently, at various other places in that country.

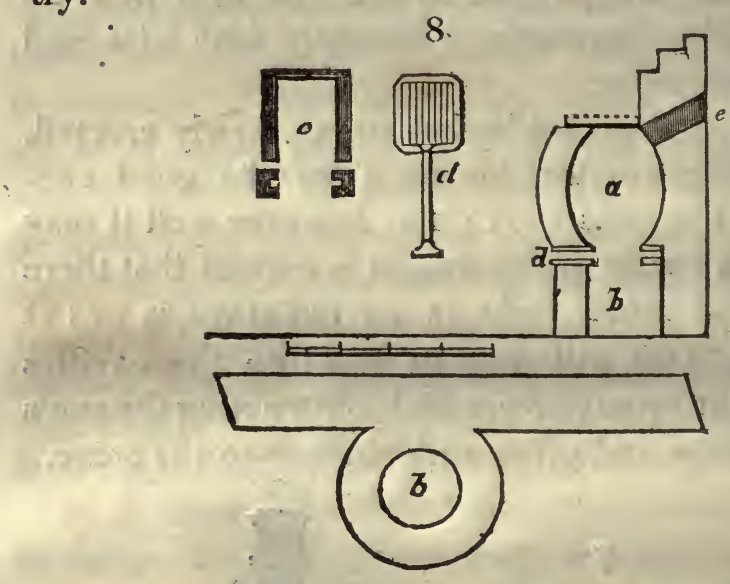

In these kiln-furnaces, (fig. 8.) the heat, after passing through the limestone in the kiln or crucible (a), enters the flue $(e)$, and passes through it in the usual manner. The grate on which the fuel burns $(d)$ is contrived to draw out by means of a grooved frame $(c)$, as soon as the lime in the crucible is burned, which then falls into the ashpit (b), and is removed. 
Soil. After numerous experiments made with mixtures, of cow, deer, sheep, pigeon, hen, and rotten stable dung, with soot, and other manures, in various proportions, with fresh pasture-soil of different qualities, he says, I can venture to recommend the following:

In the month of April or May, let the sward or turf of a pasture, where the soil is a strong rich loam, and of a reddish colour, be pared off, not more than two inches thick : let it then be carried to the pens in sheep-pastures, where sheep are frequently put for the purpose of dressing; which places should be cleared of stones, \&c. and made smooth; then let the turf be laid, with the grassside downwards, and only one course thick; here it may continue two, three, or more months, during which time it should be turned with a spade once or twice, according as the pen is more or less frequented by the above animals; who, with their urine and dung, will enrich the turf to a great degree, and their feet will reduce it, and prevent any weeds from growing.

After the turf has lain a sufficient time, it should be brought to a convenient place, and laid in a heap for at least six months, (if a twelvemonth it will be the better,) being frequently turned during that time; and after being made pretty fine with a spade, but not screened, it will be fit for use.

In places where the above mode cannot be adopted, the mixture may be made by putting a 
quantity of sheep's dung (or deer's dung, if it can be got) and turf together. But here it must be observed, that the dung should be collected from the pastures when newly fallen; also, that a larger proportion should be added, making an allowance for the want of urine.

1. Three wheelbarrows of the above reduced sward or soil; one barrow of vegetable mould from decayed oak-leaves, or leaves of other deciduous trees, and half a barrow of coarse sand, make a compost-mould for Crowns, Suckers, and Young Plants.

2. Three wheelbarrows of swarth, reduced as above, two barrows of vegetable mould, one barrow of coarse sand, and one-fourth of a barrow of soot, make a compost-mould for fruiting plants.

The above composts should be made some months before they are wanted, and very frequently turned during that time, that the different mixtures may get well and uniformly incorporated.

It is observable, that in hot-houses, where Pineplants are put in a light soil, the young plants frequently go into fruit the first season, and are then what gardeners term runners; on the contrary, where plants are put in a strong rich soil, they will continue to grow, ard not fruit even at a proper season : therefore, from the nature of the soil from whence the sward was taken, the quantity of sand used must be proportioned; when the loam is not strong, sand will be unnecessary in the compost for young plants. 
I conceive that the urine of sheep contains a greater quantity of mucilage, or oleaginous matter, than the dung of those animals : and this opinion is founded upon observations made in sheep-pastures; where, during the summer months, the effects of both are easily distinguished. I also presume that the reduced sward in the pens receives a very considerable degree of fertility from the feet of the sheep.

Where oak-leaves are not used in hot-houses instead of bark, the vegetable-mould may be made by laying a quantity of them together, in a heap sufficiently large to ferment, as soon as they fall from the trees: they should be covered for some time at first, to prevent the upper leaves from being blown away. The heap should afterwards be frequently turned, and kept clean from weeds: the leaves will be two years before they are sufficiently reduced to be fit for use.

I shall just observe, that it will be proper to keep the different heaps of compost at all times clean from weeds, to turn them frequently, and to round them up in long rainy seasons. If covered, the better: but they should be spread abroad in continued frosts, and in fine weather.

General Management. The pots he recommends are :

1. Pots for full-sized crowns Inches diameter Inches
at the top. and suckers . . . $5 \frac{1}{2^{-}}$ E 4 
2. Pots for plants to fruit the

Inches diameter at the top.
Inches deep. following season when shifted in March

3. Pots for fruiting plants

I wish it to be understood that the above dimen. sions are only used for full-sized plants, at their different periods: plants below the standard must have less-sized pots in proportion.

Sometimes, he observes, hot-beds are made for the suckers. When that is the case, they should be prepared at least fourteen days before the suckers are taken off, in order that the violence of the heat may be over: after the bed has been made ten days, it should be levelled, and covered eight or ten inches with tan; and after this has lain four or five days, in case the heat of the bed should not be violent, the pots may be plunged into it.

In respect of temperature and water, he advises only a moderate heat, and not much water, during the winter months; but an increase of both, accompanied with more air, as the season advances.

There is nothing, he says, so prejudicial to the Pine-apple plant, (insects and an over-heat of the tan excepted,) as forcing them to grow by making large fires, and keeping the hot-house warm at an improper season; which is injudiciously done in many hot-houses. It is inconsistent with rea- 
son, and against nature, to force a tropical plant in this climate in a cold dark season, such as generally happens here in the months of November and December; and plants so treated will in time show the injury done them: if large plants for fruiting, they generally show very small fruit-buds with weak stems; and, if small plants, they seldom make much progress in the beginning of the next summer.

As the length of the days, and power of the sun increases, the plants will begin to grow, and from that time it will be absolutely necessary to keep them in a regular growing state; for if young plants receive a check afterwards, it generally causes many of them to go into fruit. From the time they begin to grow they will demand a little water: once in a week or ten days, as the weather may prove more or less favourable, will be sufficient till the middle of March, which is the most eligible season to shift them in their pots. If that work is done sooner, it will prevent the plants from striking freely; and if deferred longer, it will check them in their summer's growth.

In this shifting I always shake off the whole of. the ball of earth, and cut off all the roots that are of a black colour, carefully preserving such only as are white and strong. I then put such plants as are intended to fruit the next season into secondsized pots with fresh mould entire.

The bed at this time should be renewed with $a$ little fresh tan, in order to promote its heating, and 
the pots plunged therein immediately. The hothouse should be kept pretty warm till the heat of the $\tan$ begins to arise, as it will be the means of causing the plants to strike both sooner and stronger. As soon as the heat of the bed begins to arise, it will be proper to give the plants a sprinkling of water over their leaves; and as soon as they are perceived to grow, they will require a little water once a week for a short time, and afterwards twice a week till the next time of shifting them in their pots.

During the summer months give the plants plenty of air whenever the weather is warm, and water properly, as has been described: let the pots be kept in a regular constant heat, and clean from weeds; but above all, avoid an over-heat of the tan. Some persons plunge a thermometer in the tan, with the ball of its tube as deep as the bottom of the Pine-pots; and by repeated observations, a point is fixed for the spirits in the part of the tube above the surface of the tan, to show when the pots should be raised. Whether the above, or the putting watch-sticls in the tan (which is the most common method) is practised, too much attention cannot be had whenever there is the appearance of too violent a heat in the tan.

If the above directions are strictly attended to, the plants will be grown to a large size by the beginning of August; when they should be shifted into the largest-sized fruiting-pots, with their roots and balls entire. 
But it will be proper here to observe, that in some hot-houses it is found difficult to get plants of the Antigua and Sugar-loaf kinds to fruit at a proper age ; and, in that case, I advise the shaving off the roots on the outside, and reducing the balls of them at this shifting. A greater proportion of sand should also be added to the compost, which will be the means of bringing them into a fruiting state at a proper season.

The disproportion of the second-sized and fruiting-pots is so great, as to admit of a good quantity of fresh mould at this shifting, which is absolutely necessary to support the plants till their fruit becomes ripe : it also affords an opportunity of performing, the operation of shifting the plants without injuring their roots. As there will be a large space between the ball and the side of the pot, the mould may be put round the ball with great ease; whereas, when plants are shifted into pots only a small size larger than those from whence they were taken, they are generally much injured by the operation of shifting: besides, even with the greatest care, there will frequently be spaces left hollow between the ball and the side of the pot.

A little fresh $\tan$ should be added, and the bed forked up, but not to the bottom of the pit, as the $\tan$ is liable to heat violently at this season of the year; of which when there is the least appearance, the pots should be raised immediately. The delay of doing it one day may be attended with very bad consequences. 
The plants will continue to grow very fast this and the following month, and should therefore be watered pretty plentifully, at least twice a week; and, in the summer waterings, it should be observed, that it will be of great service to the plants to be watered once a fortnight all over their leaves. If the month of October be wet and cold, the plants should not be watered above twice in that month; but if fine and clear, once a week: and here ends the watering of the fruiting plants for the season. I never give them any water in the months of November and December; and during that time I keep the hot-house in a cold state, but a bottom heat is always required; therefore the tan should have been renewed, and the old part of it screened about the end of October or beginning of November: from which time the bed will generally retain a moderate warmth till the beginning of January, when the tan should again be renewed. From that time the hot-house should be kept a few degrees warmer; and, as soon as the tan begins to ferment, the plants may have a little water given them.

In this month (January) some of the plants will appear set for fruiting, which may be distinguished by the short leaves in their centres; and from that time they should be moderately watered (till the middle of March) and the hot-house should be kept pretty warm; a little air should, however, be admitted, whenever the weather will permit. About the middle of March it will be proper 
to renew the tan-bed, and, at the same time, the plants should be divested of a few of their bottom' leaves; the mould on the top of the pots should be taken off as deep as can be done without injuring the roots, and the pots filled up with fresh compost-earth, which will add to the vigour of the plants, as well as give a neatness to the whole when finished.

It is very injurious to the plants, and greatly retards the swelling of the fruit, to remove them after this season; therefore, in case the heat of the bed should decline, a fresh heat may be got witlrout moving the plants, by taking out the tan betwixt the pots as deep as possible, and filling that space up with fresh tan. - This method is practised by some even at an earlier season.

The plants at this season will demand a kind, lively bottom heat; and whenever the weather will permit, a great quantity of air should be admitted into the hot-house, the want of a due proportion of which would cause the stems of the fruit to draw themselves weak, and grow tall; after which the fruit never swells kindly.

As the fruit and suckers begin to advance in size, the plants will require plenty of water to support them; which may be given them at least twice, and sometimes three times a week; but too much should not be given them at one time; it is better to give them less at a time, and oftener.

Sticks should be provided to support the fruit before it is grown too large; and, in tying them, 
care should be taken to leave bandage-room sufficient, making allowance for the swelling of the fruit.

When the suckers are grown to about one foot in length, they should be taken off in the same manner that has been described; and from that time the fruit will swell very fast. As soon as the fruit appears full swelled, the watering such plants as produce them should cease: but it is too general a practice (in order to have the fruit as large as can be got) to continue the watering toc long; which causes the fruit to be filled with an insipid, watery, and ill-flavoured juice.

It is easy to know when the Pine becomes ripe by its yellow colour; yet they do not all change in the same manner, but most generally begin at the lower part of the fruit. Such fruit should not be cut till the upper part also begins to change, which sometimes will be many days after, especially in the Sugar-loaf kinds. Sometimes the fruit will first begin to change in the middle, which is a certain indication of its being ripe: such fruit should be cut immediately.

Having thus laid down the culture of the Pineapple plant, whether raised from seed, by crowns, or suckers, to its final perfection in the fruit; I shall now subjoin some hints and observations; most of which, I hope, will be of use.

In treating of the culture of the Pine-apple plant, some persons have recommended the shifting of the plants, from first to last, with their balls 
entire; also the shifting of them oftener than I have here recommended. These methods I disapprove, for the following reasons :

First, it is observable that the Pine-plant begins to make its roots at the very bottom of the stem; and, as the plant increases in size, fresh roots are produced from the stem, still higher and higher, and the bottom roots die in proportion : so that, if a plant in the greatest vigour be turned out of its pot as soon as the fruit is cut, there will be found at the bottom a part of the stem, several inches in length, naked, destitute of roots, and smooth. Now, according to the above method, the whole of the roots which the plant produces being permitted to remain.on the stem to the last, the old roots decay and turn mouldy, to the great detriment of those afterwards produced.

Secondly, the first ball, which remains with the plant full two years, by length of time will become hard, cloddy, and exhausted of its nourishment, and must therefore prevent the roots afterwards produced from growing with that freedom and vigour which they would do in fresher and better mould.

Thirdly, the old ball continually remaining after the frequent shiftings, it will be too large, when put into the fruiting-pot, to admit of a sufficient quantity of fresh mould to support the plant till its. fruit becomes ripe, which is generally a whole year from the last time of shifting.

It is an object of emulation amongst gardeners 
to try to excel their neighbours in the size of their Pines. In order to produce very large fruit, I recommend the following method, which I have often practised with great success.

In the month of April or May, it is easy to distinguish, in a stove of Pines, which plants promise to produce the best fruit: this is not always the case with the largest. A few of the most promising being marked, a small iron rod, made with a sharp angular point, may be thrust down the centre of the sucker; which, being turned two or three times round, will drill out the centre, and prevent its growing. This must be performed on all the suckers as fast as they appear. Thus the plant being plentifully supplied with water, and having nothing to support but the fruit, will sometimes grow amazingly large. But this method should not be practised on too many plants, as it is attended with the entire loss of all the suckers.

It being a practice with some to fruit the Pine by setting the pot in water; while others produce the fruit by setting the plant only in water, (in a similar manner to what is often practised with Hyacinths and other bulbous roots, ) the passing over these methods in silence may, by some, be deemed an omission: but as neither of these methods can be reduced to practice with any kind of success, except on fruiting plants, and just in the hot summer months, when the situation of the plant ought to be very near to the glass, they do not seem calculated for general practice. 
However, as some persons are inclined to sup. pose that Pines raised by these methods are generally of superior quality, I shall just beg to say, that the first method, of setting the pot in water, is greatly to be preferred, and that the best time for adopting it is immediately after the plants have shown fruit in the spring.

Mr. Speechly is minute in his directions as to air, water, the use of leaves instead of bark, the application of fire, heat, \&c. ; but as all these instructions are more to be considered as applicable to the general management of the hot-house, than the particular treatment of the Pine-apple, we do not think it advisable to trouble the reader with their perusal.

Insects. Those which more immediately infest the Pine, were first described in Speechly's book. They are all species or varieties of the Linnean order Hemiptera, and genus Coccus. The first is the brown turtle bug, Coccus hesperidum (Fig. 9.) The female has at first 9 the appearance of a flat scale (a); afterwards, when depositing its eggs, it becomes fixed and turgid (b); these eggs (c) are hatched under the mother, who soon afterwards dies; the young insects, seen under a magnifier, appear like tur-
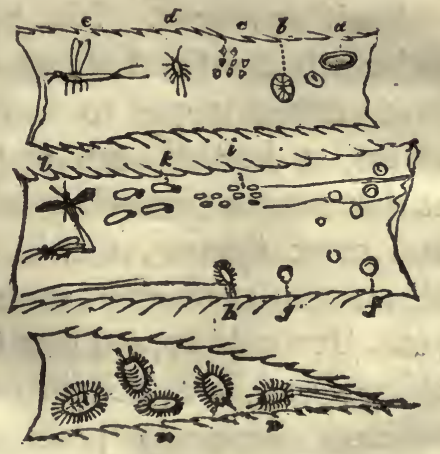
tles in miniature $(d)$. Only the males, $(e)$, which are few in proportion to the females, have wings; these devour nothing, and having performed the office of impregnation, die.

The rohite scaly bug, C. hesp. var. a ( $f$ to $l$ ) bears a considerable resemblance to the above; but the scale $(f)$ is somewhat smaller; the colour is white, and the males or flies $(l)$ not so large as those of the brown.

'The white mealy crimson-tinged bug, C. hesp.var. \& ( $n$ and $m$ ) differs from the former in being larger and crimson-coloured. Speechly considers it as viviparous. This and the former species are much the most pernicious.

Mr. Speechly's mode of destroying these and other insects, being much too elaborate for modern practice, it would be a waste of time to repeat his processes. Simple modes are always the most effectual, and nothing can be more so than M'Phail's mode of applying the steam of water ; or Baldwin's, that of horse-dung.

Fruit produced. Mr. Speechly does not seem to have had a fixed object as to the production of fruit, unless it was to have it good. Some cultivators, as Justice, aim at having all the fruit ripe at that season when they will attain the greatest size and most flavour, viz. in August and September; others aim at having some weekly throughout the year. It would appear that the former was Speechly's object, and that he did not contemplate the other as now generally practised. "Large fruiting plants," he says, " will sometimes show their fruit 
in the months of August and September, but these are generally thought of no value, and, consequently, thrown away. 'To prevent this, I frequently take such plants out of the hot-house as soon as their fruit begin to appear. I then set them in a shed or out-house for five or six weeks ; at the expiration of which time I pot them as in the month of March, after shaking off their balls. After this I plunge them into the tan."

What was the common weight of the Queen Pines produced at Welbeck, he does not inform us; but a fruit of the New Providence, produced in the gardens at Welbeck in 1794 , weighed $5 \frac{\mathrm{I}}{4} \mathrm{lb}$., or 84 oz. He generally fiuited the Queen Pine in the third season, being under two years of time; and the Providence and Antigua in the fourth season.

\section{Sect. VII.}

Cullure of the Pine Apple by James M'Phail, gardener to the late Earl of Liverpool, at Addiscombe, in Surrey, from 1788 to 1808.

Mr. M'Phail, when in practice, was reckoned one of the first growers of the Pine Apple in England; he grew the plants, and also fruited them chiefly in pits; the pots plunged in bark, and the bark inclosed by a perforated wall of his invention, and heated by linings of dung. He also grew them in larger buildings.

Form of House. No great consequence is attached to the construction of the house by this gardener. Where Pines are to be grown in a hot- 
house along with vines in Speechly's manner, he says, "I think a good method is to make it into one or more divisions of about forty feet long, sixteen feet wide;" the back wall thirteen feet, and the front wall nine feet, the upper four feet being composed of sliding sashes. The slope in the roof will, by these dimensions, be four feet, or about three inches to a foot. The pit is to be surrounded by a path, which behind will be four feet higher than in front, and, consequently, the end paths must have steps. The fire-place being placed in the back wall, and supplied from the shed behind, the flue should be carried round about the inside, stretching from the fire-place across the end and along between the path and the front wall, leaving a cavity of four or five inches wide between the flue and the wall, to admit the heat to rise freely, and to prevent the roots and stems of the vines planted in the border against the front wall from being too much heated. At that end of the division farthest from the fire, after going across the house under the back path, the flue must rise above the path, and go along close against the back wall communicating with the chimney, which stands at the end corner of the wall just above the fire-place. The flue from the fire-place along the front wall to the opposite end of the house, is to be made nearly three feet deep, seven inches wide, and when it riseth above the back side path against the back wall to the chimney, it should be about three feet feet six inches deep of brick, on edge two inches thick, besides the plas- 
tering, and covered with inch thick tiles closely joined with fine mortar to prevent the smoke from getting into the house among the plants. The mouths of the fire-places should be about sixteen inches wide, twelve inches deep, and the doors and their posts may be made of cast iron. The grates should be thirty inches long, and their bars of uncast iron made to take out at will. Some have the fire-places wholly of cast iron, one or more inches thick, in form of a square funnel about three feet in length. This appears to be a good method, because they keep in repair several years, whereas the sides of the fire-places built of brick generally require repairing yearly.

The tan-pit need not be deeper than three feet, or three feet six inches; and the path which surrounds it should not be narrower than twenty inches; but two feet, - or for the. back pit two feet and a half, will be better. The vines are introduced under the sill of the front glasses, and trained up the rafters; and Mr. M'Phail's practice is not to withdraw them in the winter season as is done by other gardeners. The surface of the tan-bed should not be nearer the glass than five or six feet. Two houses, each forty feet in length, joined together, can be kept warm with two fires, better than one house of forty feet; but in cold, exposed situations, he would recommend diminishing the length.

With respect to pits, M·Phail observes, - “ Succession Pine plants grow exceedingly well in pits covered with glazed frames, linings of warm dung 
being applied to them in cold firosty weather. The north wall of a pit for this purpose had best be only about four feet above the ground; and if about two feet high of it the whole length of the wall beginning just at the surface of the ground four feet below the height of the wall, be built in the form of the outside walls of my cucumber bed, the lining will warn the air in the pit more easily than if the wall were built solid. The linings of dung should not be lower in their foundation than the surface of the tan in the pits in which the plants grow (for it is not the tan that requires to be warmed, but the air among the plants); and as during the winter the heat of the air in the pit among the plants, exclusive of sun heat, is not required to be greater than from sixty to sixty-five degrees, strong linings are not wanted: one against the north side, kept up in cold weather nearly as high as the wall, will be sufficient, unless the weather get very cold indeed, in which case a lining on the south side may be applied. In cold frosty weather a covering of hay or of straw, or of fern, can be laid on the glass above mats in the night-time.
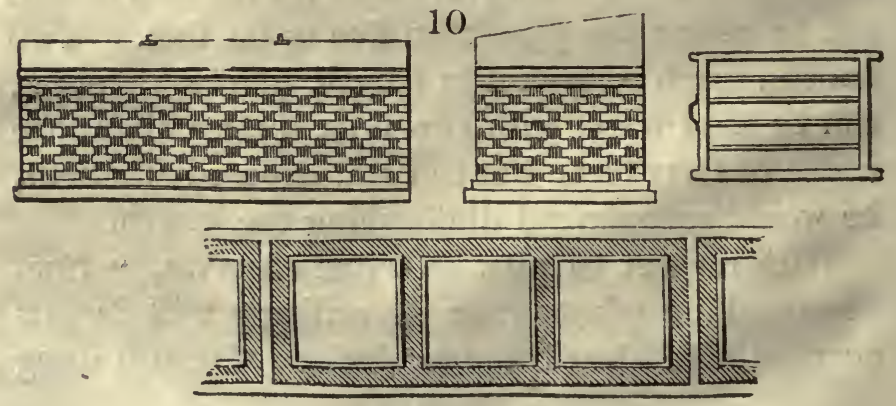
"The brick bed of myinventing, (fig. 10.)for forcing early cucumbers, answers well for growing small succession plants. A pit built on the same construction, but of larger dimensions, without cross flues, is a suitable one for growing Pine Apple plants of any size; for by linings of dung the air in it can be kept to a degree of heat sufficient to grow and ripen the Pine Apple in summer, as well as it can be done with fire heat, only it will require a little more labour and plenty of dung.

Soil. "The Pine Apple plant will grow very well in any sort of rich earth taken from a quarter of the kitchen garden, or in fresh sandy loam taken from a common, long pastured with sheep, \&c. If the earth be not of a rich sandy quality of darkish colour, it should be mixed well with some perfectly rotten dung and sand, and if a little vegetable mould is put among it, it will do it good, and also a little soot. Though Pine plants will grow in earth of the strongest texture, yet I have found by experience that they grow most freely in good sandy loam not of a binding quality.

General management. "The method which I used to cultivate the Pine Apple is the following: The fruit being partly over, and a cucumber brick bed prepared for unstruck crowns and suckers, towards the end of August or September, I planted them in rich earth in pots suitable to the size of the plants; I then had the pots plunged to their rims in the tan bed in which there was a good growing F 4 
heat; the lights were then shut down close, and as great a heat kept among the plants as the heat of the tan and sunshine could raise, and when the sun shone long and very bright, the plants were shaded a few hours in the middle of the day. The plants were thus managed till they had struck root and begun to grow, when a gentle watering was given to them, and a little air admitted daily. About the end of October or beginning of November, if the state of the bed required it, a little fresh tan was added, and if the plants by growth had become crowded, some of them were removed into another place, and the remainder plunged into the tan bed, in which they continued till February or March, when of course the bed required an addition of fresh tan, which was given it, and the plants plunged again into it at such distances one from the other as to give them room to grow; here they remained till May or June, at which time they were shifted into larger pots with the balls of earth about their roots entire, and at this shifting, if the tan bed wanted it, fresh tan was added to and mixed with the old, which in general enabled it to retain a sufficient heat till the month of August or September, when the plants, with their roots unhurt, were shifted into pots large enough to admit earth easily round their balls between their roots and the sides of the pots. In these pots. I let the plants remain in general till the fruit was over. At this time of shifting, the rotten part of the $\tan$ was taken away, and a sufficient quantity of new tan 
arded, which generally, with an addition to the upper part of it, retained its heat till the latter end of February or beginning of March; at this time the plants were divested of a few of their lower leaves, to let young roots spring freely out of their stems, the surface of the earth in the pots cleared down to the roots, and fresh earth laid on, pressing it close to the stems of the plants. After this dressing, the plants needed not to be moved again till they ripened their fruit, unless they required more bottom heat. This is the general process which I used, though I found it necessary to vary according to occurring circumstances, regarding the heat of the $\tan$ bed, the condition of the plants, and the state of the weather.

" Some large kinds of Pine Apple plants require three seasons to grow before they can bring large sized fruit, such as the black Antigua, the Jamaica, the Ripley, \&c.; therefore in the month of April or May, after they have been planted upwards of a year, it is best to take them out of the pots, and to cut off all their roots close to the stem, or leave only a few which are fresh and strong, and then plant them again in good earth in clean pots, and plunge the pots in a tan bed with a lively heat in it. After this process, a stronger heat than usual must be kept in the house, till the plants have made fresh roots and their leaves be perceived to grow, when a little water may be given to them, which, together with a good bottom and top heat, will make them grow finely. 
"Crowns and suckers taken from the parent plants later than October, should not be planted before the month of February or March; for in- the winter time, probably, they would not strike root, but rot: they may be hung or laid in a dry part of the hot-house. By some writers on the culture of the Pine it has been observed, " that any off-sets from the Pine will succeed as well when planted in the hour they are taken off, as if laid by to dry till the wound be healed, provided the parent stock received no water for the ten days preceding.' If off-sets or suckers be grown to such a size, so that they be easily separated from the parent plant, they may be planted immediately; for, in that case, it may be seen that they had begun to push forth roots, and required to be taken off and planted; but withholding water from the mother plant ten, or even twenty days, will not bring its offspring to a state of maturity fit for planting the day when taken off. So that it is best to let unmatured young suckers and crowns lie unplanted, till their natural juices be so exhausted that there may be no danger of their rotting after being planted.

“'The brick beds of myinventing, in which I struck and reared Pine Apple plants many years, were close and warm, the crannies between the lappings of the glass being filled up with putty; consequently, in these close frames, especially in the short days and long nights in winter, when the sun has little influence, the moisture arising out of the tan lodges on the glass, and drops from it, upon the plants; 
but, contrary to the opinion of some authors, who have advised to draw the water out of the hearts of plants when it falls into them in winter, I find, by experience, that it does them no harm, if the heat in the place where the plants be, is not too little. Indeed, if plants be kept in a climate which suits their nature, it is only reasonable to suppose that they are possessed of properties capable of disposing of water which happens to fall on them by accident or otherwise.

"No vegetable substance that I know of retains heat so long, and of a less violent nature, than oak bark after being used by tanners; and, as the vapours arising out of it are of a wholesome nature to plants, it is well calculated for helping to make the Pine Apple plant grow vigorously. Where the Pine Apple is wished to be cultivated, and tanner's bark cannot be procured, horse-dung well prepared, by shaking and breaking it small, will do. If plenty of the leaves of trees can be had, they are preferable to dung. When leaves cannot be collected plentifully, dung and leaves may be mixed. together, and used successfully ; and if it be ascertained that a good lively heat cannot be kept in the bed for want of good materials, let the heat of the flues warmed by fire, or linings of dung, be close or near to the pit, which will cause the heat in the bed to be more brisk and durable.

" If it be intended to make a bed of leaves, they should be collected as soon as they have all fallen from the trees, and in a wet state, and thrown to- 
gether in a large heap; and after fermenting a few weeks, they may be put into the pit for the pines. They should be well shaken, and trodden down gently when they get into a fermentation, which will keep them from sinking quickly afterwards, and prevent them from heating violently. When the heat in the bed declines much, it may be increased by turning and shaking the leaves over with a dung-fork.

" It sometimes happens that tanner's bark heats too violently; but when that takes place, it is either because there is too great a body of it put together, or because the heat of the flues is too close to the bed. If a tan bed get into a violent heat, it will not keep its heat so long as if it heated moderately; for it must lose its heat as hastily in proportion as it is deprived of its moisture by violent fermentation.

"It frequently happens that Pine Apple plants designed to bear fruit do not show their fruit early enough in the spring or fore-part of summer, to ripen their fruit before winter, when there is not sunshine enough to give the fruit any flavour. This may happen because the plants have not come to a proper growth, or their roots may have been injured by too violent a bottom heat, or by being over-watered, or they may have been shifted too late, or been put into pots too large for their roots to have filled them before the end of the growing season. To make Pine plants shew their fruit at an early time in the spring, some authors 
have recommended the cutting off some of the roots at the autumn shifting; but long experience has convinced me, that cutting off the roots, or destroying them by any means, instead of making them show fruit, is an effectual mean to prevent them from showing fruit, till they have again made long roots. The fruit of the Pine Apple is formed, probably, not less than seven or eight weeks before it appears among the leaves ; and if a plant be divested partially or totally of its roots, its growth is stopped till it has made roots of considerable length, when it will grow quickly. And, if before the roots were destroyed, the fiuit had been formed in the hidden secret centre of the plant, the fruit will grow and show itself when the leaves of the plant, excepting those on the stem of the fruit, will make no appearance of growing. This, perhaps, may be the reason which induces some persons to think that cutting off the roots of the plant causeth it to fruit sooner than it would do were the roots suffered to remain.

"If Pine Apple plants, intended for fruiting the following year, be shifted late in the autumn into pots, which their roots do not fill well before the month of January, they probably will not show fruit till late in the spring or summer months. For this reason it is advisable, when they cannot be shifted early enough in the month of August or beginning of September, so as to fill the pots with roots before the winter come on, to let them remain unshifted, till the fruit appear, and the stem of it be grown to 
its full height, and then shift the plants into larger pots, in the manner before directed, disturbing the roots of the plants as little as can be helped. After the plants are shifted, they must not get much water till the fresh growth of the roots has somewhat exhausted the moisture of the fresh earth put round them. Of two evils, it is better to give the plants too little water than too much. But let it be remembered, that while the fruit is in blossom, and for some days afterwards, the plants should not be watered all over their leaves, neither should the plants be watered all over their leaves nor fruit, after the fruit is fully swelled, nor should the earth in which their roots are, be, after that time, kept very moist, for they do not require it, because the plant has nearly performed its office, which it never has to do a second time - it dies and leaves its offspring to succeed it.

"Although the Pine Apple plant is of such a nature that it will live upwards of six months without earth or water, yet to bring its fruit to perfection, a plentiful supply of both these is required. From the time that the plants are set in earth till they perfect their fruit, it should be endeavoured to keep them constantly in a clean healthy growing state; and when they be-thus managed, they will not fail to show fruit when they be grown to a natural size. For these reasons, I would advise that no methods contrary to nature, but methods to assist, be used to make them fruit at certain periods. If Pine Apple plants be planted in rich earth, and get a 
sufficiency of heat and water, they grow luxuriantly to a great size, and do not show fruit so soon as they do when they are planted in a poor, hungry, or stiff soil.

"If the roots of Pine Apple plants be not put in too great a heat, it is a difficult matter to raise the heat in a hot-house to such a degree as is able to destroy the plants. In the brick bed of my inventing, a powerful heat can be raised by means of the linings of dung and the sun-beams, and in it the insects on Pine and on other plants may be shortly destroyed by heat and water.

"Some persons may think that the Pine Apple cannot bear to be watered all over its leaves in winter, because it is of a succulent nature, and able to live long in a hot-house without being planted in earth or set in water. But, for instance, the common house-leek is of a very succulent juicy nature, and will bear the greatest heat of a hot dry summer on the warm tiles of a house : but it is well known that this plant thrives best when it gets occasional showers of rain. The case is exactly similar respecting the Pine Apple, and several other plants, of a similar nature. In regard, however, to the best method of cultivating the Pine Apple, there have been and will be persons who differ in opinion. I here give my opinion, which is founded on practice, that there is not the least danger in watering the plants plentifully all over their leaves in winter, or in any time of the year, provided there be a sufficient heat kept up in the tan bed and in 
the air of the house. But remember, I do not recom. mend watering the Pine Apple plants all over their leaves in winter as a general rule, only when it is necessary to free the plants from insects and filth ; then the heat in the house among the plants must be kept strong, not lower than 70 in the morning, and raised to 85 or 90 in the course of the day.

It is indeed evident that some of the most able writers on the culture of the Pine Apple have wanted that experience which may by practice be obtained. They have asserted, that it is impossible to keep the Pine Apple plant throughout a severe winter without the assistance of fire. But ingenious practical gardeners have ascertained, that Pine Apple plants require nothing more than a gentle heat in the $\tan$ bed, in which the pots of plants must be plunged, and a medium heat of air of about 60 degrees, to keep them through the most severe winters in England. To maintain this temperature of heat without the assistance of fire, is no difficult matter ; it can be done by the assistance of horsedung; for a dry heat is not at all necessary to preserve the plants, and to keep them in good health, in the brick beds, in which I kept Succession Pines all the year round without the aid of fire heat. The sun for about two months in winter had very little effect to warm or dry the leaves of the plants, so that during the dull months in winter, the plants were continually in a moist state, and water standing in the hearts of some of them, and the heat of 
the air among them was fiom 55 to about 65 ; and I do not recollect of having any of the plants die for want of heat.

Insects. By many experiments which I made, it is evident, I think, that in the process of managing and cultivating the Pine Apple, all injurious insects may be destroyed, and prevented from breeding on them, by a judicious application of the elements necessary, though in a less degree in regard to heat, for the production of any vegetables or fruits whatever. That this is true, may be proved by a reference to the state of fruits and vegetables growing, either spontaneously or assisted by cultivation, in every part of the kingdom, without the aid of artificial heat or impregnated air. For instance, the strawberry, the raspberry, and some other fruits, which grow naturally in some parts of this country, and peas, beans, cabbage, and cauliflowers in gardens, and the different sorts of corn and grass in the fields. These, in unkind seasons, we see affected by blights and by insects of various kinds, which prevent them from coming to good maturity, and make them less productive than we wish them to be. But in propitious seasons, the earth being refreshed occasionally by showers of rain, they are preserved from the inroads of insects and from blights, and are enabled to produce abundant crops, for the use of man and beast."

Mr. M'Phail has thus the merit of being one of the first practical gardeners who freed themselves from the trammels of receipts and secrets for 
destroying insects. He says, " after having studiously observed the nature and causes of the vigorous growth and healthfulness of plants, and of fruittrees of different kinds, I have been induced to believe that a fruit-tree or plant of any sort requires nothing but proper cultivation in good earth, and in a kindly climate adapted to its nature, to prevent it from being injured by insects, or by blights of any kind, and to enable it to produce, of its kind, abundant crops. However, I wish it not to be understood that I disapprove of using means of any kind to destroy insects which are injurious to plants; but I conceive that all methods used for that purpose, ought to be such as are conducive to accelerate the growth of vegetables, by having at least a tendency to purify the air, and to make the circumambient atmosphere about them congenial to their nature, unless when the destruction of the insects by the hand is effected."

"Every insect has its proper plant, or tribe of plants, which it naturally requires for its nourishment, and on which it generally lays its eggs, and that on the most concealed parts of the plant; and the plant, and insect which attacks it, are always natives of the same climate, and therefore endure the same degrees of heat and cold; consequently, when plants are attacked by their natural tribe of insects, it is an exceedingly nice and curious operation to exterminate them without injuring the plants, or stopping them in their natural growth. But observing that insects increase rapidly in hot 
dry weather, and that they appear impatient of moisture, was the means of inducing me try which would bear the greatest heat and live."

"To ascertain what degree of heat a Pine Apple plant can endure without destroying it, I filled four vessels with hot water. The water in the first vessel was 130 degrees hot; that in the second 140 ; that in the third 145; that in the fourth 150 . Into each of these vessels I put a few Pine plants, divested of their roots, of their fibrous roots, and suffered them to remain in the water about an hour. The plants which had been immersed in the water heated to 140 and 145 degrees, were a little hurt in the "extremities of their leaves, but after being dried in the hot-house, they were planted, and grew as vigorous as if they had not been put into hot water; the plants put into water 130 degrees warm were not in the least injured; but those put into water heated to 150 degrees were entirely destroyed.

"By this experiment $I$ ascertained that a vegetable can endure, without hurting it, 130 degrees of heat, according to the degrees on Fahrenheit's thermometer. I am inclined to think that no animal is able to endure such a heat and live. Un. doubtedly, insects increase rapidly in hot weather in the open air, especially on the peach tree, and on other trees, against warm walls, both in the spring and summer months; and they increase most rapidly in dry weather; but the heat in the open air against walls seldom rises to 100 degrees. 
And in the hottest countries in the world, where vegetables and animals exist, the heat in the shade seldom rises to blood heat, which is about 97 . Having considered these things, and ascertained that a plant can endure a heat of 130 degrees, I determined to try another experiment, that is, to ascertain whether heat and water would destroy insects, and keep plants alive. I therefore thought of, and determined to try, the following method:

"In the month of June I selected about twenty large Pine plants, some of which had green fruit on them, and their leaves, fruit, and roots, were almost covered with insects. These plants I plunged in a $\tan$ bed, with a very gentle heat in it. The $\tan$ bed was in a brick frame designed for rearing succession plants: it was nearly five feet wide, twenty feet long, and the glass frames were close and in good repair. These plants I watered frequently and plentifully, sometimes twice a day, with water not less than 70 or 80 degrees, and sometimes 100, warm : in short, I kept the plants constantly in a moist air, by plentiful waterings without measure; and, excepting the time of giving water, I kept the lights constantly close shut down, even in the hottest sunshine, without shading the plants. In this frame I had no thermometer, but the heat was, I think, sometimes about two or three o'clock' in the afternoon, upwards of 120 degrees. This great heat and much moisture:caused the plants to grow most vigorously; and having subjected them to the said mode of management 
for a few weeks, the insects, in the course of that time, were totally destroyed, many of them lying dead on the leaves and fruit. In the spring-time, before this operation, the plants had been strewed with sulphur, which, at least, is a harmless dressing to plants of any kind, and probably may be of use in preventing insects from breeding numerously, or the means of depriving them of part of their natural food. This circumstance, however, I just heremention, because, from experiments which I have tried since then, it is probable that the effluvia arising from flour of sulphur, being scattered on the leaves, or about in the hot-house, in conjunction with heated air and moisture, may more suddenly destroy insects than heat and moisture alone; but it ought to be remembered, that if sulphur be by any means set on fire in a confined place, among plants of any kind, it will either totally destroy or greatly injure them.

"Being satisfied with my success in the abovementioned experiment, of having totally destroyed the insects on these plants without hurting them, I hesitated not to begin to water the whole of the plants under my. care, whenever they wanted it; all over their leaves and fruit, with water about 85 degrees warm. This process I continued to practise for several months, during which time I do not recollect that the thermometer was ever below 70 , and in sunshine it was raised sometimes to upwards of 110 degrees. I continued this practice longer perhaps than was absolutely necessary, but. I 
was determined to destroy the whole of the insects in the house, whether on the plants, or in the tan, or in any part of the house ; and this I certainly did accomplish effectually. Thus, by this easy, and not unnatural, mode of management, the plants became perfectly free of insects ; they were perfectly cleansed of all filth ; they grew vigorously; and the fruit swelled fine to a good size. After this I had several times Pine Apple plants from abroad, and out of hot-houses at home, full of insects, which, by the means that I have, without reserve, described, I effectually destroyed, and made the plants grow very fast indeed."

"If Pine Apple plants be kept in a strong vigorous growing state by giving them plenty of heat, and water applied occasionally all over their leaves, whether they be in frames heated with dung, or in hot-houses heated by a fire, a few insects will do them little hurt. But if the methods which I have given for cultivating the Pine Apple plant be adopted, I am persuaded all sorts of injurious insects natural to these sorts of plants will disappear on them.

"When we see human creatures lean in body for want of a sufficiency of wholesome food, or, for want. of cleanliness, lice and fleas breed upon them; and poverty in cattle for want of food has the same effect on them. Similar causes in vegetables has a similar effect, so that when Pine Apple plants are in a state of poverty, for want of a sufficiency of good earth, or of heat, or of water, insects natural 
to them, if there be any of them in the hot-house, will breed rapidly on them and hurt them. Those insects which naturally breed and live on the Pine Apple plant, appear to delight in a dry dirty situation. Where Pine Apples grow naturally and produce large fruit, they are not free of insects ; and though plants be free of insects, they will not grow well, nor produce fine fruit, unless they get enough of good earth, sufficient heat, and be watered plentifully."

Fruit produced. The green, and-some other sorts of Pine, Mr. M'Phail " ripened in a shorter period of time than two years after planting," (Gard. Rem. 8\%.) but some large kinds he found required three seasons, as the black Antigua, Jamaica, and Ripley. His object was to have his fruit come in for use between May and October, for he very justly remarks, that " the fruit of the Pine Apple, if it happen to appear ripe in winter, will have its flavour insipid." He therefore recommends, that such plants as show fruit in September or October, had better be cast away, unless there be plenty of room for them in the hot-house ; in that case they may be retained by way of experiment, and to obtain young plants from them. (Gard. Rem. 98.)

$$
\text { G } 4
$$




\section{Sect. VIII.}

Culture of the Pine Apple in Fifeshire, by Mr. Walter Nicol.

Mr. Nicol was from 1790 to 1800 , the best grower of the Pine Apple in Scotland; he had afterwards much experience as a constructor of hot-houses; and extensive observation of the practice of the best gardeners of the north.

Form of House. "Pineries," he says, "are, and may be, very differently constructed; and we find plants thriving, and plants not thriving, in all kinds of stoves, pits, \&c. The culture of Pine Apples is attended with a heavier expense than that of any other fruit under glass; especially if they be grown in lofty stoves, the erection of which is very expensive, and the keeping up proportionally more so, than that of humbler stoves, or flued pits.

" But, independently of all considerations of expense (which may not be valued by some, provided they can obtain good fruit), Pine Apples may certainly be produced in as great perfection, if not greater, and with infinitely less trouble and risk, in flued pits, if properly constructed, than in any other way. I would therefore have the Pinery detached from the other forcing-houses, and to consist of three pits in a range; one for crowns and suckers, one for succession, and one for fruiting. 
plants. The fruiting-pit to be placed in the centre, and the other two, right and left; forming a range of a hundred feet in length; which would give Pine Apples enough for a large family.

"The fruiting-pit to be forty feet long, and ten feet wide, over walls; and each of the others to be thirty feet long, and nine feet wide, also over walls. The breast-wall of the whole to be on a line, and to be eighteen inches above ground. The back-wall of the centre one to be five feet, and of the others, to be four and a half feet higher than the front. The front and end flues to be separated from the bark-bed by a three-inch cavity, and the back flues to be raised above its level.

" The furnaces may either be placed in front, or at the back, according to conveniency; but the strength of the heat should be first exhausted in front, and should return in the back-flues. The fruiting-pit would require two small furnaces, in order to diffuse the heat regularly, and keep up a proper temperature in winter; one to be placed at each end; and either to play, first in front, and return in the back; but the flues to be above, and not alongside of one another; as in that latter way they would take up too much room. The under one to be considered merely as an auxiliary flue, as it would only be wanted occasionally.

" None of these flues need be more than five or six inches wide, and nine or ten deep. Nor need the furnaces be so large by a third, or a fourth part, as those for large forcing-houses; because there should 
be proper oil-cloth covers for the whole, as guards against severe weather, which would be a great saving of fuel.

" The depth of the pits should be regulated so as that the average depth of the bark-beds may be a yard below the level of the front flues; as to that level the bark will generally settle, although made as high as their surfaces, when new stirred up. If leaves, or a mixture of leaves with dung, are to be used instead of bark, the pits will require to be a foot, or half a yard deeper.

"It may be thought too much to insinuate, that those who have large Pineries should turn them to other purposes, and erect such as are described above. There cannot be a doubt, however, respecting the satisfaction that would follow, if to have good fruit at an easy rate were the object. I have given designs for no other kinds of new Pineries these six years past, but such as these; with some variations respecting extent, however, in order to suit different purses."

- Soil. Vegetable mould, strong brown loam, pigeons' dung, and shell-marl, are Mr. Nicol's ingredients. "The vegetable mould used is that from decayed tree-leaves, and those of the oak are to be preferred; but when a sufficient quantity of them cannot be had, a mixture with those of the ash, elm, birch, sycamore, \&c. or indeed any that are not resinous, will answer very well. In autumn, immediately as the leaves fall, let them be gathered, and be thrown together into an heap; and let just as much light earth be thrown over 
them as will prevent them from being blown abroad by the wind. In this state let them lie till May, and then turn them over and mix them well. They will be rendered into mould fit for use by the next spring; but from bits of sticks, \&c. being among them, they will require to be sifted before using. Strong brown loam is the next article. This should consist of the sward of a pasture, if possible; which should, previous to using, be well reduced, by ex-. posing it a whole year to the action of the weather. Pigeon-dung, also, that has lain at least two whole years in an heap, has been frequently turned, and well exposed to the weather, is to be used. Likewise shell-marl. And, lastly, sea or river gravel, which should he sifted, and kept in a dry place; such part of it as is about the size of marrowfat peas is to be used. This is the proportion : for crowns and suckers, entire vegetable mould, with a little gravel at bottom, to strike in ; afterwards, threefourths vegetable mould, and one-fourth loam, mixed with about a twentieth part gravel, and two inches entire gravel at bottom, till about a year old. For year-olds, and till shifted into fruiting-pots, one-half vegetable mould, one-half loam; to which add a twentieth part gravel, and as much shellmarl, with three inches clean gravel at bottom. For fruiting-plants, one-half loam, a fourth part vegetable mould, and a fourth part pigeon-dung; to which add marl and gravel as above, and lay three or four inches of clean gravel at bottom. The above compositions are what I formerly used for Pine-plants with much success; and are what may 
be reckoned good medium soils for the production of Pine Apples."

General Management. Mr. Nicol plants his suckers in summer and autumn as the fruit is gathered, sticking them into the front part of the barkbed, "where they will strike root as freely as any where. If a large proportion of the crop come off early, the crowns and suckers may be potted at once, and plunged into the nursing-pit; or they may be twisted from off the stocks, and may be laid by, in a dry shed or loft for a few days, till the other operations in the Pinery be performed, and the nursing-pit be ready to receive them and the crowns, (collected as the fruit have been gathered;) which, if rooted, may be potted, and may be placed for the above time, either in a frame, or in a forcing-house of any kind, as they will sustain no injury, though out of the bark-bed for so short a time. Such .crowns as have not struck root, may be laid aside with the suckers.

"With respect to the time for taking off the suckers, it is when the bottom part becomes brown; and they are then easily displaced by the thumb, after having broken down the leaf immediately under them. But, indeed, by the time the fruit is ripe, all suckers of the stem are fit for taking off, though they will sustain no injury by being left on, even for a month, but rather improve, if the stock be healthy, and if it be well watered. Suckers that rise from the root always have fibres, and may be taken off at any time; but, as they are tardy. 
of fruiting, they should not be taken into the stock, unless in a case of necessity.

"Some think it necessary to dry, or win, all crowns and suckers before potting them, and for that purpose lay them on the shelves, \&c. of the stove for a week or ten days. By this treatment, they certainly may be hurt, but cannot be improved, provided they have been fully matured before being taken from off the fruit or stocks, and that these have previously had no water for about ten days. They will succeed as well, if planted the hour they-are taken off, as if treated in any other way whatever; and I only advise their being laid aside as above, as being a matter of conveniency."

In preparing the suckers and unstruck crowns for potting, he twists off a few of the bottom leaves, and pares the end of the stump smooth with the knife. "Then fill pots of about three or four inches diameter, and five or six inches deep, (the less for the least, and the large for the largest plants), with very fine, light earth, or with entire vegetable mould of tree leaves, quite to the brim; previously placing an inch of clean gravel in the bottom of each, and observing to lay in the mould loosely. Thrust the large suckers down to within two inches of the gravel, and the small ones and crowns, two inches into the mould; firming them with the thumbs, and dressing off the mould, half an inch below the margin of the pots. Then plunge them into the bark-bed, quite down to, or rather below 
the brim, especially of the smaller pots. If the pots be placed at the clear distance of three or four inches from each other, according to the sizes of the plants, they will have sufficient room to grow till next shifting."

The temperature of the nursing-pit in January with fire heat, he keeps as near as possible to $65^{\circ}$ mornings and evenings; and in sunshine, on good days, it may be allowed to rise to about $70^{\circ}$. In March from $70^{\circ}$ to $80^{\circ}$; and after newly potting and plunging, unstruct crowns and suckers to $80^{\circ}$ or $85^{\circ}$.

To save fuel, he covers up the Pine pits when fires are used, every evening after sunset, either with double mats, or with a thick canvas cover, mounted on rollers. This cover he removes by sun-rise in the morning, unless the weather be very severe; in which case he leaves it on during the day. By the judicious use of this cover, he finds " a considerable deal of fuel may be saved."

As to water, he says, "nurse plants require very little, perhaps once in eight or ten days, or even at greater intervals, if the weather be moist and hazy. It is safer, in winter, to give too little, rather than too much water to Pine-plants; nor should they be watered over head at this season. They should be watered in the forenoon of a sunny day, at this time of the year, in order that any water spilt on the bark, or in the hearts of the plants, may be exhaled by the heat of the sun, and by an extra quantity of air purposely admitted. 
This precaution, however, is only necessary for the sake of such crowns and suckers as have been struck late last season, and are not very well rooted; such being more apt to damp off than others that are better established." In summer he supplies water regularly and plentifully once in three days; giving the proper quantity at root, and then a dewing over the leaves. He waters frequently with the drainings of the dunghill.

Air he admits to the nursing-pits every good day. Even in hard frost, when the sun shines, two or three of the lights should be slipped down, to let the rarified air escape at top. After potting unrooted offsets, he gives no air till the heat begin to rise in the bark-bed; but as the plants indicate their having made roots, he gives air during sunshine, so as to keep down the thermometer to $85^{\circ}$ or $80^{\circ}$.

Suckers planted in summer he shifts or re-pots in the following March. He says, "Let them be shaked out entirely; the balls be quite reduced; the roots be trimmed of all straggling and decay ed fibres; and let them be replaced in the same, or in similar pots. The proper size of pots, however, in which to put crowns and suckers struck last season, is about four inches inside diameter at top, and six inches deep. A little clean gravel should be laid at the bottom of each pot, in order to drain off extra moisture; and this should be observed in the potting of Pine-plants of all sorts. I have generally observed, that if the bark heat be 
not violent, the plants will push very strong fibres into this stratum of gravel, in which they seem to delight. I therefore generally make it two inches thick in small pots, and three or four in larger ones, less or more, according to their size. From the time I first adopted this mode of potting, I hardly ever had an instance of an unhealthy plant; and this very particular, together with that of keeping the plants always in a mild bottom-heat, is of greater importance in the culture of Pines, than all the other rules that have been given respecting them, out of the ordinary way. The roots of Pines seem to delight in gravel; and I have been careful to introduce it into the mould for plants of all ages. I generally used small sea-gravel, in which was a considerable proportion of shells, or chips of shells, with other particles of a porous nature; and I have uniformly observed the finest fibres cling to these, and often insinuate themselves through the pores, or embrace the rougher particles. Therefore, if sea gravel can be obtained, prefer it; and next, river gravel ; but avoid earthy pit gravel, and rather use sharp sand, or a mixture of poundedstone, chips, and brick-bats. The plants being re-potted, plunge them in the bark-bed again, quite down to the rims of the pots, keeping them perfectly level. Eight or nine inches from centre to centre will be distance sufficient. When they are all placed, give a little aired water, to settle the earth about their roots. This need not be repeated till the heat in the bed rise to the pots, after which, 
as the plants will now begin to grow freely, they must be watered at the root once in four or five days; and they may have a dewing over head, from the fine rose of a watering-pot, occasionally, if the weather be fine."

In May, Nicol again shifts, but the plants are not to be shaked out at this time, but are to be shifted, balls entire, into pots of about six inches diameter, and eight inches deep. "If the roots be anywise matted at bottom, or at the sides, they must be carefully singled out; and in potting, be sure that there be no cavity left between the ball and the sides of the new pot. In order the more effectually to prevent which, use a small, bluntpointed, somewhat wedge-shaped, stick, to trindle in the mould with; observing that it be in a dry state, and be sifted fine; and also to shake the pot well, (potting on a bench or table), the better to settle the earth about the ball. Pots of this size should be filled to within half an inch of their brims, (the balls being covered about an inch with fresh earth), as the whole will settle about as much, and so leave a full inch for holding water, which is enough. In preparing the plants for potting, observe to twist off a few of the bottom leaves, as they always put out fine roots from the lower part of the stem. Also, before letting the plant out of hand, trim off the points of any leaves that may have been bruised or anywise injured in the shifting. Replunge the pots to the brim, as before, observing to keep them quite level, at the distance 
of fifteen inches from centre to centre of the plants on a medium; then give a little water, which need not be repeated till the heat rise to the pots."

In November, he shifts such others whose roots have filled their pots, and have become anywise matted. "Examine any you suspect to be so, and let them be shifted into pots of the next size immediately above those they are in; keeping the balls entire, and only singling out the netted fibres at bottom. The rest should be trimmed of any dead leaves at bottom of their stems, and should have a little of the old mould taken from off the surface of the pots; which replace with fresh earth ; filling the pots fuller than usual, as but little water will be required till next shifting time in the spring. The whole should then be replaced in the bark-bed as before, and should be plunged quite to the rims of the pots; giving a little water to settle the earth about their roots, which need not be repeated till the heat rise in the bed."

Plants intended to fruit in the succeeding year, are shifted finally in the August of the year preceding. The plants are again looked over in the February following, and top dressed; but such as are unhealthy, feeble, and do not stand firm in their pots, he shakes out of their balls entirely, and re-pots in the same, or in smaller pots. "Any plants," he says, "that have already started into fruit, should also be shaken out, and be fresh potted, as above; which, by the check they receive, will keep them back to a better season of 
ripening, and by the force of fresh earth, make them swell their fruit larger than they otherwise would have done. I have thus new-potted plants, even in flower, with very much success, and have swelled the fruit to a size far beyond my expectations; of which fact any one may easily satisfy himself, by fresh-potting a few plants, and comparing their progress with others treated in the ordinary way. Let the plants be re-plunged to the brim as before, keeping the pots quite level. If the plants be full-sized, and strong, they will require to be set at about twenty inches apart from centre to centre, on a medium. But they should be sorted; the smallest placed in front, and the largest at back, as in arranging plants on a stage, that they may have an equal share of sun and light. As soon as re-placed in the bark-bed, let them have a little water, to settle the earth about their roots." In May he again top-dresses, "reducing an inch or two of the earth from off the surface, and adding some fresh mould, which will invigorate the plants, cause them to push surface radicles, and so keep them the more firm and steady. This needs not be done, however, to plants whose fruit are nearly ripe; but chiefly to healthy plants new shown in flower, past the flower, or with the fruit about half: grown. And with respect to any that are unhealthy, and whose fruit are less than half grown, do not hesitate to shift them, shaking them out, trimming their roots, and retaining only healthy. fibres. 'This is a very great improvement in the 
culture of Pines, which I formerly practised, have since advised, and have seen followed with much success."

The temperature of the fruiting-pit is kept at the same degree as that of the succession department in mid-winter. This is from $60^{\circ}$ to $65^{\circ}$; but as spring approaches, he rises gradually to $75^{\circ}$, but not allowing the thermometer to pass $80^{\circ}$. From $72^{\circ}$ to $75^{\circ}$ is his temperature for March and April. In May, June, July, and August, he requires $75^{\circ}$ mornings and evenings, and $80^{\circ}$ or $85^{\circ}$ at noon. In September, after fire-heat becomes necessary, he keeps as nearly to $65^{\circ}$ as possible, and in sunshine, by the free admission of air, to about $70^{\circ}$ or $72^{\circ}$. In October, November, and December, he lowers the temperature to $60^{\circ}$ mornings and evenings, and $65^{\circ}$ in sunshine.

Air is admitted at all seasons in fine sunshine weather, and freely, as the fruit approaches to maturity, in order to enhance its flavour.

He gives water seldom in January, and not oftener than once in six or eight days in February. In March, "water may given oftener than heretofore advised, and also in larger quantities; generally a moderate watering at root once in three or four days, and a dewing over head occasionally, to refresh the leaves, and keep them clean from dust. From the time the plants are out of flower, and the fruit begins to swell, water must be applied in a very liberal manner once in two or three days, always giving the necessary quantity at root, and 
then a dewing over head. Watering to this extent, however, if the fruit be not in too forward a state, will seldom be necessary before the end of the month, or till April." In April, "water must be given in a plentiful manner, once in two or three days, in order the better to swell off the fruit. The roots have now much to do in sustaining it, and also the suckers, which will be fast advancing in growth. For this reason, water frequently with dunghill-drainings, or with water of dung, soaked on purpose; and after each watering at root, give a dewing over the leaves, as directed above." In May, June, and July, " from the time the fruit begin to colour, however, begin also to lessen the quantity of water; and towards its being fit for cutting, withhold water entirely, else the flavour will be very much deteriorated. I shall here observe, with respect to the different kinds of Pines, that the Queen and the Sugar-loaf sorts require considerably more water than the King or Havannah, and the Antigua. The difference in the manner of watering should be more particularly attended to as the fruit approach to maturity; $;$ as the latter-named kinds are naturally more juicy and watery than the former." In August, the plants that have done fruiting being removed, the succession stock which replace them are to be watered freely at root, and occasionally dewed over top. In October and November, the waterings are gradually, lessened; and in December, once in eight, ten, or twelve days, will be sufficient. 
Insects. " If Pine plants," Nicol observes, " by proper culture, be kept healthy and vigorous, insects will not annoy, but leave them. This fact I have repeatedly proved, both with respect to the Pine, and to other plants that are liable to be affected with the coccus, (the only insect that materially injures the Pine), which seems to delight in disease and decay, as flies do in carrion.

"I have received into my stock, plants covered with the pine-bug, (coccus hesperidum), without the smallest hesitation; made no effort whatever to get rid of them; and by next shifting time, in two or three months, have seen no more of them. This I have not done once, but often; and I have known my brother do the same thing. In short, I never but once in my life have tried any remedy for the $b u g$; and as I was completely successful, I shall here give the recipe, which may safely be applied to Pine plants in any state; but certainly best to crowns and suckers at striking them, or to others in the March shifting, when they are shaked out of their pots at any rate.

" Take soft soap, one pound; flowers of sulphur, one pound; tobacco, half a pound; nux vomica, an ounce; which boil all together in four English gallons of soft water to three, and set it aside to cool. In this liquor immerse the whole plant, after the roots and leaves are trimmed for potting; and this is the whole matter. Plants in any other state, and which are placed in the bark-bed, may safely be watered over head. with this liquor; and 
as the bug harbours most in the angles of the leaves, it stands the better chance of being effectual, on account that it will also there remain longest, and there its sediment will settle. In using it in this latter way, however, if repeated waterings be necessary, the liquor should be reduced in strength by the addition of a third or a fourth part water.

"The brown scaly insect, also a coccus, is often found on the Pine, and other stove plants; but I never could perceive that it does any other injury than dirty them, and so is of less importance than the other species, which eats or corrodes the leaves, in so far as it leaves them full of brown specks or blotches. The above liquor, however, is a remedy for either, and indeed for most insects, on account of its strength, and glutinous nature.

"Ants are also to be found in the Pinery; but I never could observe that they do the plants any harm, though they are generally to be found in the pots, and among the bark. They are most frequently to be met with there, if the coccus be present; and seem to feed on its larvæ, or perhaps on its fæces."

Fruit produced. He does not state any determinate object as to this subject; if the object be to have large fruit, he says, all suckers of the root and stem must be twisted off; and to retard the progress of fruit that is shown too early, he recommends re-potting the plants in February. He says, "If Pine Apples be not cut soon after they begin to colour, that is, just when the fruit is of a II 4 
greenish yellow, or straw colour, they fall greatly off in flavour and richness; and that sharp luscious taste so much admired, becomes insipid.

\section{SECT. IX.}

Culture of the Pine Apple, by Mr. William Griffin, Gardener to J.C. Girardot, Esq.at Kelham, in Nottinghamshire, and now to Samuel Smith, Esq. of Woodhall, in Hertfordshire.

Mr. Griffin has been a most successful cultivator of the Pine Apple; perhaps more so for the limited means which he possessed at Kelham, than either M·Phail or Baldwin.

Form of House. 'This is so nearly that of Speechly, that we do not consider it necessary to give the details.

Soil. Mr. Griffin laughs at those who prescribe " many different strange ingredients for composts ;" adding, that, " after numerous experiments made with mixtures of deers', sheeps', pigeons', hens', and rotten stable-dung, with soot, and other manures, in various proportions and combinations with fresh soil of different qualities from pastures and waste lands, I can venture with confidence to recommend the following: Procure from a pasture, or waste land, a quantity of brown, rich, loamy earth, if of a reddish colour the better, but of a fattish mouldy temperature; that by squeezing a handful of it together, and opening. your hand, it will readily fall apart again : be cautious not to go 
deeper than you find it of that pliable texture; likewise procure, if possible, a quantity of deers'dung: if none can be conveniently got, sheeps'-dung will do, and a quantity of swines'-dung. Let the above three sorts be brought to some convenient place, and laid up in three different heaps ridgeways, for at least six months; and then mix them in the following manner, covering the dung with a little soil before it is mixed: four wheelbarrows of the above earth; one barrow of sheep's-dung, and two barrows of swine's-dung. This composition," he adds, " if carefully and properly prepared, will answer every purpose for the growth of Pine-plants of every age and kind. It is necessary that it should. remain a year before applied to use, that it may. receive the advantage of the summer's sun and winter's frost; and it need not be screened or sifted before using, but only well broken with the hands and spade, as when finely sifted it becomes too compact for the roots of the plants."

General management. In rearing the young plants, he generally plants the crowns in the bark till they have struck root; but the suckers he pots at once, unless they are small and green at bottom, when he treats them like the crowns. The pots he uses for both crowns and suckers are five inches. diameter, and four inches deep, unless the suckers are very strong, when he puts them in pots seven. inches and a quarter wide, by six and a half inches. deep. The plants are shifted in the March following into pots nine inches in diameter, by eight inches. 
deep, " turning each singly out of its present pot, with a ball of earth entire around its roots, unless any appear unhealthy or any ways defective, when it is eligible to shake the earth from the roots, and trim off all the parts that appear not alive. He plunges them in the bark (refreshed as at each shifting) eighteen inches from plant to plant in the row, and twenty inches distance row from row."

Mr. Griffin shifts for the last time in the October of the year preceding them in which the fruit is expected; the pots he uses are twelve inches in diameter, and ten inches deep. He plunges them in the bark-bed, about twenty inches plant from plant, and two feet distance from row to row. He says, "place the first row eighteen inches from the kirb, angling them in the rows as you go on."

It is of some consequence to remark, that Griffin's practice in not divesting the plants at any one shifting of their balls of earth, differs from that of Speechly, Nicol, and most other practitioners, excepting Baldwin. It appears highly probable, that by not disturbing the balls of healthy plants, they will produce their fruit both earlier and of a larger size; for the cutting off the roots must produce a check in the growth of the plant, and their renewal must occupy its chief energies for some time, and thus lessen the vigour of the leaves; since the leaves and roots of all plants assist each other alternately as occasion requires.

Those who advocate the practice of shaking off the balls of earth, and cutting off the roots of 
Pines in the second year's spring shifting, say, that though, at first sight, it has an unnatural appearance, yet, on more minute enquiry, it will be found congenial to nature. In the first place, they say that they only cut away the lower decaying roots, and preserve all the others, unless they are bruised by the shaking off the ball; or injured by disease, or otherwise. In the next place, they state, that on attentively examining the Pineplant, it will be found, that, in its mode of rooting, it may be classed with the strawberry, vine, and crowfoot, which throw out fresh roots every year, in part among, but chiefly above, the old ones. This done, the old ones become torpid and decay, and to cut them clear away, if it could be done in all plants of this habit, would, it is said, be assisting nature, and contribute to the growth of the new roots. At the same time, it is to be observed, that encouraging, in any extraordinary degree, the production of roots, though it will ultimately increase the vigour of the herb and fruit, will retard their progress to maturity.

Speechly has the following judicious observations in allusion to those who recommend always shifting with the balls entire.

" First, It is observable, that the Pine-plant begins to make its roots at the very bottom of the stem, and as the plant increases in size, fresh roots are produced from the stem, still higher and higher; and the bottom roots die in proportion: so 
that, if a plant in the greatest vigour be turned out of its pot as soon as the fruit is cut, there will be found at the bottom a part of the stem, several inches in length, naked, destitute of roots, and smooth: now, according to the above method, the whole of the roots which the plant produces being permitted to remain on the stem to the last, the old roots decay and turn mouldy, to the great detriment of those afterwards produced.

"Secondly, The first ball which remains with the plant full two years, by length of time will become hard, cloddy, and exhausted of its nourishment, and must, therefore, prevent the roots afterwards produced from growing with that freedom and vigour, which they would do in fresher and better mould.

" Thirdly, The old ball continually remaining after the frequent shiftings, it will be too large when put into the fruiting-pot, to admit of a sufficient quantity of fresh mould to support the plant. till its fruit becomes ripe, which is generally a whole year from the last time of shifting."

In giving air and water, Mr. Griffin differs nothing from Nicol; he waters moderately in winter, and more liberally in the growing season, from March till October; want of water to keep the plants moist, he considers one of the reasons of their showing fruit prematurely. He never waters over the leaves in any stage, nor gives much at the roots in damp weather. 
With respect to temperature, this author differs from most others who have written on the Pine, but not from many very successful practitioners. He recommends $60^{\circ}$ as the heat proper for the Pine in every stage, not exceeding five or six degrees over or under. The bottom heat, which he considers proper, is from $90^{\circ}$ to $100^{\circ}$. Treatise on the Pine Apple, p. 60. and 66.

Insects. After many trials and experiments, he found the following the most effectual wash for destroying insects on Pines:-

"To one gallon of soft rain-water, add eight ounces of soft green soap, one ounce of tobacco, and three table spoonfuls of turpentine; stir and mix them well together in a watering-pot, and let them stand for a day or two. When you are going to use this mixture, stir and-mix it well again, then strain it through a thin cloth. If the fruit only is infested, dash the mixture over the crown and fruit, with a squirt, until all is fairly wet; and what runs down the stem of the fruit will kill all the insects that are amongst the bottom of the leaves. When young plants are infested, take them out of their pots, and shaking all the earth from the roots, (tying the leaves of the largest plants together,) and plunge them into the above mixture, keeping every part covered for the space of five minutes; then take them out, and set them on a clean place, with their tops declining downwards, for the mixture to drain out of their centre. When the plants. 
are dry, put them into smaller pots than before, and plunge them into the bark-bed."

Fruit produced. Mr. Griffin's object seems to have been to produce large fruit in the proper season. In the year 1802, when gardener to J. C. Girardot, Esq. at Kelham, near Nottingham, he cut twenty Queen Pines, which weighed together eighty-seven pounds seven ounces. In 1803 , one weighing five pounds three ounces. In July, 1804, one of the New Providence kind, weighing seven pounds two ounces. In August, 1804, one of the same kind, weighing nine pounds three ounces. And in 1805, he cut twenty-two Queen Pines, which weighed together one hundred and eighteen pounds three ounces.

\section{Sect. X.}

Culture of the Pine Apple, by Mr. Thomas Baldwin, Gardener to the Marquis of Hertford, at Ragley, in Warwickshire, from 1805 to the present time.

Mr. Baldwin is reputed the first Pine cultivator in England; he has given some account of his practice in a tract of a few pages, which, being sold much above the usual price of printed books, never obtained so much circulation as manuscript copies of it, which were handed about among the principal Pine-growers near London. 
Form of House. The succession, or nursing pits, according to Mr. Baldwin's plan (fig. 11.), in which the young plants are to re-

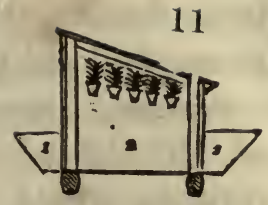
main both winter and summer, should be constructed of timber, seven feet wide, and seven feet three inches high at the back, the front being in the same proportion. The method of preparing the bed is as follows:- "Sink your pit (2.) three feet three inches deep, as long as you require, and sufficiently broad to admit of linings on each side $(1,1$.$) ; make a good drain at the bottom$ of the pit to keep it dry; then set posts, about the dimensions of six inches square, in the pit, at convenient distances, (say about the width of the top lights,) and case it round with one inch and a half deal wrought boards, above the surface, and below with any inferior boards or planks. 'The dimensions of my succession-bed or frame, are thirty-nine feet long, and seven feet wide; containing two hundred and seventy-three square feet, which will hold three hundred and fifty suckers, from the end of September till the seventh of April."”

Soil. "From old pasture or meadow ground strip off the turf, and dig to the depth of six or eight inches, according to the goodness of the soil; draw the whole together to some convenient place, and mix it with one-half of good rotten dung; frequently turn it over for twelve months, and it will 
be fit for use. This is the only compost dung for young and old plants."

General management. The general practice of Mr. Baldwin is to take the suckers from the fruiting plants about the end of September, and lay them in a warm place for about three days; he then pulls off a few of their bottom leaves, which makes them ready for planting. "In making your bed, he says, lay three-fourths of new tan at the bottom of the pit, and lay old tan upon that, to reach within three inches of the top; on the surface of this sift old tan to the thickness of three inches, beating it down well with the spade, then plant the suckers in the tan about four or five inches apart, according to the size of the plants, placing the tallest in the backside of the frame, and the shortest in the front. In this situation let them remain till the month of April following; then take up the plants out of the tan-bed, and divest them of all their root; and remember that at any future transplanting the roots must not be taken off. Plant them in pots of five, six, and seven inches diameter, according to the size of the plants, but before planting let the pots be filled with the prepared compost already mentioned. About the middle of June following, when the pots are beginning to be filled with roots, take out the plants with their balls whole, and plant them in pots about nine inches in diameter, being filled with the same rich compost, replanting them into the bed, and let them remain there till the end of 
September. Be careful at each transplanting, while the plants are out of the beds, to have the beds put into a proper state by the addition of fresh tan, \&c.

"When the plants are out of the stoves in the month of September; prepare the pits in the same manner as directed for the succession-beds, with three-fourths of new tan at the bottom, \&c.; then shift the plants into pots about fourteen inches diameter at the top, and plant them at suitable distances for fruiting; plunge the pots at first halfway into the tan, till the heat diminishes to a safe temperature, then fill up the interstices between the pots with tan, and as the plants are now stationed, let them so remain till they are fruited off for the table. The plants, young and old, had best be near the glass, and small stoves are to be preferred, because they require less fire. The glass should be closely puttied, to keep out the cold air, and to retain the warm.

"The fruiting-house during the winter should be kept at about seventy of Fahrenheit's scale. It may be left in the evening about seventy-five, and it will be found in the morning about sixty-five, so that no attendance during the night will be necessary.

"There should be no water given to the young suckers from September till April, while they remain in the tan without pots. After they are potted they require to be watered two or three times a week during the summer, according as the temper- 
ature may be. When they are removed into the fruiting-house in September, they should be watered cautiously till towards February, and as the spring advances they will require a large supply. Never water the plants in the common broad-cast method, over their heads and leaves.

$\therefore$ "Give air in the stoves and frames, both in summer and winter, when the weather will permit, from the back and ends, but not from the roof.

" Expeditious cultivation. "The New Providence, Black Antigua, Jamaica, and Enville, and the other large sorts of Ananas, will require the cultivation of three years to bring them to perfection, but the Old Queen and the Ripley's New Queen may be brought to perfection in fifteen months. To effect this, it must be observed, that some of the plants will fruit in February, or the beginning of March, and consequently that the suckers may be taken off in June, or the beginning of July; make then a good bed of tan with linings of litter round the outside to keep in the tan; make the bed to fit a large melon frame; put the suckers into pots of about nine inches diameter, filled with the compost; plunge them into the bed prepared in regular order, and throw a mat over them in hot weather for shade till they have taken root; let them remain till the end of September, and then shift them into pots of about twelve inches diameter, and plunge them in the fruiting-house." He has had fine crops of Pines raised from these suckers, many of them four pounds each, from plants only fifteen 
months old. " This method, in point both of time and expence, has greatly the advantage of the common plan of raising Pines in three years by fires, when the fruit at last is frequently small and ill-flavoured."”

"It is a peculiar recommendation of this plan, that the plants reared in frames without fire, the first year seldom or never run to fruit; whereas, on the contrary, when stoves are used first for a nursery for young plants, and next for succession plants, and lastly, for plants for the fruiting-house, it is seldom that one-third of the plants come to the forcing-house, because so many of them have run to fruit; and even those that stand are necessarily dried and stunted, being subjected to the attacks of various insects; not to mention the enormous care and expence attendant upon a three years' cultivation. The above appears to me to be the most easy and economical plan to raise Pines; one-third of the coals are sufficient, and less than one-half of the labour and buildings required for that purpose." Culture of the Ananas, p. 28.

Insects. After, as usual, many fruitless attempts, he at last discovered the following method: "Take horse-dung from the stable, the fresher the better, sufficient to make a hot-bed three feet high, to receive a melon frame three feet deep at the back ; put on the frame and lights immediately, and cover the whole with mats to bring up the heat. When the bed is at the strongest heat, take some 
faggots, open them, and spread the sticks over the surface of the bed on the dung, so as to keep the plants fiom being scorched; set the plants or suckers bottom uppermost on the sticks; shut down your lights quite close, and cover them over well with double mats, to keep in the steam. Let the plants remain in this state one hour, then take out the plants and wash them in cold water previously brought to the side of your bed, set them in a dry place with their tops downwards to drain, and afterwards plant them. This treatment is sure to kill every insect. You will observe likewise, that if your suckers are kept in the frames all the winter, stuck in the tan without soil or fire, the effluvia from the linings are sure to kill all the bugs." Cul-. ture of the Ananas, p. 33.

Fruit Produced. The general crop is produced in the usual season, viz. from June to September, or October; but some are produced every month in the year. The large sorts, as the New Providence, \&c. require three years to bring them to perfection, but the Old Queen, and Ripley's New Queen, may be brought to perfection in three months; though from the circumstances requisite to render this practicable, viz. plants fruiting in February, or the beginning of March, it must be considered more a matter of accident or curiosity than of any real advantage. It is evident, at all events, that it can never become general; for certainly no gardener would desire all his plants to come into fruit in February or March. Mr. Baldwin grows his fruit 
to a very considerable size even when produced in so short a period. "At a meeting of the Horticultural Society of London, held in October, 1817, T. Baldwin, gardener to the Marquis of Hertford, at Ragley, presented a Queen Pine of great beauty and superior flavor. It measured sixteen inches in circumference, seven inches in lengh, and weighed four pounds. The plant on which it was produced was little more than fifteen months old." Hort. Tr. vol. iii. p. 118.

Remarls. The following judicious remarks on Mr. Baldwin's plan are by Mr. M‘Phail. "Mr. Baldwin's method," he says, " appears to differ nothing in principle from the methods I practised; but we differ a little in practice, that is, in the manner of the application of the elements necessary to make the plants grow fast and vigorous, and. to produce fine fiuit; and likewise in the mode of disrooting and planting, which difference I conceive to be of little consequence. He grows his plants in good earth, enriched with plenty of well-rotted manure. He keeps the plants in a strong heat, and gives their roots plenty of water. He sets his fruiting plants in a bed of tan in the month of September, and there it appears they are stationed till the fruit be ripened the following summer. Now, I think, a bed made up in September, is not able to retain a sufficient heat for the growth of the Pine Apple plant for so long a period of time.

"Once, by way of experiment, in a small hothouse, I made up a bed in the pit of it in the month 
of October, and laid upon the surface of the bed one foot thick of good earth, and turned out of their pots fine Pine Apple plants, intended to fruit the succeeding year, and I set the plants into the earth on the surface of the bed with the balls of earth about their roots undisturbed. In this situation they grew exceedingly well, and shewed fruit very strong, but the heat in the bed under them became too faint in the month of April : and with all the atmospherical heat that I could give them, the fruit did not ripen well for want of heat to the roots of the plants; and I was not able to contrive any method to recruit it, which required to be done in the month of March or April.

"According to the foregoing account, this celebrated and experienced gardener plants the suckers of the Pine Apple in the latter end of September, and he divests them of all their roots in the month of April. In this method of process I must differ from him, because the young plants have only six months (being the slowest growing months of the year) to make roots, and then these roots are entirely cut off, which considerably retards the plants in their growth. And, according to his method, and mine also, the queen and some other sorts of the Pine, ripen their fruit in a shorter period of time than two years after planting. He says, he never waters his Pine plants in the broad-cast way over their heads and leaves. In this I also differ with him, for I think, giving the plants water all over their leaves occasionally, especially in hot 
weather, is of service to them, and which indeed is only imitating nature.

"I say not that Pine Apple plants will not do well without giving them water all over their leaves, for if hot-houses be kept in a good state of temperature for the growth of the Pine Apple, the great evaporation of the tan-bed, and of the moist earth about the roots of the plants, may supply the leaves sufficiently with water, especially in houses managed in the way this real practical gardener says he manages his Pine plants; that is, his hot-houses are very close, and he admits no air at the roof, so that the moist air which ascends up is thrown back among the plants. I would here remark, that when Pine Apple plants are watered all over their leaves when in fruit, the water should not be suffered to stand long in the heart of the crowns on the fruit, which it will seldom do if the heat in the house be good, but with a little care the plants may be watered all over their leaves, without letting it fall on the fruit, or the crowns of them.

"He recommends that beds for the culture of the Pine Apple be built of wood: excepting it be oak, which is dear, other sorts of timber will not last long in such a situation; and therefore, for this and other reasons, (given in Section VII. page 67), I think beds built of brick, in a similar way to the one I invented, are preferable, and in the end cheaper than those of wood.

"With regard to the method which this gardener useth to destroy insects on Pine Apple plants, it is 
a troublesome operation, and can be practised only on young plants, and indeed, according to his own account, insects on the Pine Apple may be destroyed in the course of their culture, which coincides exactly with the methods I used and recommend to be carried into practice by those who have the management of Pine Apple plants, and are troubled with insects. I have no doubt but his method of laying young plants in a hot-bed of rank dung, will effectually destroy the insects, though I think, however, they had best remain in the bed longer than one hour; but perhaps remaining even an hour, or a longer time, in such a dreadful situation, where I conceive no animal could long exist, might hurt the plants, if not destroy them. But let it be remembered, that if Pine plants be perfectly fiee of insects, if they are put into a hot-house where the scale or the bug insects are in the tan, or in any part of the house, the insects will find their way to creep to the Pines and breed upon them; for these insects are natural to the plant."

\section{SECT. XI.}

Culture of the Pine Apple as given in Abercrombie's Practical Gardener, edited by Mr. James Mean, head gardener to Sir Abraham Hume, Bart. at Wormleybury, in Hertfordshire.

The culture of the Pine Apple was given by John Abercrombie, in his "Every man his own 
Gardener," when that work was originally published in 1780; but we prefer taking it from the work above cited, as giving the modern practice. It is proper to observe, however, that the directions in the "Practical Gardener" are much less to be depended on than those given by M·Phail and Baldwin ; for as the first of these authors observes, in his preface to the Gardener's Remembrancer, the Practical Gardener has been evidently dressed up, and in some parts rather affectedly, by some man who knew little of the practice of gardening. As to what Mr. Mean may have done in revising the book, it is more certain that he has not done enough, than that he has done any thing, for there are many passages; besides those pointed out by M‘Phail, that appear quite ridiculous as coming from a practical gardener: Notwithstanding these faults, however, which would have escaped unnoticed in a less valuable book, "The Practical Gardener" is the best book of its kind extant.

Form of House. "The fruiting-house," he says, " need not be higher than five feet in front, and eight feet six inches at the back wall; or, whatever be the breadth of the house, the difference between the height in front and in rear, need not exceed one-third of the breadth." By this means the chamber of air to be heated will be materially reduced. To give a full command over the temperature of this air, let the lappings of the panes of glass be closed with putty.

The roof of the succession-house may be four or 
six inches lower than that of the fruiting-house; and the roof of the nursing-pit may be a foot lower than that of the fruiting-house.

Soil. The soil recommended is nearly the same as that used by Nicol. It consists of : - " 1 . Vegetable mould; 2. The top-spit earth from an upland pasture, loamy, friable, and well reduced; 3. Hard-fed dung, rotted and mellowed by at least a year's preparation; 4. Small, pearly river-gravel; 5. White sea-sand; 6. Shell-marl.

"If no vegetable mould has been provided, light rich earth, from a fallowed part of the kitchen garden, may be substituted: there is no difference of any account between one and the other, further than this: The vegetable mould is sure to be virgin earth, from which no aliment has been extracted; the mould from the kitchen garden, however you may trench, and rest, and enrich it, cannot but contain many particles which have given out their fertilizing qualities to previous crops.: Dung perfectly decomposed comes to the same thing as vegetable mould; therefore that one of them which is most attainable; or best prepared, may fitly serve instead of the other.

"Of the first three take equal quantities; making three-fourths of the intended compost. Constitute: the remaining fourth thus: Let river-gravel, sea. sand, and shell-marl, furnish each a twelfth part. The small gravel is to afford something for the roots to lay hold of; the sea-sand, to promote lightness and dryness; the shell-marl, the better to support the 
growth of fibres and integuments and parts not pulpy. Mix with the whole a fortieth part soot, to offend and repel worms. Incorporate the ingredients fully; and turn the heap two or three times before using it.".

General management. "As soon as either crowns or suckers are detached from the parent plant, directions are given to twist off some of the leaves about the base; the vacancy, thus made, at the bottom of the stem, is to favour the emission of roots. Pare the stump smooth; then lay the intended plants on a shelf in a shaded part of the stove, or of the green-house, or of any dry apartment. Let crowns and fruit off-sets lie till the part that adhered to the fruit is perfectly healed; and root-suckers, in the same manner, till the part which was united to the old stock is become dry and firm. They will be fit to plant in five or six days. As to the prolonged period for which they may remain out of culture: Pine-plants have been kept six months without mould, in a moderately warm dry state, and the only injury has been loss of time. Crowns or suckers coming off before Michaelmas should be planted without any unnecessary delay, to get established before the winter. When latefruiting plants do not afford off-sets till after Michaelmas, it is best to keep them in a dormant state during the months least favourable to artificial culture: therefore, as you obtain these late off-sets, hang them up in the house, not too near the flues, to rest till March." 
Insects. Mr. Nicol's method, and also that by M'Phail, are both quoted with approbation. The following wash is directed to be applied exclusively to the building, and by no means to the plants. " At the annual cleansing of the house, if insects are supposed to breed in the building, introduce the wash with a brush into the cracks and joints of of the wood-work, and the crevices of the wall.

Recipe for the Wash. "Of sulphur vivum take $2 \mathrm{oz}$. soft soap, $4 \mathrm{oz}$. Make these into a lather, mixed with a gallon of water that has been poured in a boiling state upon a pound of mercury. The mercury will last, to medicate fresh quantities of water, almost perpetually."

Fruit produced. To ripen eminently large fruit, he directs the removal or destruction of suckers; to retard the progress of fruit that have appeared too early, he shifts in Nicol's manner; and when fruit is ripening too fast, or too many advancing to a ripe state together, he retards a part of the plants by setting them into a dry airy place, affording both shade and shelter. "Give no water as long as you wish to suspend their progress. For the same purpose, others may be set out green; but whilst the excitment of these is lowered, they must be kept in a growing state." Practical Gardener, 643. 


\section{Sect. XII.}

Culture of the Pine Apple by Mr. James Andrews, commercial gardener, Vauxhall.

Mr. Andrews has been considered the best grower of Pines in the neighbourhood of London for many years; his principal object is to grow fruit for the market; but the demand for the plants by private gardeners, and others, has generally been so great, that he can seldom keep the plants till the last stage of their growth.

Form of House. Both pits and larger houses are used; but there is nothing particular in the form of either. Mr. Andrews seldom erects new work, but generally purchases old hot-houses and sashes at the sales of decayed gentlemen, or bankrupt tradesmen. In this respect he follows the practice of 'Mr. Lee of Hammerșith, and both have generally a stock of old sashes and rafters on hand ready to put up when wanted. But though the form of Mr. Andrews' houses may be said to be in a great degree matter of accident, - yet the arrangement of the flues within is his own. These generally enter at the front corner of one end, pass to the opposite end, return along the back wall, where they sometimes serve as a path, and at other times are placed at one side of the path, occasionally a return is made, and the chimney-top is formed in the back wall, at the opposite end to that in which the fire enters; when this is not the case, the smoke 
passes off by the back wall at the same end. The width of the pit depends on the room left by the flue; to increase it no path is formed at the ends or in front, and that along the back wall does not exceed two feet in width. The depth of the pits is from two feet and a half to three feet deep, and their distance from the glass from four to six feet. Vines are trained up the rafters and over the back path. The sashes in front open in various ways, and air is given by them, and by the sliding sashes of the roof. On the whole, Mr. Andrews' best houses greatly resemble those of Mr. Gunter, to be described in the following section.

In the pits there is nothing uncommon in the construction; they are, in general, sunk deep in the ground, which being dry at bottom, is a great saving of heat. In some the tan is enclosed by brick walls, in others by a frame of wood; some are without flues, but the greater number have a flue in front, or a steam tube, or both.

In the year $181 \%, \mathrm{Mr}$. Andrews tried the effect of steam, and was so much satisfied with it, that in the following year, he put up an extensive apparatus in the centre of his forcing department, from which branch-pipes proceed in all directions, and heat the air in the whole of his hot-houses, pits, and frames.

- Soil. As near as possible that of Baldwin's, or M:Phail's; - a rich loan, rendered sufficiently free by coarse sand, to admit the ready passage of the water. 
General management. The crowns and suckers, when they are detached at irregular seasons, as in winter, or very early in spring, are planted in any spare corner of the bark bed, till a number is collected, when they are planted in pots, according to their sizes, and plunged in common hot-beds, or pits. Mr. Andrews has no particular months for shifting, no fixed sizes of pots, and no predetermined manipulation as to shaking the plants out of their balls, or otherwise. He is present at every operation himself, and acts as the case requires. He encourages forward plants, by giving them larger pots than the rest; sometimes he looks over the nursing-pits, and selects the most vigorous plants, shifts them, and puts them into a stronger heat, leaving the others for some weeks longer: the balls of earth he does not disturb, if they do not appear hard, the roots injured, or the plant enfeebled. Sometimes he takes off the bottom of the ball, and the bottom roots, paring off any part of the stump of the plant which may appear decaying; at other times, he contents himself with removing the surface-mould, and top-dressing. In general, he places the plants somewhat deeper in the pots at each shifting:

The plants which he removes to the fruitinghouses are shifted, for the last time, about nine months before the fruit is expected; their pots are generally twelve or fourteen inches in diameter; but not of the usual proportion in depth, to lessen the risk of overheating from the tan. The depth 
is generally the same as the width. The pots are plunged up to their rims, unless the heat be very violent, and are liberally supplied with heat, air, and water. Mr. Andrews does not fear $90^{\circ}$ or $100^{\circ}$. degrees of heat in the bark bed, even when the air of the house by fire-heat is not above $60^{\circ}$ or $65^{\circ}$. In summer, he allows the thermometer to rise to $90^{\circ}$ or a $100^{\circ}$ before he gives air, and he often leaves some at the top-lights all night.

- Insects. On this subject nothing new can be gathered from the practice of $\mathrm{Mr}$. Andrews, for he has never had any worth destroying by a regular process. His practice affords an ample proof that regimen and cleanliness will never allow insects to increase to an injurious degree.

Fruit produced. We have already noticed the circumstance of Mr. Andrews' plants being often sold before they arrive at the stage for fiuiting. His stock, however, has been lately greatly increased by the erection of additional houses, and the easy mode of heating them from the steam apparatus; he now, therefore, sends a number to market, and chiefly in the winter season, and early in spring, when the price is highest. Their fruit weigh from one to four pounds, and are almost exclusively of the Queen Pine. 


\section{Sect. XIII.}

Culture of the Pine Apple, as practised by Mr. Gunter, at Earlscourt, near Kensington; Mr. Grange, at Kingsland; and Mr.Wilmot, of Isleworth.

The family of Mr. Gunter have long possessed the very extensive gardens of Earlscourt, and grown in them kitchen vegetables, excellent hardy fruits, and melons, for the London market; but it is only within the last seven years that they have commenced the culture of the Pine Apple for the same purpose. This Mr. R. Gunter has done on the most liberal and extensive scale, and with great and merited success.

Form of House. Like Mr. Andrews, Mr. Gunter uses both pits and large houses; in the pits he both nurses the plants, and fruits them, and in the large houses he fruits the Pine Apple, and produces very early grapes at the same time.

The large houses (fig. 12.) are, in what may be

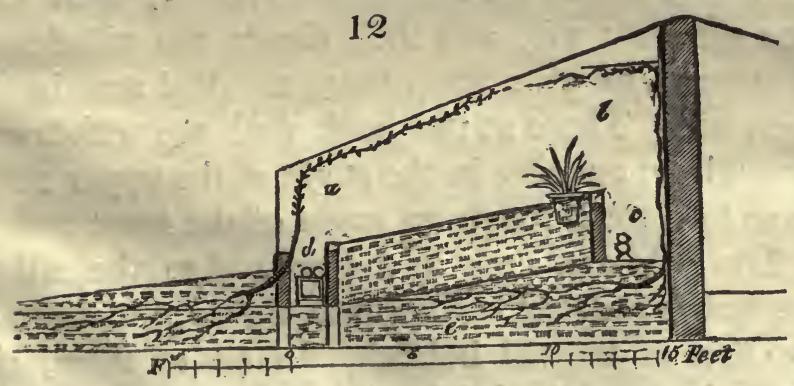


called the usual form; they differ from M'Phall's, and the houses built by Speechly, and originally by Nicol, in not having a path in front; and from those of Mr. Aiton, erected in the royal gardens at Kensington, in the pit being farther from the glass. They are about fourteen feet wide inside measure; the pit is ten feet three inches wide, three feet deep, three and a half feet from the glass in front $(a)$, and about six feet and a half behind $(b)$. The back path $(c)$ is a border regularly dug and manured, to encourage the roots of the vines, which pass under the bark bed to the front border. Each house is forty feet long, and has a flue proceeding from the back wall to the front, and along the front to the opposite end, returning to the back wall in the usual manner. As the houses are all heated by steam, however, these flues are erected merely by way of security, in case of any accident happening to the boiler or the pipes $(d, e)$, and are therefore seldom used. Besides the vines trained over the back path, there are others which are led up the rafters; both root into excellent soil, and their shoots are withdrawn in autumn to give them three months' rest in the open air. Those at the back wall are withdrawn through an opening in the angle of the upper sash ; those in front through an angle of the front sash.

The pits are sunk in the ground to the sill of the sashes in front, and within eighteen inches, or two feet of the sill behind. In all of them, the tan is inclosed by brick walls; they are generally 
about seven feet wide within walls, but some are as wide as fourteen feet, with the front wall six inches above ground, and the back wall two feet ten inches. The sashes in these broad pits are in two lengths, as in hot-house roofs; none of them have any flues, being all heated together, with the hot-houses, and various other descriptions of pits, by an extensive steam apparatus. This apparatus was erected by Mr. Mainwaring, of Blackfriars, and is one of the most complete of its kind, excepting in the circumstance of the steam-pipes having what are technically called spigott and faucet joints, which, it is alleged, are more apt, by their contraction and expansion, to allow the escape of the steam than the flanched joints. The advantage of the former mode of jointing is, that the steam-tube contracts and expands in parts; and, of course, that this contraction and expansion must be very trifling on every part; whereas, when iron tubes are joined by flanches, they become, in effect, one tube; and the contraction, or expansion, takes place throughout their whole length.

Soil. Good garden earth, enriched with wellrotted hot-bed dung; the soil of the open garden at Earlscourt, is a rich black loam, and seems to suit the Pine Apple as well as virgin carth brought from a distance.

General management. Much the same as that of Mr. Andrews. Mr. Gunter tried to substitute the heat of steam for that of tan, as a bottom heat, but 
did not succeed. He formed a chamber, or vacuity of about six inches in depth, and covered it with perforated oak-plank; on this he placed the earth, in which, in some cases, he turned the plants out of the pots; and, in others, plunged the pots in the earth, or in rotten tan. The steam was admitted to fill the chamber; the quantity of heat imparted to the earth was very great, but, contrary to his expectation, no vapour ascended into the mould, which became excessively dry and husky; nor was he able, by frequent waterings, to keep it in a state fit for vegetation; the roots of the plants in it, in spite of every precaution, become shrivelled and dry.

Insects. None of any consequence have yet appeared at Earlscourt, nor is it likely they will ever become numerous there, while steam is used. Were they to become ever so abundant, keeping the air of the house filled with steam for two or three days together, would effectually destroy them.

Fruit produced. The object of every commercial gardener is to have some fruit ripening in every month of the year, but especially in winter, when the price is high. In summer great numbers are imported, or sent in from the hired-out gardens of country gentlemen, which greatly reduces the market value below the real value, or actual cost of production.

The Pine Apple is extensively cultivated by $\mathrm{Mr}$. Grange, of Kingsland, and Mr. Wilmot, of Isleworth, in nearly the same manner as by $\mathrm{Mr}$. 
Andrews and Mr. Gunter. Those of Mr. Wilmot's are, at present, in the most luxuriant and prosperous state; Mr. Grange's are also in a very respectable condition. In both, the plants are grown and fruited in pits, and larger houses, which resemble those of Earlscourt (fig. 12.) as nearly as possible; in both, also, the heat is communicated by steam.

\section{Sect. XIV.}

Culture of the Pine Apple, by Mr. Isaac Oldacre, gardener to Lady Banks, at Spring-grove, Middlesex.

Mr. Oldacre is an excellent kitchen-gardener, and an ingenious and curious man. He was several years head-gardener at one of the Emperor of Russia's residences near Petersburg, and has the merit of having introduced from that country, the German mode of rearing mushrooms. Having returned to this country about the year 1813, for his health, he some years afterwards became gardener to Sir Joseph Banks, in whose gardens he has cultivated the Pine Apple with moderately good success, and we have introduced this Section on purpose to notice some peculiarities of treatment which he adopts, and some strange opinions which he holds, or lately held.

Form of House. The plants are brought forward in dung, or tan-frames, or hot-beds, and also in flued-pits; but generally fruited in houses 
combining the culture of the Vine and the Pine. Mr. Oldacre has two of these houses, one is built of timber, in the usual way, (fig. 13.) and the other is

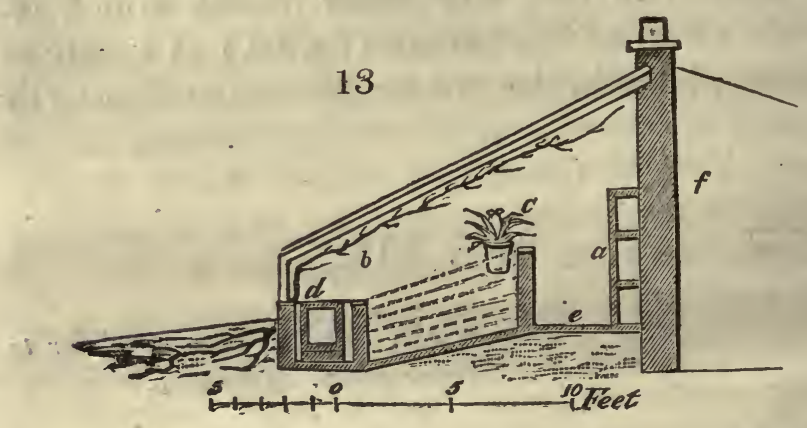

of the same form, but roofed with copper sashes. A full command over the air of these houses is obtained by the returns made by the flue in the back path (a); the curb of the pit is about three feet from the glass in front $(b)$; and about five feet from it behind $(c)$; vines are trained up the rafters, but none are grown in the back path $(e)$, which is paved.

- In addition to the flues, steam is also employed as a medium of communicating heat. But the apparatus was erected chiefly as matter of patriotism, when steam first came in vogue, and is on a very imperfect plan, and of little real use. The boilers are placed over the furnaces, and the same fire which heats the water of the boiler, passes along the flue; the steam tube of the boiler is laid on 
the top of the flue, and extends no farther than it extends. It is evident, therefore, that scarcely any advantage can result from the use of the boiler, unless it be that the heat is thus sent more effectually to the opposite end of the house to that at which the fire enters, or that the vapour is very readily admitted from the steam-pipe to fill the air of the house. None of these advantages, however, will compensate the expense of the apparatus; the first is hardly wanted where houses are placed in a connected range, as the two outside ends of the houses are kept warm by the flues entering there; and in the other houses a warm end is placed against a cold one.

Soil. At first, Mr. Oldacre used good sound loam and dung, with a little sand, when he found it necessary; but he has for the last four years grown his fruiting plants chiefly in powdered bones, in which he thinks they thrive better, and produce more highly-flavoured fruit. We have not, however, been able to discover any thing in the appearance of either fruit or plants, to lead us to suppose that powdered bones are more congenial to the Pine plant than good loam and dung; his plants are certainly not equal to Mr. Baldwin's, nor superior to those grown by Mr. Andrews, or Mr. Aiton. We, therefore, consider their thriving in this compost a proof more of the hardy nature of the Pine, than of any thing else; we have no, doubt it would grow in powdered granite, or K 4 
coal, or almost any powder, not even excepting gunpowder, if a due proportion of well-rotted manure were added, and water, heat, light, and air, duly supplied.

General management. In this, Mr. Oldacre has nothing particular; he is careful not to let the temperature of either frames or pits, containing Pine plants fall under $60^{\circ}$ in winter, but is not afraid of a heat of $90^{\circ}$ or $100^{\circ}$ in summer. After shifting, and occasionally during very hot weather, he shades the plants in the frames and successionpits, well knowing that the want of. abundant and extended roots must lessen that supply of moisture essential to the vigour of plants, during high sunshine, when evaporation is so powerful. His fruiting-plants he keeps in large pots, rather broad than deep, and so liberally supplies them with water, that evaporation and transpiration go on even in the hottest sun-shine, without injuring the plants. He waters often with liquid manure, generally the drainings of dunghills; frequently steams the house by watering the paths and flues when the steam apparatus is not at work; sometimes he waters the plants over the top; and at all times he keeps up a good bottom heat.

-It may be further noticed, that in the hottest weather, from June to September, he permits the temperature of the atmosphere of the house to rise to upwards of 100 degrees during the day, but leaves sufficient number of sashes open during the 
night, to-lower the heat of the air within very nearly to that of the air without. This is perfectly natural treatment, consistent with what takes place in those countries where the Pine Apple is grown in the open air, and consonant with the practice of Mr. Knight.

Insects. These he keeps off by regimen, watering with clear water, and filling the house with steam. In short, Mr. Oldacre's opinions and practices, as far as circumstances have required practice, are in perfect unison with Mr. M'Phail's : and it is not, perhaps, too much to assert, that experience will bring every gardener to the same result.

Fruit produced. Mr. Oldacre considers that the fruit he produces in the copper-roofed house is never so high-flavoured as that grown in the other with a timber roof, though the treatment be in all other respects the same. This certainly appears a very singular circumstance, and not to be accounted for in the present state of human knowledge. The bars of iron, or copper sashes, might possibly (but not probably) make some difference in the electrical state of the air of the house, but this is the utmost degree of variation we can conceive a metallic roof capable of making. If it admits more light, or abstracts more heat, these are effects easily counteracted, if desired, and must have been so, if they existed in any degree, as Mr. Oldacre asserts the culture in both houses was exactly alike. 
On the whole, we must suspend our opinion on this subject; or rather conclude that it is more probable, Mr. Oldacre is mistaken in thinking the culture he gives to the plants in both houses the same, than that the single circumstance of a metallic roof on one of them, should make such difference in its produce. This report, which had been made current at the Horticultural Society, excited the attention of Sir Thomas Baring, who, having an extensive range of metallic hot-houses, at East Stratton Park, his seat in Hampshire, soon afterwards sent a very fine Pine Apple to the Society, to be tasted at one of their meetings. At this meeting we were present, but though we tasted of this Pine Apple, yet not having sufficient opportunity of comparing it with any other, we could not discern any difference. When a great many fruits are tasted in rapid succession, and of each such small portions as hardly to afford its real taste, the impression on the palate is evanescent; or at any rate, it is not, perhaps, too much to say, that under such circumstances, it is difficult to form a solid judgment.

\section{SECT. XV.}

Culture of the Pine Apple, by William Townsend Aiton, Esq. gardener to the King, at Kerw and Kensington.

IT is only within the last four years, that the Pine culture, in the royal gardens, has been above. 
mediocrity; before 1817 , and as far back as we have had an opportunity of observing, they were in a very poor state, those at Kew more particularly. At present, the Pines in both the gardens mentioned, are equal to any within ten miles of London; and, with the exception of the New Providence, Black Antigua, and some other sorts, are not surpassed, even by those of Mr. Baldwin. The culture pursued in the royal gardens, is as simple as it is successful; and as economical as if the fruit were grown for the market by a commercial gardener. The whole does the highest credit to Mr. Aiton, and those whom he employs.

Form of House. The plants are struck, and brought forward in pits, or frames, (fig.14.) con-

\section{4}

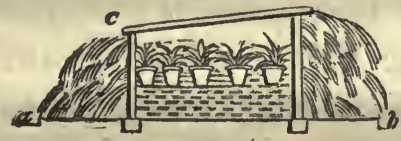

structed exactly in Mr. Baldwin's manner, with this difference, that the sub-soil at Kensington being moist, they are raised on a small platform $(a \ldots b)$ above the surface, instead of being sunk under it, as Baldwin's are. They have, also, the addition of a gutter in front $(c)$, which, though at first sight it may appear trifling, yet, in practice, is of very material consequence, by keeping the lining dry, and not chilling and interrupting the 
heat in the very part where it should penetrate to the interior of the pit.

Occasionally some plants are fruited in these pits, especially at Kew, but, in general, they are removed to a low house (fig. 15.) of a most econo-

\section{5}

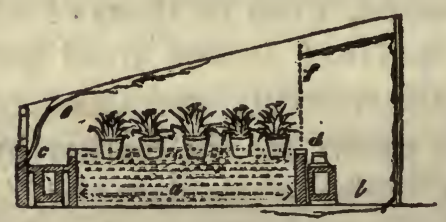

mical and judicious construction, and calculated both for the growth of Pines and Vines. This house is fifteen feet wide within walls ; the pit $(a)$, is nine feet wide; the back path $(b)$,-forms a border for the roots of the Vines; the pit is surrounded by a flue $(c, d)$; the curb, or plate is two feet three inches from the glass in front $(e)$, and four feet eight inches from it behind $(f)$; the Vines are planted in the back border $(b)$, and trained under the roof directly over it and over the back flue; and others are planted in the front border $(g)$; and trained up the rafters.

The length of the houses in the royal gardens at Kensington, varies from thirty-three to fifty feet (fig. 16.): each house has two furnaces, one for constant use, and another for giving an extra sup- 
16

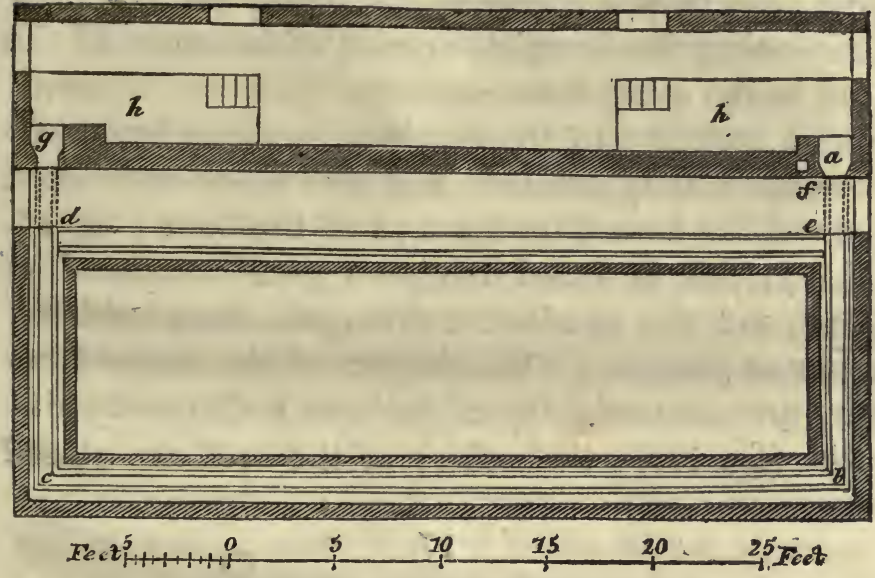

ply of heat in very severe weather. The first $(a)$, proceeds directly to the front corner $(b)$, thence along the front to the opposite end (c), then along the back of the pit $(d, e)$, passing under the back path, or border, and terminating in a chimney $(f)$ beside the furnace.

The other furnace is placed at the opposite end of the house $(g)$; has a short flue under the back path, which conducts it to the back course of the principal flue (at $d$ ), which it joins, and the smoke of the two fires moves in the same tunnel, (from $d$ to $e$ ) and passes out by the same chimney. When this second furnace is not in use, its connection with the flue of the first is cut off by. a damper at the point of junction $(d)$. A very small fire made 
in this furnace in severe weather, not only adds to the heat of the house by its own power, but by increasing the draught, or rate of burning, of the fire in the other furnace.

In addition to the fire heat, a steam apparatus has been lately erected, and the tubes conducted round the houses on the tops of the flues ( fig. 15 . $d, e)$; this is found to give a great command of heat, and also to admit of filling the house with vapour at pleasure. The height of the house from the ground to the top of the back wall, is only nine feet (fig. 17.); the rafters of the 100 are placed

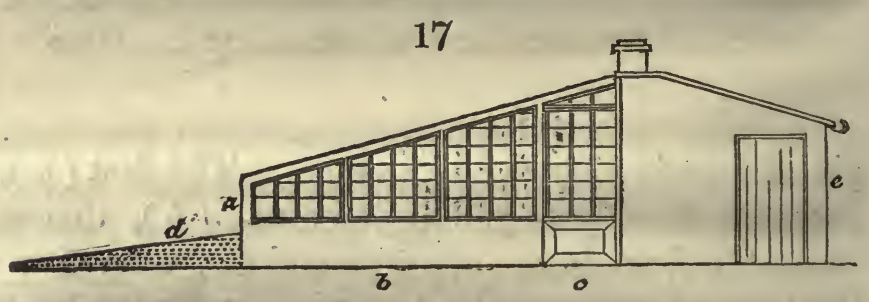

about four feet apart, centre from centre; or about twenty-four sashes are given to every hundred feet; the front sashes $(a)$, are only eighteen inches high, and slide past each other; the middle end sash ( $b$ ), also slides; the sill of the door $(c)$, and the back path, or border, are on a level with the outer surface of the ground, to admit the easy wheeling in of tan, \&c.; the front border $(d)$, is raised considerably above it, on account of the wet bottom; the back sheds are low and neat, and the furnaces sunk three feet below, the surface 
( fig. 16, $h h$ ) to give them a better draught; and this also serves to drain the back border.

The houses are placed in pairs, the furnaces for general use at the extreme ends of the range, and the auxiliary ones in the middle, where the steamboiler is also placed, but worked by a fire apart.

On the whole, no plan of Pine-stove that has yet appeared, is more simple, neat, economical, and complete than this; the only fault we have to them, is, that owing to the great thickness of wood employed on the bars of the sashes, they are rather dark and gloomy within; but this might easily be remedied by the substitution of light iron rafters, with wooden framed sashes sliding in them, but the bars of the sashes formed of iron. It is true, gloomy as these houses are, the Pines thrive in them as well as can be wished, but probably by having more light, they might thrive, so as to surpass all expectation.

Soil. Good yellow loam, with a third of rotten dung, and some road grit to serve as sand. This is well mixed together, and passed through a wide screen, and the pots are well drained with three or four pieces of potsherd.

General management. This differs in little or nothing from that of Mr. Andrews; and only from that of Mr. Baldwin in the crowns and suckers being struck in pots, instead of the bark, as is Mr. Baldwin's practice. Supposing the crowns and suckers potted in September, they are not: disturbed till the following March; such as are very 
forward, are shifted at once into large pots, and will show fruit in the course of that autumn, or within the year, and ripen their fruit in November or December, very desirable periods for the royal table, equally expeditious, as in Mr. Baldwin's mode, and more so than in Cuba or Jamaica. The plants which are in a less forward state are disrooted entirely, put into pots according to their sizes, nursed all the summer in the pits, and moved to the larger houses in autumn, where they show fruit at various periods, during the winter, and in the following season; thus ripening their fruit at different periods, from eighteen months to two and a half years, from the time they were taken from the parent plants. The pots in which these plants are fruited, seldom exceed twelve inches in diameter.

Insects. Various modes of getting rid of these was attempted both at Kew and Kensington; that which was finally successful was steeping for two or three hours in strong. tobacco-water, as recommended by Miller; then washing in pure water two or three times - drying, planting, shading, and applying a brisk bottom heat, a moist atmosphere, and giving a little air. This recovered the plants, and future regimen continued them in the vigorous state of health in which they now are:

Fruit produced. The object, and it is most successfully attained, is to have handsome Pines on the royal table every day in the year; they cannot, of course, be very high-flavoured in the winter 
and spring months; but appearance, in some cases, is every thing - they look well, the golden hue of the Apple, mimic grandeur of the crown, and the presence of such a rare fruit at an uncommon season, accords well with the pomp and splendour of a royal table. As to flavor, indeed, by the time the desert appears on great occasions, the palate is generally seasoned with wine, and a few drops of alchohol are already transferred to the ventricles of the brain ; when that is the case, every fruit has just what flavor it ought to have; for the fine phrensy of a warmed imagination knows no degree of merit but the superlative. 


\section{CHAP. V.}

IMPROVEMENTS RECENTLY ATTEMPTED IN THE CULTURE OF THE PINE APPLE.

The Pine Apple has never been so generally cultivated in this country as it might have been, from an idea that its culture is attended with more difficulty and expense than that of all other fruits; and, also, from the circumstance of the greater number of gardeners being ignorant of its cultivation. With respect to the difficulty of cultivating this fruit, every gardener, who knows any thing about it, knows it is much easier grown and fruited than the cucumber early in spring, or the melon at any period of the year. In short, with the single difference of requiring an artificial temperature, it is as easy, or easier to grow than a common cabbage: - it is not nearly so liable to insects as that plant is in dry seasons; and of two plantations, the one of crowns or suckers of Pines, and the other of seedling cabbages, we may venture to assert, that more of the former will perfect their fruit than those of the latter will perfect their loaf or head.

With respect to the expense of cultivating the Pine Apple, it must be acknowledged that it is greater than that required to cultivate any other 
fruit; from the length of time requisite to bring it to perfection; the keeping up a high temperature during the winter months, and the unremitting attention required throughout the year. Another source of expense, and in some cases of difficulty, has been the procuring of tan, or other materials, to supply a bottom heat; and the last one that may be mentioned is, that gardeners who undertake to cultivate the Pine Apple, generally are paid a higher remuneration than those who confine themselves to the other fruits.

These circumstances have lately induced some amateurs, and also some practical gardeners, to devise means of simplifying the culture of the Pine Apple, and lessening the expenses attending it. The principal amateurs are T. A. Knight, Esq. the President of the Horticultural Society, and Peter Marsland, Esq. of Woodbank, near Stockport; the principal practical gardeners are Mr. Gunter, of Earlscourt, Mr. Hay, a Horticultural architect in Edinburgh, and some others, who have made less extensive trials. 


\section{Sect. I.}

Of the improvements in the culture of the Pine Apple, proposed by T. A. Knight, Esq. F.R.S. P.H.S., of Downton-Castle, Herefordshire.

Mr. Knight's improvements consist chiefly in the disuse of bottom heat, and in the application of a much higher temperature during sunshine at all seasons, but especially in the summer season, and a much lower temperature during winter, and during the night, at all times, than is generally adopted by gardeners.

Mr. Knight had no experience in the culture of the Pine Apple till the year 1819. In that year, he informs us (in a paper published in the third volume of the Horticultural Transactions) that he tried the effect of a very high temperature during the day, in bright weather, and of comparatively low temperature during the night, and in cloudy weather. A fire of sufficient power only to preserve the house in a temperature of about $70^{\circ}$ during summer, was employed; but no air was given, nor its escape facilitated, till the thermometer, perfectly shaded, indicated a temperature of $95^{\circ}$, and then only two of the upper lights, one at each end, were let down about four inches. The heat of the house was, consequently, sometimes raised to $110^{\circ}$, during the iniddle of bright days, and it generally 
varied in such days from $90^{\circ}$ to $105^{\circ}$, declining during the evening to about $80^{\circ}$, and to $70^{\circ}$ in the night. Late in the evening of every bright and hot. day, the plants were copiously sprinkled with water, nearly of the temperature of the external air. The melon, water-melon, Guernsey lily, figtree, nectarine, orange and lemon, mango, Avoado-pear, Mammee-tree, and several other plants, part of them natives of temperate climates, grew. in this hot-house so managed " through the whole summer, without any one of them being etiolated, or any way injured, by the very high temperature to which they were occasionally subjected ; and from. these and other facts," Mr. Knight continues, " which have come within my observation, I think myself justified in inferring, that in almost all cases in which the object of the cultivator is to promote the rapid and vigorous growth of his plants, very high temperature, provided it be accompanied by bright sunshine, may be employed with great advantage; but it is necessary that the glass of his house should be of good quality, and that his plants be placed near it, and be abundantly supplied with sand and water." In the above case liquidmanure was employed.

- It is added, "My house contains a few Pine Apple plants, in the treatment of which I have deviated somewhat widely from the common practice; and I think with the best effects, for their growth has been exceedingly rapid, and a great many gardeners, who have come to see them, have 
unanimously pronounced them more perfect than any which they had previously seen. But many of the gardeners think that my mode of management will not succeed in winter, and that my plants will become unhealthy, if they do not perish in that season; and as some of them have had much experience, and I very little, I wish, at present, to decline saying more relative to the culture of that plant." Hort. Trans. iii. 465.

The above information, the result of $\mathrm{Mr}$. Knight's experiments in 1819, was communicated to the Horticultural Society in the autumn of that year. On the 7 th of March following, a paper was read to the Society on the same plants, of which the following is a transcript:

Of those gardeners who doubted whether the plants would stand the winter, it is stated, "The same gardeners have since frequently visited my hot-house, and they have unanimously pronounced my plants more healthy and vigorous than any they had previously seen : and they are all, I have good reason to believe, zealous converts to my mode of culture.

"I had long been much dissatisfied with the manner in which the Pine Apple plant is usually treated, and very much disposed to believe the barkbed, as Mr. Kent has stated, (Hort.Trans.iii. 288.) ' worse than useless,' subsequent to the emission of roots by the crowns or suckers. I therefore resolved to make a few experiments upon the culture of that plant; but as I had not at that period, 
(the beginning of October,) any hot-house, I deferred obtaining plants till the following spring. My hot-house was not completed till the second week in June (1819,) at which period I began my experiment upon nine plants, which had been but very ill preserved through the preceding winter by the gardener of one of my friends, with very inadequate means, and in a very inhospitable climate. These, at this period, were not larger plants than some which I have subsequently raised from small crowns, (three having been afforded by one fruit,) planted in the middle of August, were in the end of December last; but they are now beginning to blossom, and in the opinion of every gardener who has seen them, promise fruit of great size and perfection. They are all of the variety known by the name of Ripley's Queen Pine.

"Upon the introduction of my plants into the hot-house, the mode of management, which it is the object of the present communication to describe, commenced. They were put into pots of somewhat more than a foot in diameter, in a compost made of thin, green turf; recently taken from a river-side, chopped very small, and pressed closely, whilst wet, into the pots; a circular piece of the same material, of about an inch in thickness, having been inverted, unbroken, to occupy the bottom of each pot. This substance, so applied, I have always found to afford the most efficient means for draining off superfluous water, and subsequently of facilitating the removal of a plant 
from one pot to another, without loss of roots. The surface of the reduced turf was covered with a layer of vegetable mould obtained from decayed leaves, and of sandy-loam, to prevent the growth of the grass-roots. The pots were then placed to stand upon brick-piers, near the glass; and the piers being formed of loose bricks (without mortar), were capable of being reduced as the height of the plants increased. The temperature of the house was generally raised in hot and bright days, chiefly by confined solar heat, from $95^{\circ}$ to $105^{\circ}$, and sometimes to $110^{\circ}$, no air being ever given till the temperature of the house exceeded $95^{\circ}$; and the escape of heated air.was then, only in a slight degree permitted. In the night, the temperature of the house generally sunk to $70^{\circ}$, or somewhat lower. At this period, and through the months of July and August, a sufficient quantity of pigeons' dung was steeped in the water, which was given to the Pine plants, to raise its colour nearly to that of porter, and with this they were usually supplied twice a day in very hot weather; the mould in the pots being kept constantly very damp, or what gardeners would generally call wet. In the evenings, after very hot days, the plants were often sprinkled with clear water, of the temperature of the external air; but this was never repeated till all the remains of the last sprinkling had disappeared from the axillæ of the leaves.

"It is, I believe, almost a general custom with gardeners, to give their Pine plants larger pots in 
autumn, and this mode of practice is approved by Mr. Baldwin. (Cult. of Anan. 16.) I nevertheless cannot avoid thinking it wrong; for the plants, at this period, and subsequently, owing to want of light, can generate a small quantity only of new sap; and consequently, the matter which composes the new roots that the plant will be excited to emit into the fresh mould, must be drawn chiefly from the same reservoir, which is to supply the blossom and fruit: and I have found, that transplanting fruit-trees, in autumn, into larger pots, has rendered their next year's produce of fruit smaller in size, and later in maturity. I therefore would not remove my Pine plants into larger pots, although those in which they grow are considerably too small.

- "As the length of the days diminished, and the plants received less light, their ability to digest food diminished. Less food was in consequence dissolved in the water, which was also given with a more sparing hand; and as winter approached, water only was given, and in small quantities. " "During the months of November and December, the temperature of the house was generally little above $50^{\circ}$, and sometimes as low as $48^{\circ}$, and once so low as $40^{\circ}$. Most gardeners would, I believe, have been alarmed for the safety of their plants at this temperature; but the Pine is a much hardier plant than it is usually supposed to be ; and I exposed one young plant in December to a tem: perature of $32^{\circ}$, by which it did not appear to sus. 
tain any injury. I have also been subsequently informed by one of my friends, Sir Harford Jones, who has had most ample opportunities of observing, that he has frequently seen, in the east, the Pine Apple growing in the open air, where the surface of the ground, early in the mornings, showed unequivocal marks of a slight degree of frost.

" My plants remained nearly torpid, and without growth, during the latter part of November, and in the whole of December; but they began to grow early in January, although the temperature of the house rarely reached $60^{\circ}$; and about the 20th of that month, the blossom, or rather the future fruit, of the earliest plant, became visible; and subsequently to that period their growth has appeared very extraordinary to gardeners who had never seen Pine plants growing, except in a bark-bed or other hot-bed. I believe this rapidity of growth, in rather low temperature, may be traced to the more exciteable state of their roots, owing to their having passed the winter in a very low temperature comparatively with that of a bark-bed. The plants are now supplied with water in moderate quantities, and holding in solution a less quantity of food than was given them in summer.

"In planting suckers, I have, in several instances, left the stems and roots of the old plant remaining attached to them; and these have made a much more rapid progress than others. One strong sucker was thus planted in a large pot 
upon the 20th of July, (1819;) and that is (March 1820) beginning to show fruit. Its stem is thick enough to produce a very large fruit; but its leaves are short, though broad and numerous; and the gardeners who have seen it, all appear wholly at a loss to conjecture what will be the. value of its produce. In other cases, in which I retained the old stems and roots, I selected small and late suckers, and these have afforded me the most perfect plants I have ever seen; and they do not exhibit any symptoms of disposition to fruit prematurely. I am, however, still ignorant whether any advantage will be ultimately obtained by this mode of treating the Queen Pine; but I believe it will be found applicable with much advantage in the culture of those varieties of the Pine, which do not usually bear fruit till the plants are three or four years old.

"I shall now offer a few remarks upon the facility of managing Pines in the manner recommended, and upon the necessary amount of the expense. My gardener is an extremely simple labourer, he does not know a letter or a figure; and he never saw a Pine plant growing, till he saw those of which he has the care. If I were absent, he would not know at what period of maturity to cut the fruit; but in every other respect he knows how to manage the plants as well as I do ; and I could teach any other moderately intelligent and attentive labourer, in one month, to manage them just as well as he can : in short, I do not think the skill necessary to raise a Pine Apple, according to the mode 
of culture I recommend, is as great as that requisite to raise a forced crop of potatoes. The expense of fuel for my hot-house, which is forty feet long, by twelve wide, is rather less than sevenpence. a-day here, where I am twelve miles distant from coalpits : and if I possessed the advantages of a curved iron-roof, such as those erected by Mr. Loudon, at Bayswater, which would prevent the too rapid escape of heated-air in cold weather, I entertain no doubt, that the expense of heating a house fortyfive feet long, and ten wide, and capable of holding eighty fruiting Pine plants, exclusive of grapes or other fruits upon the back wall, would not exceed fourpence a day. A roof of properly carved iron bars, appears to me also to present many other advantages : it may be erected at much less cost, it is much more durable, it requires much less expense to paint it, and it admits greatly more light." Hort. Trans. iv. 72.

Mr. Knight adds, "I have not yet been troubled with insects upon my Pine plants (having only had nine plants for about as many months), and have not, of course, tried any of the published receipts for destroying them. Mr. Baldwin recom: mends the steam of hot fermenting horse-dung: I conclude the destructive agent, in this case, is aimmoniacal gas; which Sir Humphry Davy informed me he had found to be instantly fatal to every species of insect; and if so, this might be obtained at a small expense, by pouring a solution of crude muriate of ammonia upon quick-lime; the 
stable, or cow-house, would afford an equally efficient, though less delicate, fluid. 'The ammoniacal gas might, I conceive, be impelled, by means of a pair of bellows, amongst the leaves of the infected plants, in sufficient quantity to destroy animal, without injuring vegetable life : and it is a very interesting question to the gardener, whether his hardy enemy, the red spider, will bear it with impunity."

In the year 1820, in June, Mr. Knight had such a house as he has hinted at, erected. Its general appearance (fig. 18.), is simple, and the roof ad-

18

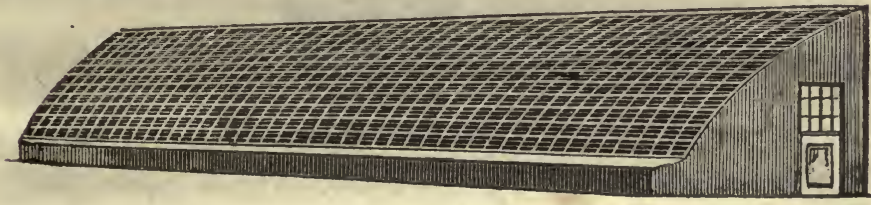

mits as much light, as any roof that can be constructed in the present state of knowledge, in the combination of wrought iron and common glass.

The plan of this house, or pit (fig. 19.), is fifty

19

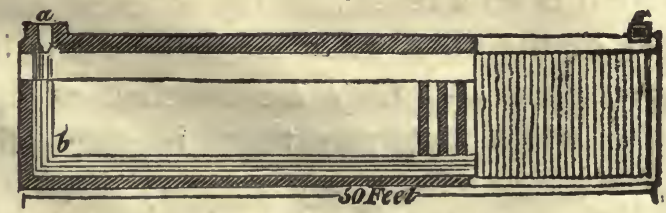

feet in length, and ten feet wide; the furnace $(a)$ 
is placed at one end; the flue proceeds from it directly to the firont parapet $(b)$, and passing along close under it to the opposite end, there terminates in a chimney $(c)$. Instead of a pit, a curious stage is constructed, by forming cross walls $(d)$, or rather piers, connected by arches, and finished by a gradation of flat surfaces, or steps, on which the pots are placed, so as to stand as near the glass as possible (fig. 20.)

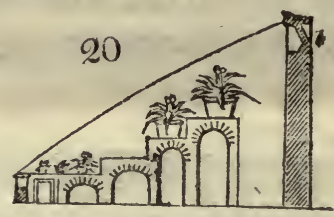

Air is admitted by shutters, which open outwards, immediately under the stone plinth of the parapet (fig.20. a), in which the lower ends of the iron bars are fixed; and allowed to escape by similar shutters, opening outwards, immediately under the stone coping of the back wall (b), in which the upper ends of the same bars are leaded in. The path behind is on a level with the exterior surface; the width of the cross walls the length of a brick, or nine inches, and they are finished with foot tyles; the width between them is about fifteen inches, by which means, any ordinary sized person may pass from the back path to the front flue, and water or examine the plants on each side. 
This house being finished, was immediately stocked with Pines, some figs, and various other plants, all of which, Mr. Knight stated verbally, in May 1821, to various members of the Horticultural Society, succeeded admirably; but by neglect of the gardener, or rather labourer, who attended them, they were killed by an over-heat in Mr. Knight's absence from home. *

The house was again stocked with plants, which Mr. Knight, in a paper read to the Horticultural Society, in November last (1821), stated to be in a most thriving condition; and a friend of ours who had made an extensive gardening tour in the North and West of England, and who saw the Pine plants at Downton Castle, also in November, declares they appeared the most magnificent he had seen on his journey ; " the plants," he says, "were stocky, and the leaves long, broad, and green; the largest were in pots fourteen inches in diameter, and their leaves reached to the glass."

In the paper alluded to, Mr. Knight goes on to say, "I possess more than sufficient evidence to enable me to assert with confidence, that, in the culture of the Pine Apple, the bark bed, or other hot-bed, if the plants be plunged intoit, is worse

*'The poor man had probably overheated himself, and comparing by his feelings the temperature of the Pinery with his own, found the latter much in its usual state; not knowing " a letter or a figure," of course, he could not take a hint from the thermometer. 
than useless, after the scions, or crowns, have emitted roots; and that the Pine Apple, when treated in the manner I have recommended, is a fruit of most extremely easy culture.

"It is contended, in favour of the bark-bed, that the soil in inter-tropical climates is warm, and that the bark-bed does no more than nature does in the native climate of the Pine Apple. And if the bark-bed could be made to give a steady temperature of about ten degrees below that of the day temperature of the air in the stove, I readily admit that Pine plants would thrive better in a compost of that temperature, than in a colder. But the temperature of the bark-bed is constantly subject to excess, and defect, and I contend, and can prove, that the above-mentioned temperature is very nearly given in my stove. For the temperature of the day being about $90^{\circ}$ or $95^{\circ}$, and that of the night $70^{\circ}$, the mould in the pots will necessarily acquire nearly the intermediate temperature of $80^{\circ}$. It is true, that two disturbing causes are in action; the evaporation from the mould, and porous surface of the pots, and the radiant heat of the sun. But these causes operate in opposition to each other, and probably nearly negative the operation of each other, as far as respects the temperature of the mould in the pots.

' "A very great number of gardeners have within the last twelve. months visited my garden. Some of these were at once convinced of the advantages of the mode of culture which they saw; others 
have paid a second, or third visit; but every one has ultimately declared himself a zealous convert. I have never yet seen plants of the same age equally strong, nor any producing fruit better, nor indeed so well swelled; nor any equal in richness and flavour. But I have never taken off, nor shortened. a root, nor taken any other measures to retard the period of fructification, with the prospect of obtaining larger fruit; and my plants have almost always showed fruit when fourteen or fifteen months old, though propagated from small and young suckers, or crowns. A great part of my Queen Pines (I have hitherto scarcely ever cultivated any other varieties) have, however, at that age, shown fruit with eight, and some with nine rows of pips ; and I often see fruit of less weight growing upon plants of nearly double that age. Whether I shall be able to retard the period of fructification, or not, I have yet to learn; but I believe, I shall succeed by crowding my plants close together, so that each may receive less light.

“ Pine plants will, however, grow perfectly well in composts of different kinds; but I have found that they have succeeded best when the materials have been fresh, and retaining their organic form, particularly if the pots be large, relatively to the size of the plants, which, I think, they always ought to be, for the mode of culture recommended. I have used, with advantage, the haulm of beans cut into lengths of about an inch.

"Very contrary to the conclusions which I should 
have been led to draw from writings upon the culture of the Pine Apple, I have constantly found that my plants succeed best in the part of my house where the flue first enters; and where the temperature is very high, varying from about $85^{\circ}$ to $105^{\circ}$, and the air excessively dry. I have pointed out this circumstance to every gardener, whom I have seen in my house, and all have expressed their astonishment at the circumstance. I expected that this excess of heat would have occasioned the plants to show fruit prematurely, but this has not occurred in a single instance. What would be the quality of the fruit, if it were to be ripened in so high a temperature, I have not yet had an oppor. tunity of knowing.

"In raising young plants, I have deviated from the ordinary mode of practice by breaking off the suckers when very young; that is, when they are not more than four or five inches long. The fruit is much benefited by their absence; and the cuttings, if placed very close together in a hot-bed, are made to emit roots with little trouble, and afford better plants than they do when they are suffered to remain long upon the parent stem. When the whole are removed at an early period, one or more very strong suckers usually spring outbelow the level of the soil ; and from these, suffering only one to remain attached to the parent stem, and preserving the roots as entire as possible, I have propagated with much advantage, and have obtained plants which showed fruit strongly at seven months, dating from 
the period at which the sucker appeared, like a strong head of asparagus, at the surface of the soil.

"The success of my experiments, in the first house which I erected, (and to which the foregoing account exclusively refers,) led me to erect another house (figs. 18. 19. and 20.) in the summer of 1829 . In this I attempted to obtain the greatest possible influence of light, and command of solar heat; inferring, from having observed Pine Apples to ripen tolerably well with very little light, that I should be able to ripen them in perfection late in the autumn, and early in the spring, particularly at the latter period, in which, alone, I set a very high value upon the species of fruit. The height of the back wall (fig. 20.) of this house is eight feet six inches, and that of the front wall is one foot six inches, and its breadth ten feet, inside measure, with an iron curviliar roof, (fig. 18.) of the kind of bar invented by Mr. Loudon, of Bayswater. This house is fifty feet long, (fig. 19.) and capable of containing two hundred fruiting Pine plants. The curvature of the roof rises just one foot in twelve. The glass is laid in a composition of two parts white lead, with oil, and three of flint sand, and the overlaps of the glass are closely filled with the same material. It is, consequently, very nearly air-tight; and no means are given for the air to enter, or escape, except by apertures immediately under the copings of 
the front and back wall, ( $a$ and $b$, fig. 20.) which can be efficiently closed at any time. It is, consequently, an instrument of very great power, and requiring, of course, much attention to ventilation : of which I had rather a lamentable proof in the last spring, when my plants were all burned, and spoiled in a few hours; the person who had the care of them having left them in a bright day closely shut up. The fault was: not, however, in any degree in the house; for the plants were, previously, much the strongest, and the best I ever saw; and I believe, they would have afforded most beautiful fruit. I furnished the house again with plants as expeditiously as I could, chiefly in July; and I have since kept the temperature of it nearly between $70^{\circ}$ and $95^{\circ}$, with a wish to make the plants show fruit and blossom in the present month (October.) In this, I have in part succeeded, though many of my plants have flowered a fortnight or three weeks sooner than I wished. The fruit is swelling well, and, I believe, will receive sufficient light through the winter to enable it to ripen in much perfection. The excellence of a few Pine Apples, which ripened in this house in the last winter, leads me almost to doubt, whether the fruit in it will not ripen better, early in the spring, than in the middle of the summer, for I have observed that this species of plant, though extremely patient of high temperature, is not, by any means, so patient of the action of very continued bright light, as many other plants : and much less 
so than the Fig and Orange tree : possibly, having been formed by nature for inter-tropical climates, its powers of life may become fatigued, and exhausted by the length of a bright English summer's day in high temperature. Being a plant of low stature, nature has also probably given it the power to ripen its fruit and seed, in the shade of other plants, in its native climate; and I discovered in the last summer, that it possesses the power to ripen its fruit perfectly in a lower temperature than I previously thought it capable of growing in.

"In the month of June, I gave a couple of Pine plants, which had shown fruit at six months old, and were of small size, and no value, to a child of one of my friends, to be placed in a conservatory, in which no fires were kept during the summer. In July, a storm of hail destroyed nearly, or fully, half the glass of the conservatory; and its temperature, through the summer and autumn, had been so low, that the Chasselas grapes in it were not ripe in the second week in September. In the second week of the present month (October) one of the Pine Apples became ripe, having previously swollen to a most extraordinary size, comparatively with the size of the plant; and upon measuring accurately the comparative width of the fruit, and of the stem, I found the width of the fruit to exceed that of the stem in the proportion of seven and three-quarters to one. The fruit had, of course, been propped during all the latter part of the summer, the stem M 3 
being wholly incapable of supporting it. The taste and flavour of this fruit were excellent, and the appearance of the other, which is not yet ripe, and is of a larger size, is still more promising. I purpose to profit by this result in the next summer; and I hope to be able to communicate some further information to the Society in the autumn. I feel perfectly confident, that if the roots of these plants had grown in a hot-bed of any kind, their sap would have been impelled into other channels; and that their fruit would not have attained, in any degree, the state of perfection which I have described."

This is the latest printed account of Mr. Knight's experiments on the Pine Apple. It would be premature to draw any general conclusions in so early a stage of their progress, and might excite prejudice to anticipate the final result. That the Pine plant will grow and thrive without what is technically called bottom heat, is an obvious truth, since no plant in a state of nature is found growing in soil warmer than that of the superincumbent atmosphere. But to imitate nature, is not always the best mode of culture; for the more correct the imitation, the less valuable would be the greater part of her products, at least as far as horticulture is concerned. What would our celery, cabbage, and apples be, if their culture were copied from nature? Though the Pine Apple will grow well without bottom heat, it may grow with bottom 
Theat still better; and though the heat of the earth, in its native country, may never exceed that of the surrounding atmosphere, it does not.follow that earth heated to a greater degree may not be of service to it, in a state of artificial culture. But admitting, for the sake of argument, that the Pine plant could be grown equally well with, as without bottom heat; still it appears to us that the mass of material which furnishes this heat, will always be a most desirable thing to have in a Pine stove, as being a perpetual fund of heat for supplying the atmosphere of the house, in case of accident to the flues or steam apparatus. Besides it appears from nature, as well as from observing what takes place in culture, that the want of a steady temperature and degree of moisture at the roots of plants is more immediately and powerfully injurious to them than atmospheric changes. Earth, especially if rendered porous and spungelike by culture, receives and gives out air and heat slowly; and while the temperature of the air of a country, or a hot-house, may vary twenty or thirty degrees in the course of twenty-four hours, the soil at the depth of two inches would hardly be found to have varied one degree. With respect to moisture, every cultivator knows, that in a pro. perly constituted and regularly pulverized soil, whatever quantity of rain may fall on the surface, the soil is never saturated with water, nor, in times of great drought, burnt up with heat. The porous texture of the soil and sub-soil being at once favour- 
able for the escape of superfluous water, and adverse to its evaporation, by never becoming so much heated on the surface, or conducting the heat so far downwards as a close compact soil.

These properties of the soil relatively to plants can never be completely attained by growing plants in pots, and least of all by growing them in pots surrounded by air. In this state, whatever may be the care of the gardener, a continual succession of changes of temperature will take place in the outside of the pot, and the compact material of which it is composed being a much more rapid conductor of heat than porous earth, it will soon be communicated to the web of roots within.

With respect to water, a plant in a pot surrounded by air is equally liable to injury. If the soil be properly constituted, and the pot properly drained, the water passes through the mass as soon as poured on it, and the soil at that moment may-be said to be left in a state favourable for vegetation. But as the evaporation from the surface and sides of the pot, and the transpiration of the plant goes on, it becomes gradually less and less so, and if not soon re-supplied, would become dry and shrivelled, and either die from that cause, or be materially injured by the sudden and copious application of water.

Thus, the roots of a plant in a pot surrounded by air, are liable to be alternately chilled and scorched by cold or heat, and deluged or dried up by superabundance or deficiency of water, and no- 
thing but the perpetual care and attention of the gardener to lessen the tendencies to these extremes could at all preserve the plant from destruction.

To lessen the attention of the gardener, therefore, to render the plant less dependent on his services, and, above all, to put a plant in a pot as far as possible on a footing with a plant in the unconfined soil, plunging the pot in a mass of earth, sand, dung, tan, or any such material, appears to us a most judicious part of culture, and one that never can be relinquished in fruit-bearing plants with impunity. Even if no heat were to be afforded by the mass in which the pots were plunged, still the preservation of a steady temperature which would always equal the average temperature of the air of the house, and the retention, by the same means, of a steady degree of moisture, would, in our opinion, be a sufficient argument for plunging pots of vigorous growing, many-leaved, or fruit-bearing plants.

Such are the observations that we think may be made relatively to $\mathrm{Mr}$. Knight's plan, without prejudice to whatever new lights he may throw out on the subject. Had it been brought forward by a less eminent horticulturist, it would not have claimed so much attention, as the plan of growing Pines without bottom-heat is generally considered to have been tried first by M. Le Cour, and subsequently by various others, and abandoned. In Mr. Knight's hands, however, whether it fail or succeed, it is certain of doing good, by the obser- 
170 IMPROVEMENTS IN THE CULTURE OF

vations it will elicit from the fertile and ingenious mind of so candid and philosophical a horticulturist.

Sir William Edward Rous Boughton has erected a house or pit at Downton Hall, similar to that of Mr. Knight, but rather wider.* Pines are grown in it on Mr. Knight's plan, but the plants were not in a thriving state in November last. Charles Holford, Esq. of Hampstead, is also a disciple of Mr. Knight as to the culture of this fruit, but he has not yet been very successful.

\section{Sect. II.}

Of other Improvements in the Culture of the Pine Apple, by different persons.

WE shall first notice the improvements which respect bottom-heat, and begin with noticing an attempt made by Mr. Thomas Jenkins, of the Portman Nursery, London, to warm both the pots in which the plants are grown, and the air of the house, by the heat generated by fermenting stabledung placed in a vault beneath.

It is only within the last three years that Mr. Jenkins has begun to grow the Pine Apple to any

* The roofs, both of this house and that of Mr. Knight, were furnished by Messrs. W. \& D. Bailey, of Holborn, London. 
extent; he brings forward the plants in hot-beds and deep frames, inclosing beds of tan, and heated by linings of dung. As an economical part of the construction, we may mention that he substitutes wattled hurdles for the lower part of the frame, in contact with the tan, by which means a saving in the first cost is effected, and the heat of the dung penetrates much more readily to the tan.

Most of the plants are fruited in these pits, but some are fruited in a house, ( $f i g .21$.) which

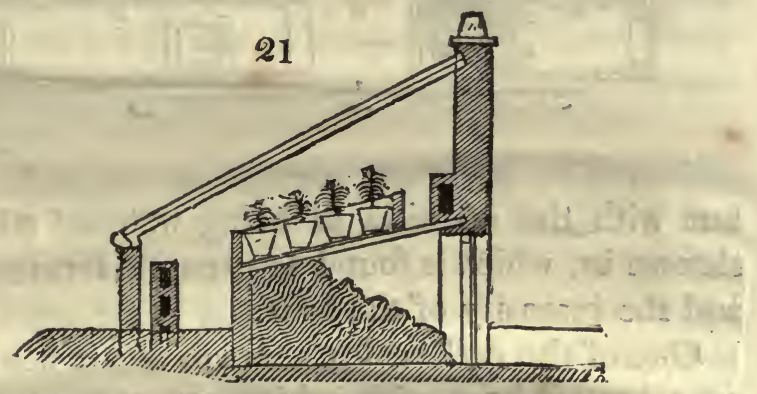

" though furnished with flues, yet these have been very little used. The heat imparted to the plants is produced by the fermentation of stable-dung in a pit below the plants, the top of which is covered by tiles supported by iron rafters, with the joints closely cemented, to prevent the passage of steam into the house. The pots are neither bedded in tan, nor in mould, but stand on the tiles, and the interstices between them warm the air of the house." 
172 IMPROVEMENTS IN THE CULTURE OF

The dung is managed as in West's pit ( $f g$. 22.),

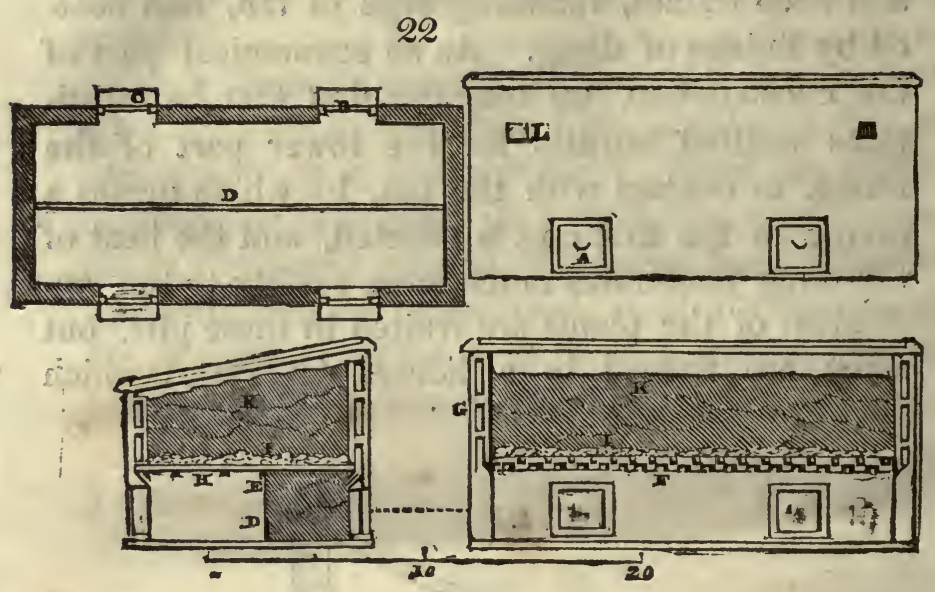

but with the addition of being watered after it is thrown in, which is found to promote fermentation, and the intensity of the heat.

One of the earliest instances of steam being used as a bottom-heat with which we are acquainted, was that by Mr. Butler, gardener to the Earl of Derby, at Knowlesly, near Liverpool, in or about 1792. It had been used twenty years before, but chiefly for other purposes. Speechly, in 1796, knew only two instances in which steam was applied as bottom-heat; and, with M'Phail, does not think it will finally answer as a substitute for tan. Instances in which it is adopted, are now much more numerous ; but time sufficient has not elapsed, 
and the opinions of gardeners are yet too unsettled on its merits to enable us to recommend it for adoption in general practice. For heating the atmosphere of hot-houses, there seems little (or at least much less) doubt of its being preferable to fire-heat.

Count Zubow, at St. Petersburg, employed steam to heat a pit or cistern of water, over which, at about three inches distance, a frame, covered with faggots, was placed, and on this was laid the earth, in which his Pines and other exoties were planted without being in pots. The plan is said to have succeeded, and a wholesome temperature to have been obtained and communicated to the mould above the faggots.

Mr. Gunter, as before observed, (Chap. IV. sect. 13.) had already tried the use of steam as a bottom heat without success.

Mr. John Hay, horticultural architect, tried the use of steam so early as 1794, when gardener at Preston Hall, near Edinburgh, and he gives the following account of his apparatus and success in the Memoirs of the Caledonian Horticultural Society. "The application of steam to forcinghouses early caught my attention. The first that I designed and executed in Scotland on this plan, were at Preston Hall in Mid-Lothian, in the year 1794. The fruiting Pine-stove, which is in the general suite of houses, with two peach-houses on the west, were originally adapted to steam. I en- 
174. IMPROVEMENTS IN THE CULTURE OF

tertained the hope, that steam thrown into a chamber, in the bottom of the plant pit, would act as a proper substitute for bottom heat in place of tan, as none of that substance was to be found nearer than four miles distant, and when wanted was often difficult to be procured. Other more general considerations also made me desirous of procuring some substitute, particularly the necessity of repeatedly shifting the plants to renew the heat, when the bark in the plant-pit gets cold: these shiftings, besides the trouble, often retard, the growth of the plants. Again, if the heat of the fermentation of the tan rise much above ninety-six degrees, (which it often does), and if the pots be fully plunged in the tan at such a time, many instances have been known of the roots of the plants being burned, and some of them being destroyed altogether. This, indeed, may be considered as one of the principal reasons why so many are unsuccessful in the culture of this fine fruit. With the view of obviating the above difficulties, the bottom of the fruiting Pine-pit was constructed with a chamber below, into which steam was introduced by means of copper and lead pipes from a boiler placed in the shades behind : the top of the chamber was constructed of rafters, on which were placed broad grey slates, laid on loose, without filling up the vacancies between them. The not making them close, I afterwards found to be an error; for the moisture, from the condensation of 
the steam, penetrating through the openings at the joining of the slates, communicated too much wetness to the bottom of the pots; but I found, that there was a sufficient quantity of heat to be obtained from the steam for heating the plant-pit, provided the bottom were close. I therefore discontinued this plan; and I had not an opportunity of making any farther experiment on the subject in this place. From the same boiler, I conducted into the two peach-houses adjoining, a range of pipes furnished with steam-cocks. They passed the whole length of the houses, (101 f. 6 in.). By. means of these, the peach-houses were regularly steamed near one hour a-day in the evening, in the time of flowering and of fruit-setting. Steaming; it may be remarked, is very important at these times. In after periods, when I had not an apparatus for the purpose, I always steamed the peach-house with a large piece of cast-iron, made red hot in one of the furnaces, and put into a white-iron pail nearly full of water; the whole water thus evaporating into steam. I was always successful, while in practice as a gardener, in raising a full crop of peaches; and think that much was owing to attention to steaming.

" I afterwards erected Pine-stoves for John Hervey, Esq. of Castlesemple, to be heated by steam; and one of the plant-pits had a chamber below, with a close bottom, into which chamber, steam was thrown by means of cast-iron pipes. About 
the same time, I was applied to by Sir Hew Hamilton Dalrymple, Bart. (through Mr. James Dodds, his gardener), to examine his Pine-stoves at Bargany, and to report whether I thought they could be improved, as he hitherto had not been so successful in Pine-Apples as he expected. One principal cause was, the difficulty of obtaining tan. Upon my report, it was to be determined, whether to give up the Pine-Apple culture altogether; or endeavour to improve the stoves.

" "Upon examining, I advised the heating of the atmosphere of the houses with steam; and in place of using tan, the heating of the bottom of the plantpit with steam also." This advice was adopted, and eighteen months after the plan was executed, the gardener, Mr. James Dodds, gives the followaccount of his success.

" "It is now eighteen months since I first began to heat the Pine-stoves here with steam. I have thus been enabled to give it a fair trial, and I am fully satisfied that it is superior to the old method of heating by fire-flues. 'I have found the plants to grow more luxuriantly, and perfectly clean of any kind of insects. The moist heat arising from steam is well known to be hostile to all kinds of vermin. It is, besides, more economical : our Pinestoves here are seventy feet long, it formerly took two fires to keep up the heat of the atmospheric air of the house, whereas in the new method of heating by steam, one fire to heat the boiler is suf- 
ficient, except in very cold nights, when I have found it necessary to light a very small fire to the flue, to meet the decline of the steam in the morning, and this only, to the fruiting-house in the spring months, when the Pines begin to show their fruit. In short, I have found no difficulty in keeping up the heat of the house to sixty degrees, by making up the fire to the boiler at ten o'clock at night, and at six o'clock in the morning.

"With regard to the bottom heat for the Pineplants, by steam from the same boiler, I find, by allowing the steam to remain in the chamber below the plants about two hours a day, the pit is kept constantly at the temperature of from ninety to ninety-five degrees, which I have found to be as high as the roots of the plants are able to bear. I would, therefore, say ninety degrees to be the standard height, which I have myself adopted, allowing it to fluctuate down. If our succession Pine-pit had been altered to have been heated by steam, as the fruiting one is, which the boiler is perfectly able to do, the saving in tan alone would more than pay the interest of all the money laid out on erecting the whole steam apparatus.

"The above is my candid opinion on the subject, as far as my practice has enabled me to speak. I am, \&c.

\section{"JAMES Dodds."}

The best stoves for combining the culture of the Pine and Vine in Scotland, have been constructed. 
by Mr. Hay, of which fine examples occur at Lord Duncan's, Lundie-house, near Dundee, and the Earl of Roseberry's, at Dulmeny-park ( $f i g .23$.$) ,$ near Edinburgh.

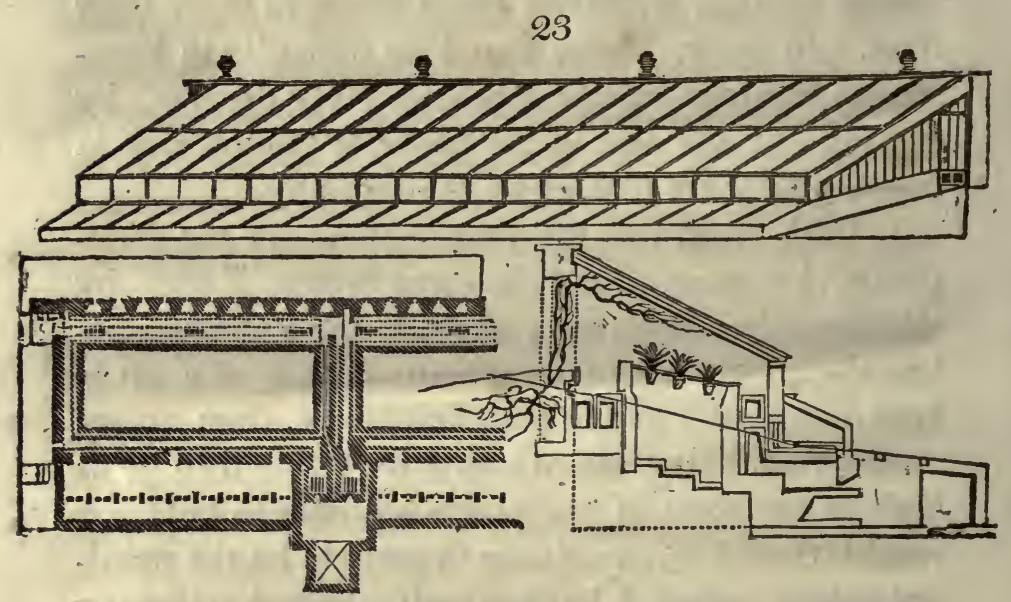

As substitutes for tan, leaves are the common resource, but any vegetable matter of slow putrefaction may be employed, as chopped spray of hedges or copse, wood-shavings, saw-dust, \&c. and in Scotland, it has been found that flax-dressers' refuse keeps up a moderate heat for a longer period than any other material.

The mode of employing the vigour remaining in the old stock or plant after the fruit is cut, to nourish, for a certain time, the sucker or suckers which may be growing on it, was practised by Speechly; but scarcely to the extent which it has been carried lately. This, we think, a considerable 
improvement, if kept within certain limits ; but, if carried too far, what might be gained by the sucker coming earlier into fruit, would be lost by the retardation of the plant's own suckers.

On Nov. 3. 1818. "A Queen Pine, grown by Peter Marsland, Esq. of Woodbank, near Stockport, was exhibited to the Horticultural Society. It weighed three pounds fourteen ounces, measured seventeen inches in circumference, and was peculiarly well-flavoured. The singularity of this Pine was its being the produce of a sucker which had been removed from the parent-root only six months previous to the time the fruit was cut. The plant on which the sucker grew had produced a fruit, which was cut in October, 1817; the old stem, with the sucker attached, was allowed to remain in the Pine-pit till May, 1818; at that time the sucker was broken off, potted, and plunged into a fresh pit; it soon after showed fruit, which, in the course of four months, attained to the weight and size above stated. Mr. Marsland is in the practice of producing Pines in this way with equal success and expedition. His houses are all heated by steam." Hort. Trans. iv. 52.

On the 17th of Oct. 1819, specimens of the New Providence, globe, black Antigua, and Enville, were exhibited, all which were produced in a similar manner to the above. P. Marsland considers, that " though not of the largest description, yet as far as beauty of form and richness of flavour are concerned, they would not yield to fruit of 
more protracted growth." The success which has attended this gentleman's mode of " treating the Pine, so as to insure the production of fruit within twelve months from the cutting of their previous produce, has been perfectly satisfactory ;" and the following is his account of it. "In November, 1819, as soon as the fruit had been cut from the Pine plants, which were then two years old, all the leaves were stripped off the old stocks, nothing being left but a single sucker on each, and that the strongest on the plant; they were then placed in a house where the heat was about sixty degrees, and they remained till March, 1820. At this period the suckers were broken off from the old stocks, and planted in pots from eight to twelve inches in diameter, varying according to the size of the sucker. It may be proper, however, to observe, that the length of time which the young sucker is allowed to remain attached to the mother plant, depends in some degree upon the kind of Pine; the tardy fruiters, such as the black Antigua, and others, require to be left longer than the Queen, and those which fruit readily.

"After the suckers had been planted, they were removed from the house, where they had remained while on the old stock, to one in which the temperature was raised to seventy-five degrees. Immediately upon their striking root, the largest of the suckers showed fruit, which swelled well, and ripened between August and November, being, on the average, ten months from the time the fruit 
was cut from the old plant, and seven months from the time the sucker was planted. The fruit so produced, though, as may be expected, not of the largest description, I have invariably found to be richer and higher flavoured than that grown on older plants. The suckers of inferior strength will not show fruit in the same season, but in the following they will yield good fruit, and strong suckers for a succeeding year's supply. Those suckers are to be preferred which are produced on plants that have ripened their fruit in November, for those taken from plants whose fruit is cut in August, or earlier, are apt to show fruit in January or February, while yet remaining on the mother-plant. But whenever this happens, the sucker should be broken off immediately upon being perceived, and planted in a pot so as to form a root of its own, to maintain its fruit." Hort. Trans. iv. 392.

This experiment shows what can be done; though it must be obvious that a considerable part of the saving in time is lost by the small size of the fruit. Mr. Baldwin, in our opinion, has hit on the proper use of this mode, the principle of which, as already observed, consists in the employment of the -otherwise lost vigour of the old stock. He contrives to produce tolerably sized fiuit, and to have such a degree of vigour in his suckers, as that they are able, in their turn, to throw out other vigorous suckers to succeed them. In aid of this, he often earths up the old stock, so as to cover the lower end of the sucker; and partially wrenching it off, he, by these means, obtains for it 
a good stock of roots before he renders it an independent plant.

Where heat is to be supplied from fermenting horsedung, we should recommend for trial a pit invented by J. West, of Castle Ashby, in Northamptonshire. ( $f g .22$.$) Nine years' experience enable its in-$ ventor to recommend it for neatness of appearance, the power of regulating the heat to the greatest nicety, and for forcing asparagus, strawberries, and the most delicate kinds of cucumbers. By raising the walls of the pit higher above the earth, it is evident it would answer equally well for growing Pines, or forcing shrubs or tall growing plants.

The dung is placed in a chamber (E) three feet and a half deep, being about eighteen inches below the surface-line; the walls (G) which surround it are nine-inch brick-work; both on the front and at the back of the chamber are two openings (A), about to feet six inches square each, with moveable doors, through which the dung is introduced; the doors fit at bottom into grooves (в), and are fastened by a wooden pin and staple at top. In front of the doors, is a small area (c) sunk in the ground, surrounded by a curb of wood, by which the introduction or removal of the dung is facilitated. Along the centre of the chamber is a bar (D), which serves as a guide for packing the dung ; and across the top, at intervals of twelve inches, are placed, on their edges, cast-iron bars (H), two inches wide, and three quarters of an inch thick, to support a layer of small wood, bushes and leaves (I), over which is laid the soil for the plants (K). 
Just below the level of the bars all round the dungchamber, are holes ( $F$ ), passing in a sloping direction through part of the wall into a cavity (G) in the upper part of the wall at the back front and both ends of the pit. In the exterior part of the back wall, are holes with plugs (L), to let out the steam and heat at discretion.

At the commencement of forcing, half the chamber is filled longitudinally with dung, and if the doors are kept shut, this will afford sufficient heat from twelve to eighteen days. As the. heat declines the other half of the chamber is filled, and the temperature is kept up by additions to the top of the dung, on either or both sides, as it settles. When the united heat of the two sides ceases to be sufficient, the side first filled must be cleared out, and mixed with fresh dung and replaced, and so on, adding and turning as circumstances require. Hort. Trans, iv. 220.

As an improvement on the construction of this pit, we would suggest the perforation of the whole of the side walls ( $f g .24 . a$ ), in order to admit the

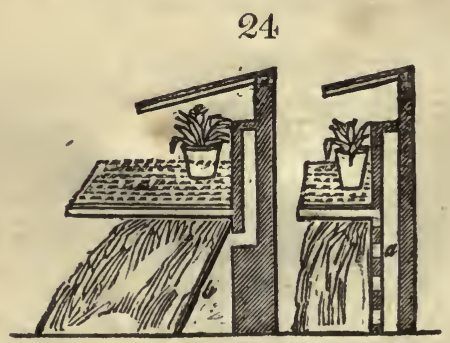

steam more readily than it can find admittance by the single range of openings adopted by Mr. West. 
184. IMPROVEMENTS IN THE CULTURE, \&C.

Where pits on Mr. West's plan are already built, a substitute for this perforation in the side walls may be found in the application of a wattled hurdle against them ( $f g .24 . b$ ), as has been adopted by Mr. J. B. Mackay, in the Comte de Vande's garden at Bayswater.

Remarks. - All the schemes of improvement detailed in this section, are either of a nature never to become general, if they do succeed, as that of Count Zuboff; or not yet sufficiently proved by experience to be recommended for adoption, as the application of steam as a bottom heat by Mr. Hay. We therefore leave them to work their way with the public; and, in the mean time, till these, as well as Mr. Knight's experiments have established something better, we recommend all those who wish to grow the Pine Apple in the first style of excellence, and at a moderate expence, to adopt the pits and houses of Mr. Baldwin or Mr. Aiton; and to imitate their practice, or that of $\mathrm{Mr}$. Andrews.

\section{THE END.}


RETURN TO the circulation desk of any University of California Library or to the

NORTHERN REGIONAL LIBRARY FACILITY Bldg. 400, Richmond Field Station University of California Richmond, CA 94804-4698

ALL BOOKS MAY BE RECALLED AFTER 7 DAYS 2-month loans may be renewed by calling

(415) 642-6233

1-year loans may be recharged by bringing books to NRLF

Renewals and recharges may be made 4 days prior to due date

DUE AS STAMPED BELOW

\section{APR 201990}




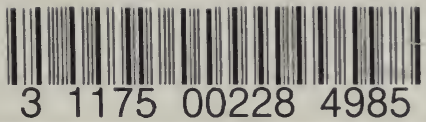

SB Loudon, J. C.

375 The different modes of cultivating the

L88 pineapple.

\section{EW}

$5 / 78 \mathrm{reb}$. 


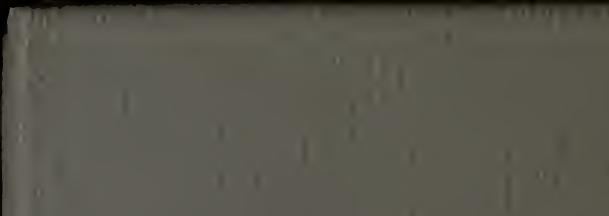

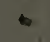<smiles>C1CCCCC1</smiles>

III 